FHWA/IN/JTRP-2000/4

Final Report

\begin{abstract}
A METHODOLOGY TO ESTIMATE LOAD AND NON-LOAD SHARES OF HIGHWAY PAVEMENT ROUTINE MAINTENANCE AND REHABILITATION EXPENDITURES
\end{abstract}

Zongzhi Li

Kumares C. Sinha

April 2000 
FINAL REPORT

FHWA/IN/JTRP-2000/4

\title{
A METHODOLOGY TO ESTIMATE LOAD AND NON-LOAD SHARES OF HIGHWAY PAVEMENT ROUTINE MAINTENANCE AND REHABILITATION EXPENDITURES
}

\author{
by \\ Zongzhi Li \\ Graduate Research Assistant \\ and \\ Kumares C. Sinha \\ Professor of Civil Engineering \\ Purdue University \\ School of Civil Engineering \\ Joint Transportation Research Program \\ Project No.: C-36-54DDD \\ File No.3-3-56 \\ SPR-2332 \\ Prepared in Cooperation with the \\ Indiana Department of Transportation and \\ The U.S. Department of Transportation \\ Federal Highway Administration
}

The contents of this report reflect the views of the authors who are responsible for the facts and the accuracy of the data presented herein. The contents do not necessarily reflect the official views of the Federal Highway Administration and the Indiana Department of Transportation. This report does not constitute a standard, a specification, or a regulation.

Purdue University

West Lafayette, Indiana 47907

April 2000 


\section{TECHNICAL Summary}

INDOT Research

Technology Transfer and Project Implementation Information

TRB Subject Code: 15-2 Cost Allocation

Publication No.: FHWA/IN/JTRP-2000/4, SPR-2332

April 2000

Final Report

\section{A METHODOLOGY TO ESTIMATE LOAD AND NON-LOAD SHARES OF HIGHWAY PAVEMENT ROUTINE MAINTENANCE AND REHABILITATION EXPENDITURES}

\section{Introduction}

A critical component of a highway cost allocation study is to determine the cost responsibilities of various vehicle classes related to highway pavement maintenance and rehabilitation expenditures. In the past, the load and non-load shares of maintenance and rehabilitation expenditures were determined using a number of approaches, ranging from arbitrary percentages to rational assumptions. As pavement maintenance and rehabilitation continue to increase as a portion of annual highway expenditures, the

\section{Findings}

The study revealed that the shares of pavement repair expenditures attributable to load and non-load factors depend on several factors, such as the type of improvement (routine maintenance or rehabilitation), pavement type, and other variables. For routine maintenance, the load and non-load shares were found to be 25-75 for flexible pavements, $36-64$ and $60-40$ for Jointed Concrete Pavements (JCP) and Continuously Reinforced Concrete (CRC)

\section{Implementation}

In the present study, it was revealed that the load shares of pavement maintenance and rehabilitation expenditures for flexible and composite pavements were lower than those for rigid pavements, regardless of pavement repair category. Furthermore, for each pavement type, it was found that pavement segments that had received non-structural repairs (i.e., routine maintenance) had a relatively smaller load development of an improved procedure to address the issue of load and non-load shares of such expenditures has become more important. The scope of the present study includes the development of appropriate econometric models to relate pavement maintenance and rehabilitation expenditures to traffic loading and various non-load factors. The models are then used to estimate the shares of load and non-load factors. pavements, and 30-70 for composite pavements. The load and non-load fractions of rehabilitation expenditures used to repair pavement damage were found to be $30-70$ for flexible pavements, $80-20$ for JCP, and 40-60 for composite pavements. It is expected that the results of this study would facilitate the apportionment of pavement maintenance and rehabilitation expenditures in a fair and equitable manner. 
pavements in the network in question and the various categories of past pavement repair activities. It should also utilize, as much as possible, current data on the network usage, condition, and maintenance expenditures. The observations and results from this study can be salient inputs for the update of the highway cost allocation study for Indiana, particularly in allocating pavement maintenance and rehabilitation expenditures.

\title{
Contact
}

For more information:

Prof. Kumares Sinha

Principal Investigator

School of Civil Engineering

Purdue University

West Lafayette IN 47907

Phone: (765) 494-2204

Fax: (765) 496-1105

\author{
Indiana Department of Transportation \\ Division of Research \\ 1205 Montgomery Street \\ P.O. Box 2279 \\ West Lafayette, IN 47906 \\ Phone: (765) 463-1521 \\ Fax: (765) 497-1665

\section{Purdue University} \\ Joint Transportation Research Program \\ School of Civil Engineering \\ West Lafayette, IN 47907-1284 \\ Phone: (765) 494-9310 \\ Fax: (765) 496-1105
}


TECHNICAL REPORT STANDARD TITLE PAGE

\begin{tabular}{|c|c|c|}
\hline $\begin{array}{l}\text { 1. Report No. } \\
\text { FHWA/IN/JTRP-2000/4 }\end{array}$ & 2. Government Accession No. & 3. Recipient's Catalog No. \\
\hline \multirow{2}{*}{\multicolumn{2}{|c|}{$\begin{array}{l}\text { 4. Title and Subtitle } \\
\text { A Methodology to Estimate Load and Non-Load Shares of Highway Pavement Routine } \\
\text { Maintenance and Rehabilitation Expenditures }\end{array}$}} & $\begin{array}{r}\text { 5. Report Date } \\
\text { April } 2000\end{array}$ \\
\hline & & 6. Performing Organization Code \\
\hline \multicolumn{2}{|l|}{$\begin{array}{l}\text { 7. Author(s) } \\
\text { Zongzhi Li and Kumares Sinha }\end{array}$} & $\begin{array}{l}\text { 8. Performing Organization Report No. } \\
\text { FHWA/IN/JTRP-2000/4 }\end{array}$ \\
\hline \multirow{2}{*}{\multicolumn{2}{|c|}{$\begin{array}{l}\text { 9. Performing Organization Name and Address } \\
\text { Joint Transportation Research Program } \\
\text { 1284 Civil Engineering Building } \\
\text { Purdue University } \\
\text { West Lafayette, Indiana } 47907-1284\end{array}$}} & 10. Work Unit No. \\
\hline & & $\begin{array}{l}\text { 11. Contract or Grant No. } \\
\text { SPR-2332 }\end{array}$ \\
\hline \multirow{2}{*}{\multicolumn{2}{|c|}{$\begin{array}{l}\text { 12. Sponsoring Agency Name and Address } \\
\text { Indiana Department of Transportation } \\
\text { State Office Building } \\
100 \text { North Senate Avenue } \\
\text { Indianabolis. IN } 46204\end{array}$}} & $\begin{array}{l}\text { 13. Type of Report and Period Covered } \\
\text { Final Report }\end{array}$ \\
\hline & & 14. Sponsoring Agency Code \\
\hline
\end{tabular}

15. Supplementary Notes

Prepared in cooperation with the Indiana Department of Transportation and Federal Highway Administration.

\section{Abstract}

The present study focused on the estimation of load and non-load shares of pavement maintenance and rehabilitation expenditures. The information provides the basis for the allocation of pavement-related expenditures in a highway cost allocation study. A comprehensive database was developed in the study, and an aggregate performance approach was used based on econometric models. This approach utilizes the marginal effect of traffic loading to quantify the load and non-load shares of pavement routine maintenance and rehabilitation expenditures. The study revealed that the share of pavement damage attributable to load and non-load factors depends on several factors such as the type of improvement (routine maintenance or rehabilitation), pavement type, and other variables. For routine maintenance, the load and non-load shares were found to be 25-75 for flexible pavements, 36-64 and 60-40 for Jointed Concrete Pavements (JCP) and Continuously Reinforced Concrete (CRC) pavements, and 30-70 for composite pavements. The load and non-load fractions of rehabilitation expenditures used to repair pavement damage were found to be $30-70$ for flexible pavements, $80-20$ for JCP, and 40-60 for composite pavements. It is expected that the results of this study will facilitate the apportionment of pavement routine maintenance and rehabilitation expenditures in a fair and equitable manner.

\section{Key Words}

Highway cost allocation, load and non-load shares, pavement routine maintenance and rehabilitation, flexible pavements, rigid pavements, composite pavements.
18. Distribution Statement

No restrictions. This document is available to the public through the National Technical Information Service, Springfield, VA 22161

\begin{tabular}{|c|c|c|c|}
\hline $\begin{array}{c}\text { 19. Security Classif. (of this report) } \\
\text { Unclassified }\end{array}$ & $\begin{array}{c}\text { 20. Security Classif. (of this page) } \\
\text { Unclassified }\end{array}$ & $\begin{array}{c}\text { 21. No. of Pages } \\
161\end{array}$ & 22. Price \\
\hline
\end{tabular}




\section{TABLE OF CONTENTS}

Page

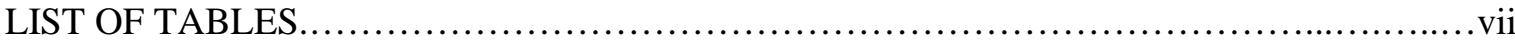

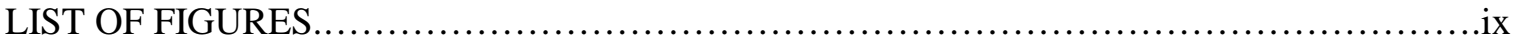

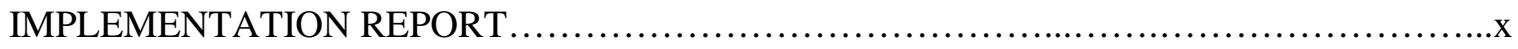

LIST OF ABBREVIATIONS ................................................................

CHAPTER 1 INTRODUCTION.............................................................

1.1 Background Information.................................................................

1.1.1 Effects of Pavement Routine Maintenance and Rehabilitation........................1

1.1.2 Roles of Load and Non-load Factors..............................................

1.2 Literature Review.............................................................

1.2.1 Pavement Performance Modeling .............................................6

1.2.2 Pavement Maintenance and Rehabilitation Cost Models............................10

1.2.3 Load/Non-load Effects in Cost Allocation.........................................12

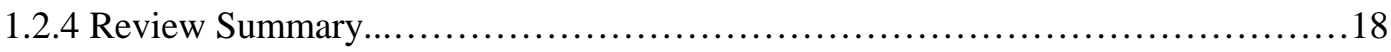

CHAPTER 2 PROBLEM STATEMENT AND STUDY OBJECTIVES.......................20

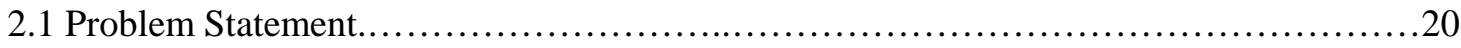

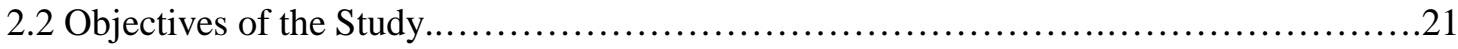

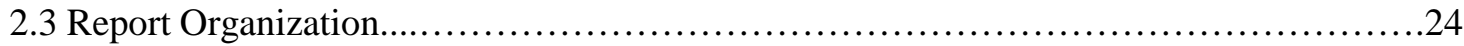

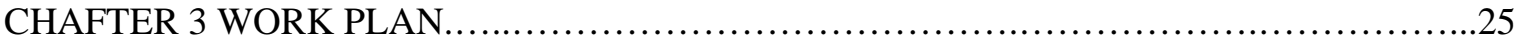

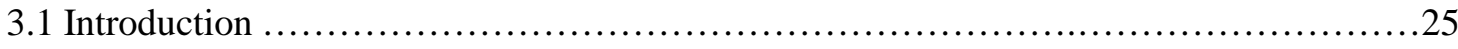

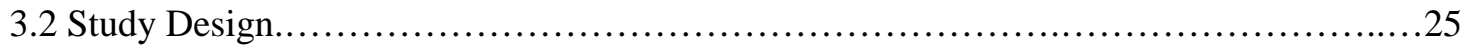




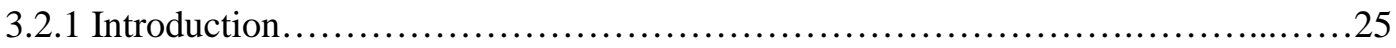

3.2.2 Design of Experiment.................................................. 27

3.2.3 Procedure for Determining Load and Non-load Shares of

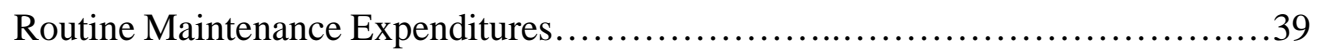

3.2.4 Procedure for Determining Load and Non-load Shares of

Rehabilitation Expenditures...........................................42

3.3 Data Collection and Processing ................................................45

3.3.1 Data Collection ....................................................45

3.3.2 Data Processing and Validation............................................45

3.3.3 Data Preparation....................................................... 50

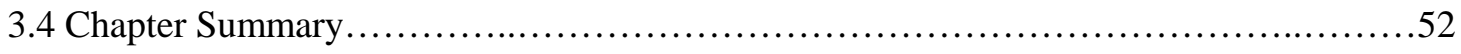

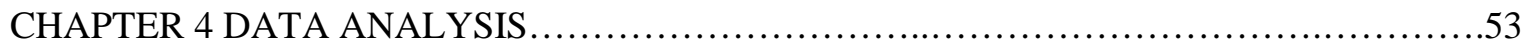

4.1 Pavement Segments with Routine Maintenance Work..............................53

4.1.1 Model Development for All Pavement Types ..............................54

4.1.2 Estimation of Load and Non-load Shares of Pavement

Routine Maintenance Expenditures.....................................63

4.2 Pavement Segments with Rehabilitation Work.................................66

4.2.1 Model Development for All Pavement Types ..............................66

4.2.2 Estimation of Load and Non-load Shares of Pavement

Rehabilitation Expenditures...........................................77

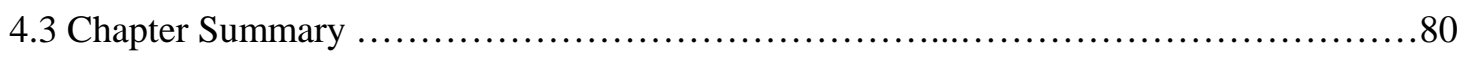

CHAPTER 5 SUMMARY, CONCLUSIONS AND RECOMMMENDATIONS..................81

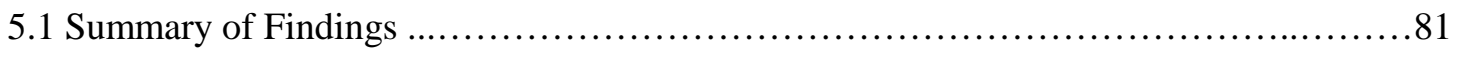

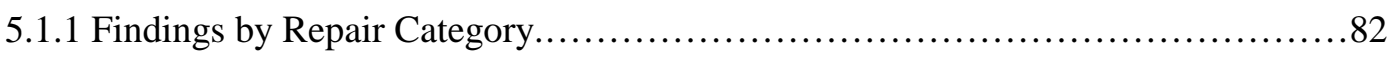

5.1.2 Findings by Pavement Type.......................................... 84 
5.1.3 Findings by Approaches Used........................................... 86

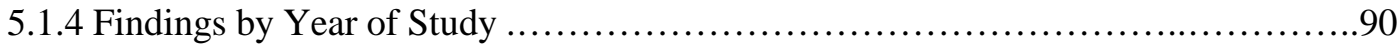

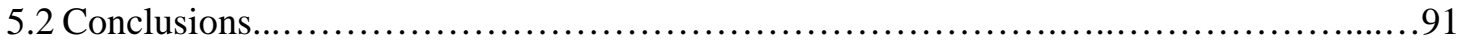

5.3 Recommendations and Directions for Future Work and Research ......................92

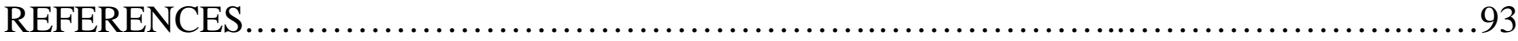

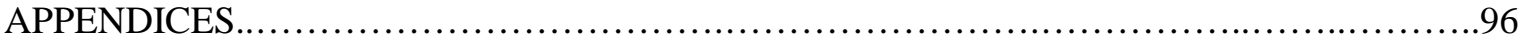




\section{LIST OF TABLES}

Table

$1 \quad$ Modeling Approaches for Deterministic Models......................................

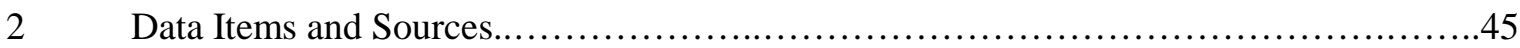

3 The Available Data Items for All Interstate, State and U.S. Roads for the

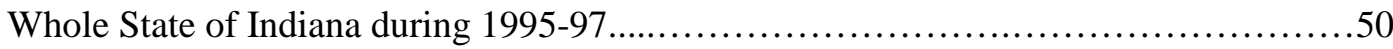

4 Tabulated Results of Cost Model for Flexible Pavements with Maintenance Work........56

5 Tabulated Results of Cost Model for JCP Pavements with Maintenance Work..............58

6 Tabulated Results of Cost Model for CRC Pavements with Maintenance Work...........60

7 Tabulated Results of Cost Model for Composite Pavements with Maintenance Work.....62

8 Summary of the Average Annual Maintenance Expenditures, IRI Change,

Annual ESALs and Thickness for All Pavement Types..............................63

9 Summary of Load Shares of Pavement Routine Maintenance Expenditures...............65

10(a) Tabulated Results of Cost Model for Composite Pavements with Rehabilitation Work...69

10(b) Tabulated Results of Cost Model for Composite Pavements with Rehabilitation

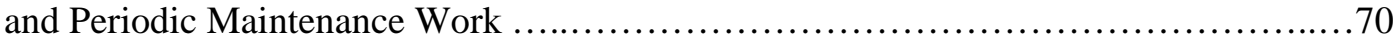

11(a) Tabulated Results of Cost Model for JCP Pavements with Rehabilitation Work ..........72

11(b) Tabulated Results of Cost Model for JCP Pavements with Rehabilitation and Periodic Maintenance Work .................................................. 73

12(a) Tabulated Results of Cost Model for Composite Pavements with Rehabilitation Work....75

12(b) Tabulated Results of Cost Model for Composite Pavements with Rehabilitation and Periodic Maintenance Work .76 
13 Summary of Rehabilitation and Periodic Maintenance Expenditures, IRI Change,

Cumulative ESALs, and Thickness for All Pavement Types............................77

14 Summary of Load Share of Rehabilitation and Periodic Maintenance Expenditures for

Flexible, Rigid and Composite Pavements.................................... 79

15 Comparison of Results between Current Study and 1984 Indiana HCAS Approaches.....87 


\section{LIST OF FIGURES}

Figure $\quad$ Page

1 Comparison of Pavement Performance Curves without and with Routine Maintenance by Time or Load Domain ........................................................

2 Possible Performance Curves for a Given Pavement ...................................

3 Comparison of Pavement Performance Curves between Routine Maintenance and

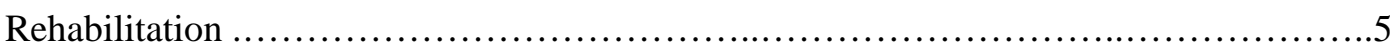

$4 \quad$ Graphic Description of Pavement Performance..................................... 14

$5 \quad$ Proportionality Assumption of Pavement Performance.................................15

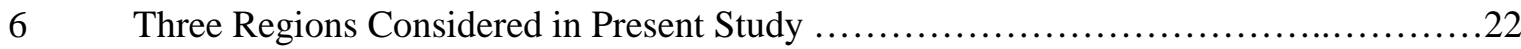

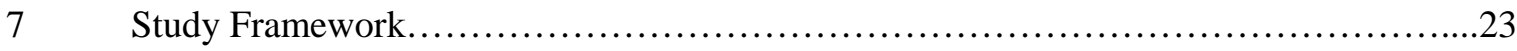

8 Procedure for Determining the Load Share of Pavement Routine Maintenance

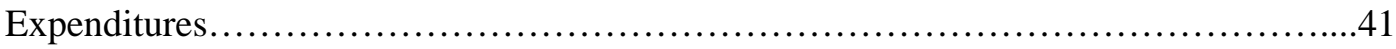

9 Procedure for Determining the Load Share of Pavement Rehabilitation and

Periodic Maintenance Expenditures............................................44

10 Load and Non-load Shares of Pavement Routine Maintenance Expenditures.............83

11 Load and Non-load Shares of Pavement Rehabilitation Expenditures...................83

12 Load and Non-load Shares of Repair Expenditures for Various Pavement Types..........85

13 Comparison of Load and Non-load Shares of Pavement Repair Expenditures............88 


\section{IMPLEMENTATION REPORT}

The present study revealed that the shares of pavement routine maintenance and rehabilitation expenditures attributable to load and non-load factors are sensitive to the pavement repair category, the pavement type and the year of study. For routine maintenance, the load and non-load shares were found to be 25-75 for flexible pavements, 36-64 and 60-40 for Jointed Concrete Pavements (JCP) and Continuously Reinforced Concrete (CRC) pavements, and 30-70 for composite pavements. The load and non-load fractions of rehabilitation expenditures used to repair pavement damage were found to be 30-70 for flexible pavements, $80-20$ for JCP, and 4060 for composite pavements. This is important as it was generally found that the load shares of pavement routine maintenance and rehabilitation expenditures for flexible and composite pavements were lower than those for rigid pavements, regardless of pavement repair category.

The results further suggest that as pavement composition is increasingly dominated by reinforced concrete, the load share of pavement repair expenditures increases, and pavement becomes relatively less vulnerable to non-load factors of pavement deterioration. Furthermore, for each pavement type, pavement segments that had received non-structural pavement repairs, i.e., routine maintenance, had a relatively smaller load share of repair expenditures as compared to those segments that had received structure-enhancing repairs (rehabilitation). Therefore, it would be unfair to conduct allocation of pavement routine maintenance and rehabilitation expenditures without due recognition of the type of pavement repair, in particular, the allocation of JCP pavement expenditures.

The results and observations from this study can be salient inputs for the update of the highway cost allocation study in Indiana, particularly in allocating pavement routine maintenance and rehabilitation expenditures. 


\begin{abstract}
The present study focused on the estimation of load and non-load shares of pavement maintenance and rehabilitation expenditures. The information provides the basis for the allocation of pavement-related expenditures in a highway cost allocation study. A comprehensive database was developed in the study, and an aggregate performance approach was used based on econometric models. This approach utilizes the marginal effect of traffic loading to quantify the load and non-load shares of pavement routine maintenance and rehabilitation expenditures. The study revealed that the share of pavement damage attributable to load and non-load factors depends on several factors such as the type of improvement (routine maintenance or rehabilitation), pavement type, and other variables. For routine maintenance, the load and non-load shares were found to be $25-75$ for flexible pavements, 36-64 and 60-40 for Jointed Concrete Pavements (JCP) and Continuously Reinforced Concrete (CRC) pavements, and 30-70 for composite pavements. The load and non-load fractions of rehabilitation expenditures used to repair pavement damage were found to be 30-70 for flexible pavements, $80-20$ for JCP, and 40-60 for composite pavements. It is expected that the results of this study will facilitate the apportionment of pavement routine maintenance and rehabilitation expenditures in a fair and equitable manner.
\end{abstract}

Key Words:

Highway cost allocation, load and non-load shares, pavement routine maintenance and rehabilitation, flexible pavements, rigid pavements, composite pavements. 


\section{ACKNOWLEDGMENTS}

The authors wish to acknowledge the assistance provided by Messrs. Clem Ligocki, Chris Kubik and Shuo Li of INDOT and Larry Heil of FHWA who served on the Study Advisory Committe. Thanks are also extended to the following INDOT staff who provided much assistance in various aspects of data collection: Ron Adams, David Andrewski, Mahlon Bartlett, Youlanda Belew, Eric Conklin, William Flora, Sedat Gulen, Marcia Gustafson, Cordelia Jones-Hill, Athar Khan, Geraldine Lampley, Scott MacArthur, John Nagle, Samy Noureldin, Mohammed Shaikh, Jay Wasson, John Weaver, and Nayyar

Zia. The help of Pam Beneker of the Indiana Climate Center at Purdue University in obtaining data on climatic conditions in Indiana is also acknowledged. The authors are particularly thankful to Professor Patrick McCarthy of the Economics Department at Purdue University for his guidance on the statistical aspects of the study. 


\section{CHAPTER 1 INTRODUCTION}

\subsection{Background Information}

A critical component of a highway cost allocation study is to determine cost responsibilities of various vehicle classes for highway pavement maintenance and rehabilitation expenditures. The issue of proper identification of the load share of such expenditures has been an important topic of investigation among researchers in cost allocation studies concluded in past few decades. In the past, the load and non-load shares of maintenance and rehabilitation expenditures were determined using a number of approaches ranging from arbitrary percentages to rational assumptions. As the proportion of yearly pavement maintenance and rehabilitation expenditures out of total annual highway expenditures continues to increase, it is particularly important that an improved procedure be developed to address the issue of load and non-load shares of such expenditures. Only with an appropriate assignment of cost responsibilities can an equitable highway taxation structure be developed.

\subsubsection{Effects of Pavement Routine Maintenance and Rehabilitation}

\subsubsection{Effects of Pavement Routine Maintenance}

American Association of State Highway and Transportation Officials (AASHTO) [1976]

defines maintenance as a program to preserve and repair elements of a system to an accepted configuration. Routine pavement maintenance comprises those activities undertaken on a regular or continuous basis to serve as preventive measures against deterioration of the pavement or as corrective measures to repair minor pavement damages. Activities such as crack sealing, shallow 
and deep patching, pothole patching, cutting relief joints, joint and bump burning, and shoulder maintenance are basic routine maintenance activities.

It is generally agreed that an improved pavement performance can be achieved by conducting routine pavement maintenance. This concept may be presented schematically as shown in Figure 1, where the pavement condition is expressed in terms of Present Serviceability Index (PSI) as a function of time [Fwa and Sinha, 1986]. Alternatively, PSI may be expressed as a function of cumulative loading, that is PSI-ESALs (An ESAL represents equivalent 18kips single axle loads).

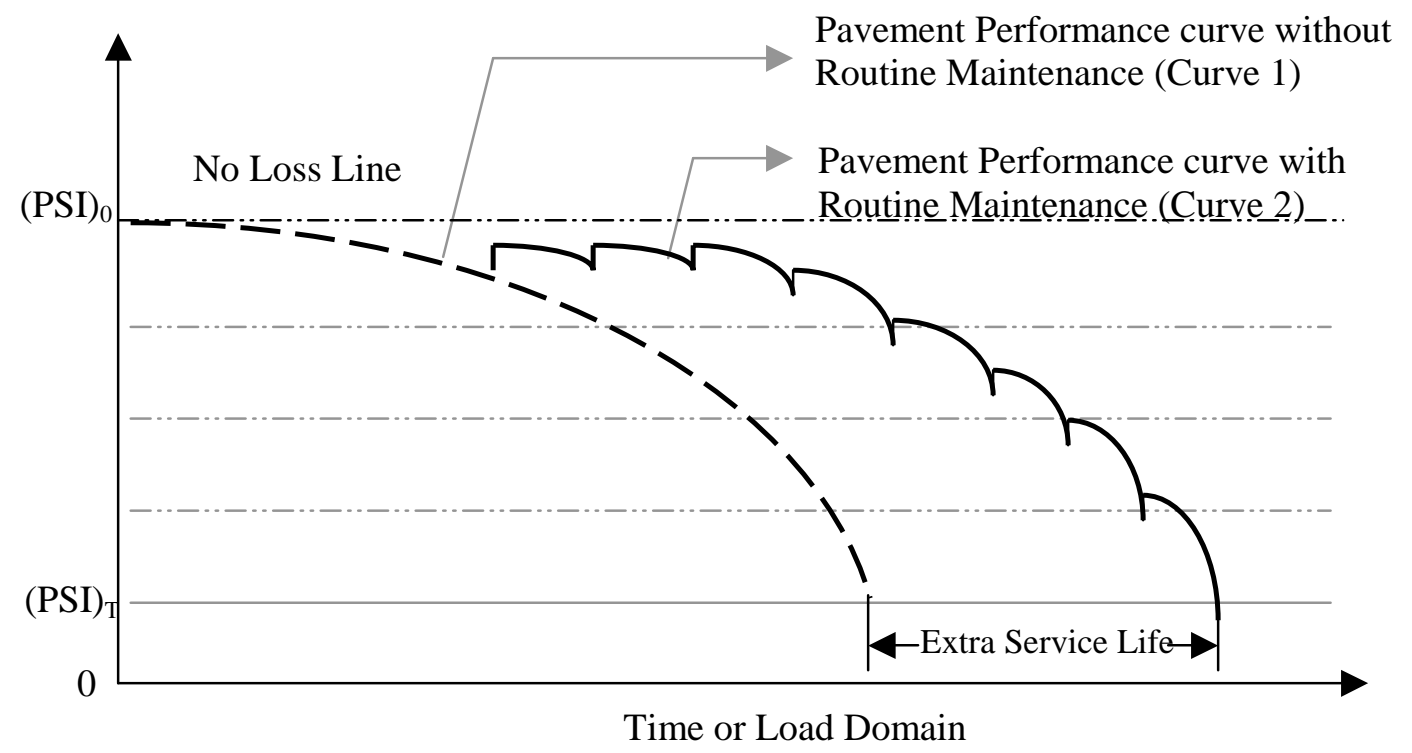

Figure 1. Comparison of Pavement Performance Curves Without and With Routine Maintenance by Time or Load Domain

As shown in Figure 1, pavement service life is longer when maintenance is executed. The time domain incorporates pavement condition at the time of analysis but it makes no reference to past history of the pavement. However, for the load domain, PSI-ESAL loss (i.e., area bounded by the pavement performance curve and the no-loss line) is computed over the entire analysis period and therefore is also a function of the past conditions of the pavement. Because the effect of maintenance is a cumulative result of repetitive maintenance activities during the same 
analysis period for which PSI-ESAL loss is computed, it is obvious that PSI-ESAL value is a more suitable parameter and is therefore used for the analysis of routine maintenance effects [Fwa and Sinha, 1986].

To attain a quantitative assessment of the effectiveness of routine maintenance, it is necessary to assume that higher maintenance expenditures are associated with higher levels of routine maintenance activities and vice versa. When this assumption is valid, a group of curves that show possible pavement performance can be obtained for a specified pavement as shown in Figure 2.

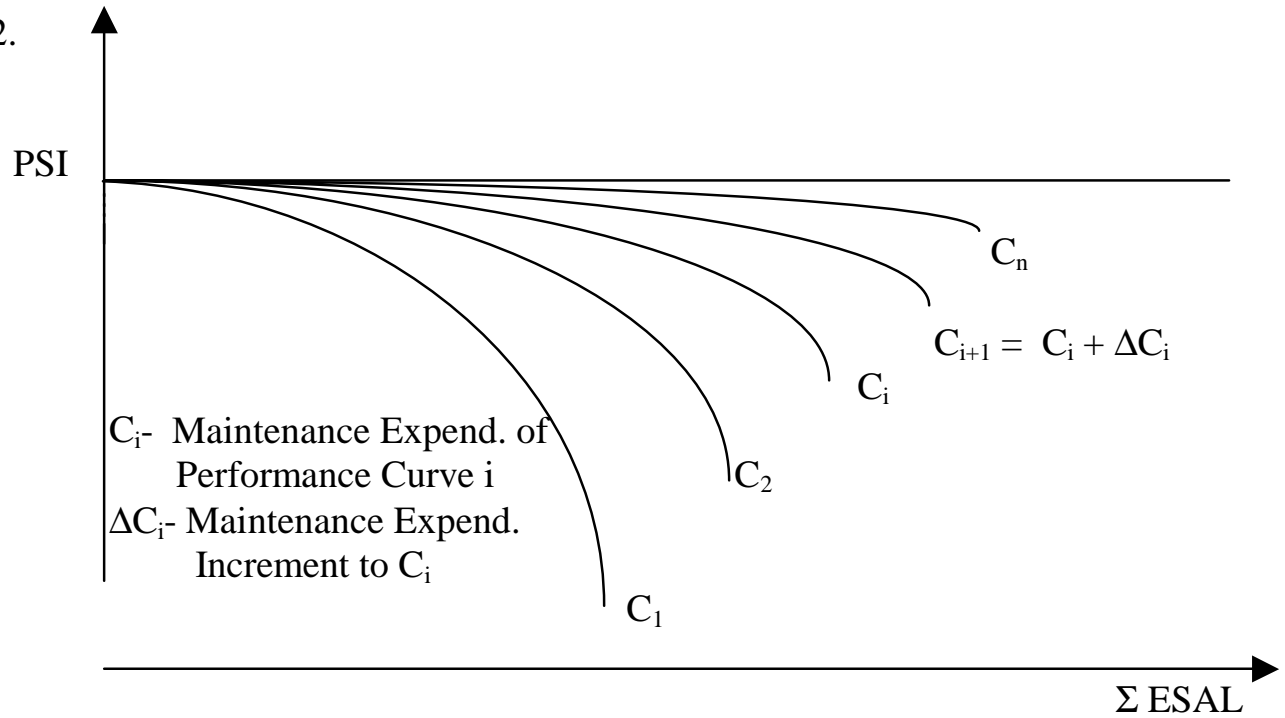

Figure 2. Possible Performance Curves for a Given Pavement effects [Fwa and Sinha, 1986]

The increment of maintenance expenditures from curve $\mathrm{i}$ to curve $\mathrm{i}+1$ is given by $\Delta \mathrm{C}_{\mathrm{i}}$. The corresponding difference in PSI-ESAL loss is denoted $\Delta \mathrm{A}_{\mathrm{i}}$. The PSI-ESAL loss decreases when the cost is increased from $\mathrm{C}_{\mathrm{i}}$ to $\mathrm{C}_{\mathrm{i}}+\Delta \mathrm{C}_{\mathrm{i}}$ and represents the amount of improvement in pavement performance achieved. As the maintenance cost increment ( $\Delta \mathrm{Ci})$ becomes very minimal, the following index provides a measure of improvement in pavement performance for a unit change in maintenance expenditures.

$$
\mathrm{M}_{\mathrm{i}}=\lim \left(\Delta \mathrm{A}_{\mathrm{i}} / \Delta \mathrm{C}_{\mathrm{i}}\right)=(\mathrm{dA} / \mathrm{dC})_{\mathrm{i}}
$$

$$
\Delta \mathrm{C}_{\mathrm{i}} \rightarrow 0
$$


where

$\mathrm{M}_{\mathrm{i}} \quad$ = Pavement Routine Maintenance Effectiveness Index (PRMEI) evaluated at the routine maintenance level represented by $\mathrm{C}_{\mathrm{i}}$ in Figure 2;

$\mathrm{A} \quad=$ PSI-ESAL value;

C = Maintenance costs;

$\Delta \mathrm{A}_{\mathrm{i}} \quad=$ Additional PSI-ESAL value and

$\Delta \mathrm{C}_{\mathrm{i}} \quad=$ Increment of maintenance expenditures from curve $\mathrm{i}$ to curve $\mathrm{i}+1$.

Equation (1-1) expresses that if PSI-ESAL is plotted against maintenance expenditures, the slopes of such a plot give the value of $\mathrm{M}$ at different levels of maintenance expenditures.

\subsubsection{Effects of Pavement Periodic Maintenance and Rehabilitation}

Pavement periodic maintenance is defined as higher level work undertaken at longer intervals of pavement life and has a greater degree of impact on pavement service life. Periodic maintenance activities can also be both preventive as well as corrective, depending upon the level of deterioration, and they include resealing and thin overlays.

Pavement rehabilitation activities, such as pavement resurfacing and reconstruction, are regarded as those aimed at improving a pavement's structural as well as functional condition.

The no-loss line represents the performance curve assuming there is no pavement deterioration, as shown in Figure 3. The serviceability level is improved to no-loss level after the implementation of rehabilitation. The effectiveness of rehabilitation work in terms of PSI-ESAL value is represented by area A. Also, the maintenance effectiveness is represented by area B, which is the difference of PSI-ESAL value between zero maintenance and field performance curves. 


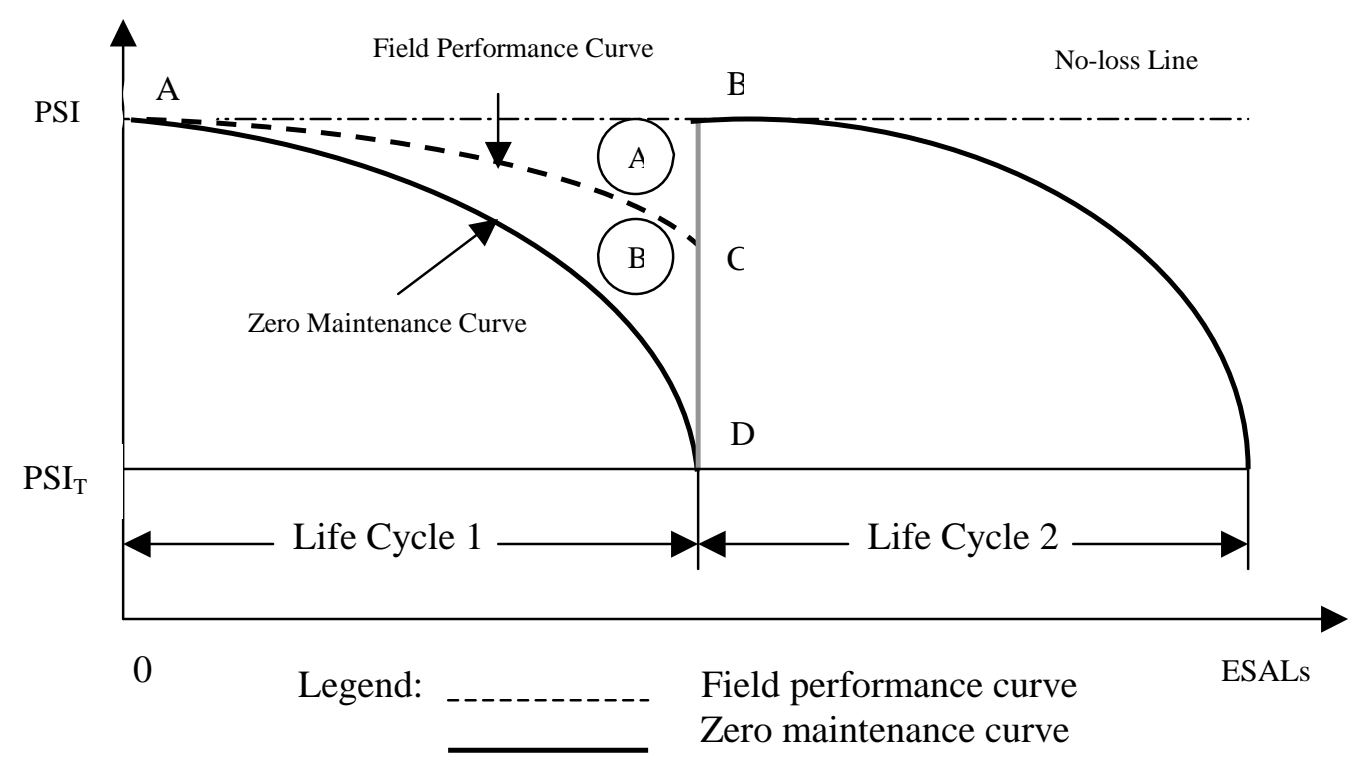

Figure 3. Comparison of Pavement Performance Curves Between Routine Maintenance and Rehabilitation

\subsubsection{Roles of Load and Non-load Factors}

In general, pavement condition deteriorates due to load, environment and the interaction between them. Pavement deterioration caused by traffic loading is exacerbated by pavement age and climatic conditions, particularly under extreme weather conditions. Fine-grained subgrades with higher moisture content are less resistant to the force transmitted through a pavement with heavy load. Pavement cracking is made more severe by a higher freeze index and a greater number of freeze-thaw cycles. These conditions allow infiltration of water and subsequently result in damage to pavement structures. Asphalt in flexible pavement loses its flexibility after certain years of use. All this evidence indicates that weather has an important part to play in pavement damage. 


\subsection{Literature Review}

A comprehensive literature review was undertaken to document of pavement performance modeling, pavement cost modeling, load and non-load effects on pavement damage and repair, and highway cost allocation studies in general.

\subsubsection{Pavement Performance Modeling}

Pavement performance refers to the manner in which pavements deteriorate after cumulative use. Many highway agencies have developed different kinds of pavement performance models for their Pavement Management System (PMS). According to Lytton [1988] there are generally two types of performance models: deterministic and probabilistic. While the deterministic models predict a single number for the life of a pavement or its level of distress or other measure of its condition, the probabilistic models predict a distribution of such events. The deterministic models are mainly concerned with pavement response, structural, functional and damage performance after the passage of a number of loads. On the other hand, the probabilistic models are developed by using survivor curves (a graph of probability versus time), Markov and Semi-Markov transition processes for pavement deterioration.

As seen in Table 1, deterministic models utilize two broad alternative approaches in evaluating pavement performance and the relevant maintenance and rehabilitation expenditures: the disaggregate approach and the aggregate approach. The disaggregate approach evaluates pavement condition and related expenditure by estimating the extent and amount of individual pavement distresses. For instance, the typical distresses on asphalt concrete pavements include raveling, patch-failure, pothole formation, alligator cracking, transverse cracking, longitudinal joint condition, edge cracking, widening cracks, pumping, etc. The aggregate approach is based on the overall pavement performance and the total maintenance and rehabilitation expenditures. An example is the use of Present Serviceability Index (PSI) by American Association of State Highway and Transportation Officials (AASHTO) for in-service pavement performance, which 
jointly considers various forms pavement distress. The disaggregate approach requires detailed damage data of individual distress types and is therefore often hampered by unavailability of data. On the other hand, the data needs for the aggregate approach are less demanding. Pavement distress is generally defined as a defect or deformation of any element of the pavement, resulting in a decrease in serviceability. Pavement distresses are symptoms of structural or functional failure. The term pavement damage is generally interchangeable with pavement distress but is often associated with structural failure.

Table 1. Modeling Approaches for Deterministic Models

\begin{tabular}{|l|c|c|c|c|}
\hline \multirow{2}{*}{ Modeling Approach } & \multicolumn{4}{|c|}{ Deterministic Models } \\
\cline { 2 - 5 } & Primary Response & Structural & Functional & Damage \\
\hline Disaggregate & $*$ & $*$ & & \\
\hline Aggregate & $*$ & & $*$ & $*$ \\
\hline
\end{tabular}

\subsubsection{1985 Austin Research Engineers (ARE) Study}

An example of the use of a disaggregate response variable for pavement performance modeling is the ARE study [Butler, 1985] carried out in 1985. Using regression analysis, that study established pavement prediction models with pavement distress and pavement serviceability as functions of maintenance and rehabilitation treatments and various load and nonload related factors. The effectiveness of maintenance and rehabilitation treatments was determined according to their frequency (number of applications of a treatment during analysis period) and impact (the change in pavement condition and strength after the implementation of the maintenance and rehabilitation measures). The limitation of the ARE approach is that it is only applicable for modeling serviceability of flexible pavements and that it requires a considerable amount of input data. 


\subsubsection{SHRP Evaluation of AASHTO Design Equations}

The data generated by Strategic Highway Research Program (SHRP) were used to evaluate the AASHTO design equations [SHAP, 1994]. On the basis of the data from 244 General Pavement Studies (GPS) in-service flexible pavement test sections across the country, the study concluded that the existing AASHTO flexible pavement design equations do not adequately predict the pavement performance of the SHRP LTPP test sections. The formula overestimates the level of Equivalent Single Axle Loads (ESALs) needed to cause a measured loss of PSI, relative to observed values.

The authors argue that the use of composite PSI also presents some limitations in the use of the AASHTO equation. According to them, with composite indices of this type, where all distresses are lumped together, it is difficult to identify the distress type that may be responsible for a reduction in performance. In other words, one can not tell if the pavement is deteriorating as a result of increased rutting, increased roughness, one of the other distresses that may be present, or some combination of all of the above. This, in the author's opinion, makes it difficult to identify the causes for this change in performance.

They further state that, by lumping all the structural properties together, the contribution each specific layer makes to the performance of the pavement structure is also masked. It quickly becomes evident, when comparing the performance of these test sections versus their predicted performance, that one-inch of asphalt will not always be equivalent to 3.1 inches of granular base, as the structural number concept suggests. This relationship will naturally vary, depending on the structural properties of the other layers incorporated in the pavement, the environmental conditions in which the pavement is situated and numerous other factors.

As such, equations for individual distress including alligator cracking, rutting, transverse (or thermal) cracking, increases in roughness, and loss of surface friction, were developed. The equations are of the general form shown below: 
$D=N^{B} 10^{C}$

where

D = Distress in appropriate units (e.g. inches of rutting or inch/mile of roughness increase);

$\mathrm{N}=$ Number of cumulative ESALs in 1000's (KESALs);

B $\quad=b_{0}+b_{1} X_{1}+b_{2} X_{2}+\ldots \ldots+b_{n} X_{n} ;$ and

$\mathrm{C} \quad=\mathrm{c}_{0}+\mathrm{c}_{1} \mathrm{X}_{1}+\mathrm{c}_{2} \mathrm{X}_{2}+\ldots \ldots+\mathrm{c}_{\mathrm{n}} \mathrm{X}_{\mathrm{n}}$

$\mathrm{b}_{0}, \mathrm{~b}_{1}, \mathrm{~b}_{2}, \ldots \ldots, \mathrm{b}_{\mathrm{n}} ;$ and $\mathrm{c}_{0}, \mathrm{c}_{1}, \mathrm{c}_{2}, \ldots \ldots, \mathrm{c}_{\mathrm{n}}$ are coefficients;

$\mathrm{X}_{1}, \mathrm{X}_{2}, \ldots \ldots, \mathrm{X}_{\mathrm{n}}$ are parameters related to pavement design and construction standards, and climatic features.

\subsubsection{Australian Road Research Board (ARRB) Pavement Model}

In the ARRB study [Martin, 1994], independent variables used for modeling included pavement and subgrade strength, cumulative traffic loading, environmental effects, pavement maintenance (containment and restoration), rehabilitation (improvement) practices. Maintenance practices in the ARRB model are quantified in terms of dollars per lane-km of expenditure.

The ARRB pavement model used road roughness as the dependent variable representing pavement surface condition. The model involves a simple addition of non-load related roughness changes (environmental) and load-related roughness changes (heavy vehicle axle loads). In equation form this postulation is as follows:

$$
\begin{aligned}
R(t)=R_{0}+R_{0} * A *\left\{\frac{I+100}{S N C}\right\}^{a} * t^{b} * & \left(\frac{1}{(M E+G)^{d}}+\frac{B * L^{c}}{(M E+G)^{d}}\right)-R(t)_{\text {before rehab. }} * g-T * h-K \\
& (\text { Non-load term) }(\text { Load term) }
\end{aligned}
$$

where

$\mathrm{R}(\mathrm{t}) \quad=$ Road roughness measured at time $\mathrm{t}$;

$\mathrm{R}_{0} \quad=$ Initial road roughness (i.e. roughness at time $\mathrm{t}=0$ ); 
I $=$ Thornwaithe Index $=(100 \mathrm{D}-60 \mathrm{~d}) / \mathrm{E}_{\mathrm{p}}$, $\mathrm{D}=$ Soil drainage $(\mathrm{cm}), \mathrm{d}=$ Soil deficit $(\mathrm{cm})$ and $\mathrm{E}_{\mathrm{p}}=$ Evaporation $(\mathrm{cm})$;

SNC = Modified structural number;

$\mathrm{L}=$ Traffic load in average cumulative ESALs (CESALs/lane/year * $\left.10^{6}\right)$;

ME =Average annual maintenance expenditure $(\$ /$ lane $-\mathrm{km})$ sum of routine and periodic maintenance expenditure;

$\mathrm{G}=$ Constant for maintenance expenditure for each arterial road group;

$\mathrm{R}(\mathrm{t})_{\text {before rehab. }}=$ Roughness before rehabilitation (overlay) treatment;

$\mathrm{T} \quad=$ Thickness of an asphalt overlay $(\mathrm{mm}) ;$ and

a, b, c, d, g, h, K, A and B are calibration constants for each arterial road group.

The maintenance expenditure (ME) appears in above equation because maintenance expenditure affects both load and non-load related roughness. The researchers argued that maintenance expenditure is directed more towards load-related road wear, and they claim that generally not possible to estimate the separate influence of maintenance expenditure on these two forms of road wear.

\subsubsection{Pavement Maintenance and Rehabilitation Cost Models}

\subsubsection{Small Marginal Cost Model}

In Small's study [Small et al., 1989], marginal cost was defined as the change in the total social cost of travel on existing roads, including costs of road maintenance and costs incurred by all its users, brought about by adding one vehicle of a particular type and weight at a particular place and time.

Two dimensions concerning road investment were considered in this study: capacity and duration. Pavement width and thickness were used as representative measures of road capacity 
and durability respectively. Costs related to capacity and duration were categorized as congestion costs and road wear costs respectively. Road wear costs include maintenance costs and user costs.

In the study, the average maintenance cost per axle passage was obtained using the total cost of maintenance divided by the number of standard axle passages that the pavement withstands before requiring maintenance. The marginal maintenance cost is considered to be lower than the average value in that discounted cost of maintaining the road is less than the cost used for calculating the average maintenance cost. The marginal maintenance cost was obtained by computing the product of the average maintenance cost and a coefficient (smaller than 1 ).

To establish the value of the coefficient, the maintenance interval was first determined as the ratio between pavement durability and annual traffic loading. Then with the assumption that pavement roughness grows linearly with cumulative load and exponentially with time [Paterson, 1987], the annualized maintenance cost in perpetuity was calculated as a function of annual traffic, and pavement width and thickness. The marginal maintenance cost was found by partially differentiating the annualized maintenance cost with respect to annual traffic.

The study utilized the following equation

$$
M C_{m}=r * \frac{\partial M}{\partial Q}=r * \frac{\partial M}{\partial T} * \frac{d T}{d Q}=-\left\{\frac{r^{2} e^{r T} C(W)}{\left(e^{r T}-1\right)^{2}}\right\} * \frac{(d T)}{(d Q)}
$$

where

$$
\begin{array}{ll}
\mathrm{MC}_{\mathrm{m}} & =\text { Marginal cost of maintenance; } \\
\mathrm{r} & =\text { Discount rate; } \\
\mathrm{T} & =\text { Overlay interval; } \\
\mathrm{C}(\mathrm{W}) & =\text { Cost of overlay; and } \\
\mathrm{dT} / \mathrm{dQ} & =\text { Rate of change of overlay interval with respect to annual traffic loading. }
\end{array}
$$




\subsubsection{Load/Non-load Effects in Cost Allocation}

\subsubsection{Study to Determine Allocation of Pavement Damage Due to Trucks}

As part of a comprehensive study sponsored by the Ontario Ministry of Transportation, Hajek et al. [1998] developed a procedure for quantifying the pavement costs of proposed changes in regulations governing truck weights and dimensions.

The first plan of the study was the assessment of the composition of new traffic stream. This was done for each year of the 20 -year analysis period and for four alternative regulatory scenarios for truck weights and dimensions. The traffic stream composition was expressed as an overall change in ESAL-km compare with the base scenario. The next step was to allocate the new traffic streams to the road network by dividing the highway system into 20 representative categories (reflecting pavement, structure and traffic load uniformity) and using ESALs per lane per kilometer of each category. In the third phase of the study, marginal pavement costs specifically for ESALs were then calculated by developing a series of functions relating the pavement life-cycle costs obtained for different pavement sections, the designed number of ESALs, and differentiating these functions to obtain marginal costs of providing the pavement structure to service one additional ESAL. The cost impact was calculated separately for the 20 categories, each year of the analysis period, and for each truck regulatory scenario. The final result was the total pavement cost which was expressed in terms of the present worth of pavement costs for the analysis period.

\subsubsection{1994 Oregon Highway Cost Allocation Study}

In the 1986 and 1994 Oregon Highway Cost Allocation Studies [Oregon DOT, 1987, 1995], vehicles were classified as basic vehicles (autos and smaller load-carrying units weighting 6,000 lb. or less) and heavy vehicles (trucks and buses weighting over 6,000 lb.). A special survey of county and city road expenditures was conducted to evaluate the impact of 
environmental factors on pavement maintenance costs. County roads and city streets are built with lower standards and weather condition tends to have a greater effect on pavement maintenance for these roads. Other maintenance expenditures, including safety items, drainage, pavement marking, vegetation control, snow removal and extraordinary maintenance, were considered the common responsibility of all road users, and were allocated using vehicle miles of travel (VMT) of each vehicle class.

\subsubsection{1992 Virginia Highway Cost Allocation Study}

In the 1992 Virginia Highway Cost Allocation Study [VIDOT, 1993], expenditure categories included construction, bridge, maintenance and others. Site preparation, roadway geometry and pavement costs included in the construction category were allocated using average daily traffic volume for minimum facility requirements and ESAL proportions for jointly occasioned costs. Right-of-way, design and construction costs were apportioned by VMT.

A large number of maintenance activities were summarized under pavement repair and replacement, shoulder maintenance, special purpose facilities. Other maintenance activities included signage, snow removal, drainage and vegetation. Expert judgement was used to separate pavement maintenance costs into weight-related and non-weight-related portions. The weightrelated portion of cost was distributed to user groups based on ESALs and the environmental share of damage by VMT.

\subsubsection{1997 Federal Highway Cost Allocation Study}

In the 1997 Federal Highway Cost Allocation Study [U.S. DOT, 1998], pavement reconstruction, rehabilitation and resurfacing (3R) costs were divided into load-related and nonload-related components. The nonload-related components is the portion that is related to factors such as pavement age and climate, etc. Reconstruction, rehabilitation and resurfacing costs for pavement were allocated to different vehicle classes on the basis of each vehicle's 
estimated contribution to pavement distress. Pavement distress models were used for the estimation of the relative cost responsibility of different vehicle classes for load related pavement $3 R$ costs on the different highway functional classes. The non-load related pavement $3 R$ costs were allocated in proportion to VMT for each vehicle class. The pavement distress models also estimate the share of total costs that related to pavement age and climate, etc.

\subsubsection{The 1984 Indiana Highway Cost Allocation Study}

Fwa and Sinha [1987] developed an aggregate damage approach to relate pavement performance to routine maintenance expenditures. This approach was based on the pavement serviceability index concept used in American Association of State Highway Officials (AASHO) road test in early 1960's. The concept of PSI-ESALs value as an aggregate representation of pavement deterioration due to cumulative use under a certain level of maintenance treatment was introduced. Based on the relationship between different maintenance level and PSI-ESALs value, zero maintenance performance curve was obtained through extrapolation.

In this model, factors that influence the performance of a highway pavement were classified into the following major categories: traffic loading, environmental effects, pavement routine maintenance, and pavement characteristics.

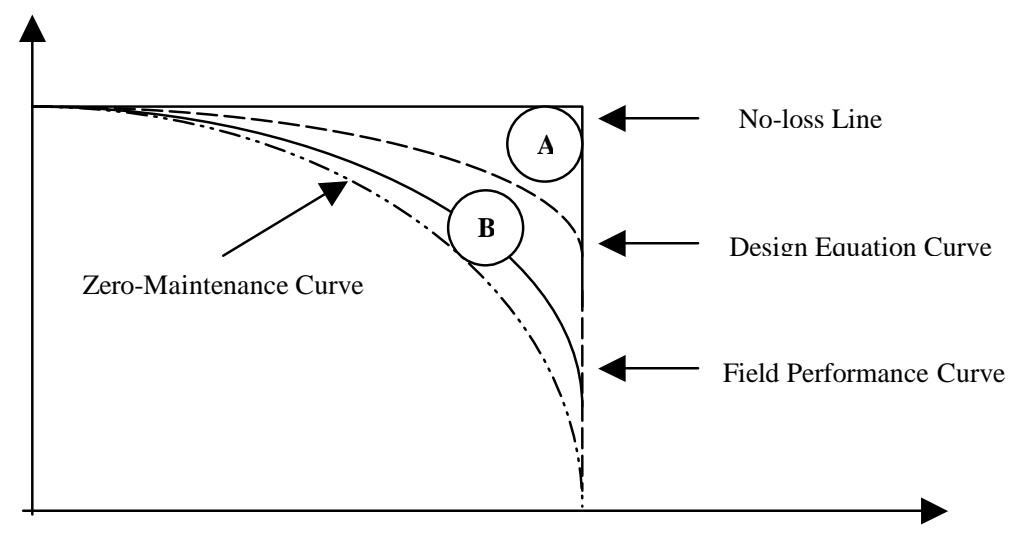

Figure 4. Graphic Description of Pavement Performance [Fwa and Sinha, 1987] 
For the effects of environment and traffic loading, it was first assumed that the deterioration of a zero-maintenance pavement could due to three effects: pure environmental, pure traffic loading, and an interaction between pure environmental and pure traffic loading.

An assumption of linear proportionality was made, as illustrated below:
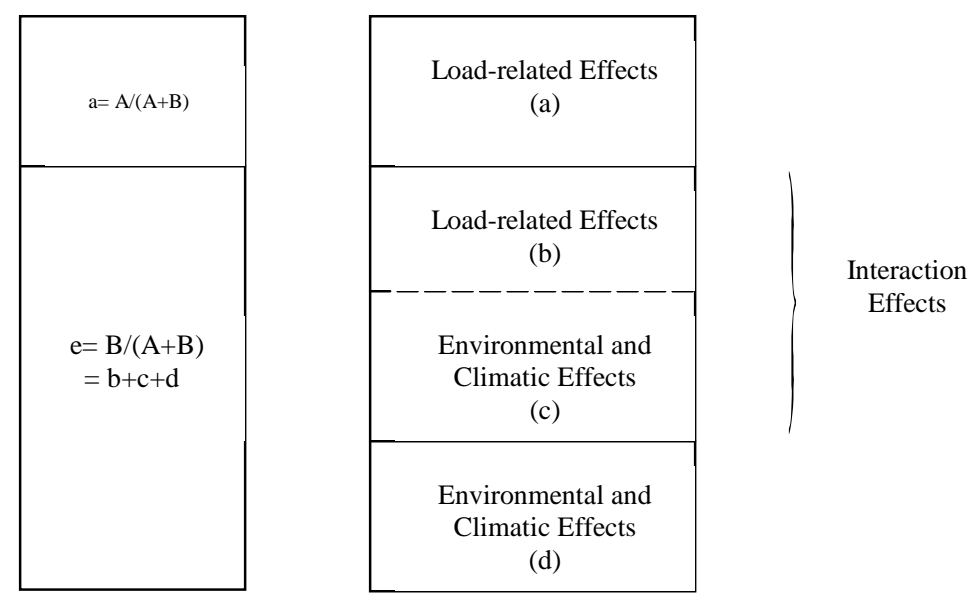

Figure 5. Proportionality Assumption of Pavement Performance [Fwa and Sinha, 1987]

Proportionality Assumption

$$
\begin{aligned}
& \frac{b}{(b+c+d)}=\frac{a}{(a+b+c+d)} \\
& \frac{c}{(a+b+c)}=\frac{d}{(a+b+c+d)}
\end{aligned}
$$

Equation (1-5) implies that the share of the traffic loading effects in the interaction is directly proportional to the share of the pure traffic loading effect in the overall effect. Similarly, equation (1-6) indicates that the share of the environmental effect in the interaction is also directly proportional to the share of the pure environmental effect in the overall effect. 


\subsubsection{Cost Allocation Implications of Flexible Pavement Deterioration Models}

Rilett et al. [1990] carried out a study to explore the cost allocation implications of current models used to predict the deterioration of flexible pavements. These models, according to the researchers, allow the separation of highway pavement life-cycle costs into joint and common costs and facilitate the allocation of joint costs to various vehicle classes on the basis of pavement damage characteristics. The study identified the following major types of pavement deterioration: surface distress associated with fatigue cracking, low temperature cracking, rutting, raveling, and bleeding or flushing; and roughness due to differential subgrade volume change, reduction in surface friction (skid resistance), and reduction in serviceability. The reduction in serviceability was of primary interest to the Ontario flexible pavement model, because this parameter not only represents a primary operating function for a pavement, but can also be directly related to vehicle operating cost. The model was derived from the load-related flexible pavement deterioration observed at the AASHO Road Test, the load-related and non-load- related pavement deterioration recorded at a long-term road test at Brampton, Ontario, and some theoretical analysis.

The first step in the study was the conversion of alternative pavement strategies into equivalent granular thicknesses using layer equivalencies based on the behavior of layered elastic systems and field observations. Then the deflection at the surface of the subgrade under the equivalent granular thickness was calculated for a standard dual-tire load $(40 \mathrm{kN})$. Also, a relationship was established between this theoretically estimated subgrade deflection and the number of standard axle load repetitions to failure observed at the AASHO Road Test. This step of the Ontario study uses this relationship and the ESAL pattern expected at a pavement site to estimate the Ride Comfort Index (RCI) loss due to traffic loading. A 0-10 scale is used for the RCI, and could be considered equivalent to twice the present serviceability index. 
In the fourth step, the RCI loss due to the environmental effects was estimated. RCI loss functions versus number of years in service for different magnitudes of subgrade deflection were developed from an integration of the experience at the AASHO and Brampton Road Tests. Finally, the RCI losses due to load and environment are then added to estimate the RCI versus age history of given pavement strategy. When a minimum acceptable level of RCI is reached, the pavement is overlaid and the performance of the resurfaced pavement is estimated in a similar way.

It was found that the traffic-related cost decreases with increasing initial pavement life (defined as the life cycle before the first overlay) because the environmental portion of the initial pavement costs increases with increasing initial pavement life and these initial pavement costs represent the bulk of the life cycle costs. The traffic-related portion of the total cost ranges from about one-third at lower traffic volumes to one-quarter at the higher traffic volumes.

\subsubsection{Load and Non-Load Implications from the SHRP Evaluation of}

\section{$\underline{\text { AASHTO Design Equations }}$}

Equations for individual distress including alligator cracking, rutting, transverse (or thermal) cracking, increases in roughness, and loss of surface friction, were developed as part of the study that suggested improvements to the AASHTO Design Equations [SHRP, 1994]. The equations are shown in section 1.2.1.2.

By designating some new variables and taking common logarithms of each side of the equation, the above equation can be transformed to estimate required layer thickness when allowable levels of distress are established and other independent variables (such as viscosity, environmental variables, other layer thickness, etc.) are defined. The transformed equation is as follows: 
$X_{T}=\frac{\left(\log _{10} \frac{D}{N^{B}}\right)-C_{X}}{C_{T}}$

where

$\mathrm{X}_{\mathrm{T}} \quad=$ Thickness of the base or HMAC;

D = Distress (in inches of rutting or inch/mile of roughness increase);

$\mathrm{N}=$ Number of cumulative ESALs in 1000's (KESALs);

B $\quad=b_{0}+b_{1} X_{1}+b_{2} X_{2}+\ldots \ldots+b_{n} X_{n} ;$ and

$\mathrm{C}_{\mathrm{X}} \quad=\mathrm{c}_{0}+\mathrm{c}_{1} \mathrm{X}_{1}+\mathrm{c}_{2} \mathrm{X}_{2}+\ldots \ldots+\mathrm{c}_{\mathrm{n}} \mathrm{X}_{\mathrm{n}}-\mathrm{C}_{\mathrm{T}} \mathrm{X}_{\mathrm{T}}$; and

$\mathrm{C}_{\mathrm{T}} \quad=$ Coefficient of the term $\mathrm{C}_{\mathrm{i}} \mathrm{X}_{\mathrm{i}}$ that includes the layer thickness of interest $\mathrm{X}_{\mathrm{T}}$.

$b_{0}, b_{1}, b_{2}, \ldots . ., b_{n} ;$ and $c_{0}, c_{1}, c_{2}, \ldots . ., c_{n}$ are coefficients; $X_{1}, X_{2}, \ldots \ldots, X_{n}$ are parameters.

This equation established the relationship between the pavement thickness and traffic load (expressed as KESALs). The load share of pavement damage could be determined as the ratio between load-related thickness and the actual thickness of the pavement.

\subsubsection{Review Summary}

Some available literature indicate that aggregate measures, such as roughness, are more appropriate for modeling pavement damage. As stated by Lytton [1988], one of the primary requirements for pavement performance modeling is the selection of variables for which data are available. As disaggregate approaches require extensive data needs that are often not available, most studies have resorted to the use of aggregate approaches.

The performance models that were reviewed generally incorporate the effects of environment and traffic volumes and loads. Therefore, such models facilitate the isolation of the effects of load and non-load factors of pavement deterioration. The Australian Road Research Board (ARRB) Pavement Model especially provides a simplified form that facilitates the separation of load and non-load effects, but obviously does not incorporate the interaction effects 
of load and the environment. The Small model provides yet another simple and practical way of determining the load and non-load effects of pavement damage and this concept was considered for current study. The FHWA and the Indiana Highway Cost Allocation Studies present systematic and comprehensive approaches for the determination of load and non-load shares of pavement damage. 


\section{CHAPTER 2 PROBLEM STATEMENT AND STUDY OBJECTIVES}

\subsection{Problem Statement}

All costs related to pavement maintenance and rehabilitation can be grouped into two classes: attributable and common costs. Attributable costs are those that can be related to specific vehicle classes. These include costs that are entirely attributable to a single vehicle class, a group of vehicle classes or to all vehicle classes, mostly in terms of vehicle loads.

On the other hand, common costs are those that can not be related to specific vehicular characteristics and vehicle use. A large part of the common costs results from the effects of age, weather, salt and other chemicals applied on highway surfaces.

To date, no consensus exists among researchers about the procedure to estimate the proportion of load and nonload-related expenditures. Consequently, there is a wide range of values available in the literature. For instance, in the 1997 Federal Highway Cost Allocation Study [U.S. DOT, 1998], about $80 \%$ of the pavement maintenance and rehabilitation expenditures was attributed to load-related factors of pavement damage. The Australian Road Research Board (ARRB) Pavement Model [Martin, 1994] suggested that load-related expenditures could be as much as $88 \%$. In 1984, the Indiana Highway Cost Allocation Study [Sinha et al., 1984] estimated that $70 \%$ of the pavement damage could be considered to be due to load factors, and $30 \%$ due to non-load factors. On the other hand, a recent study in Canada [Rilett et al., 1990] assessed the cost allocation implications of flexible pavement deterioration models and concluded that load share of pavement damage amounted to $25-35 \%$.

The scope of the present study involved the development of appropriate econometric models to relate pavement maintenance and rehabilitation expenditures with traffic loading and 
various non-load factors. The models were then used to estimate the share of load and non-load factors of these expenditures.

\subsection{Objectives of the Study}

The major work items within the scope of the present study included the following:

i) Analysis of pavement condition using International Roughness Index (IRI);

ii) Establishment of a function that relates maintenance and rehabilitation expenditures to pavement condition;

iii) Development of a function that relates pavement condition to load and non-load factors of pavement damage;

iv) Development of a function to relate maintenance and rehabilitation expenditures to marginal load-related factors; and

v) Determination of the load share of pavement repair costs.

In order to accomplish these tasks, an integrated database was established. This database contains data on pavement routine maintenance, rehabilitation, pavement condition, regional and climatic features, subgrade material characteristics, traffic, pavement age, and pavement design and construction features, for nearly 10,000 one-mile segments of pavements comprising the state highway network in Indiana.

Three regions, three highway classes, and three pavement types were considered in the current study. The three regions are northern, central and southern Indiana classified in accordance with INDOT jurisdictional divisions. As shown in Figure 6, northern region is comprised of LaPorte (L) and Fort Wayne (F) districts, central region consists Crawfordsville (C) and Greenfield (G) districts, and southern region consists of Vincennes (V) and Seymour (S) districts. The three highway classes are Interstate, State and U.S. Roads. The three pavement 
types are flexible, rigid and composite pavements. The framework of the current study is presented in Figure 7.

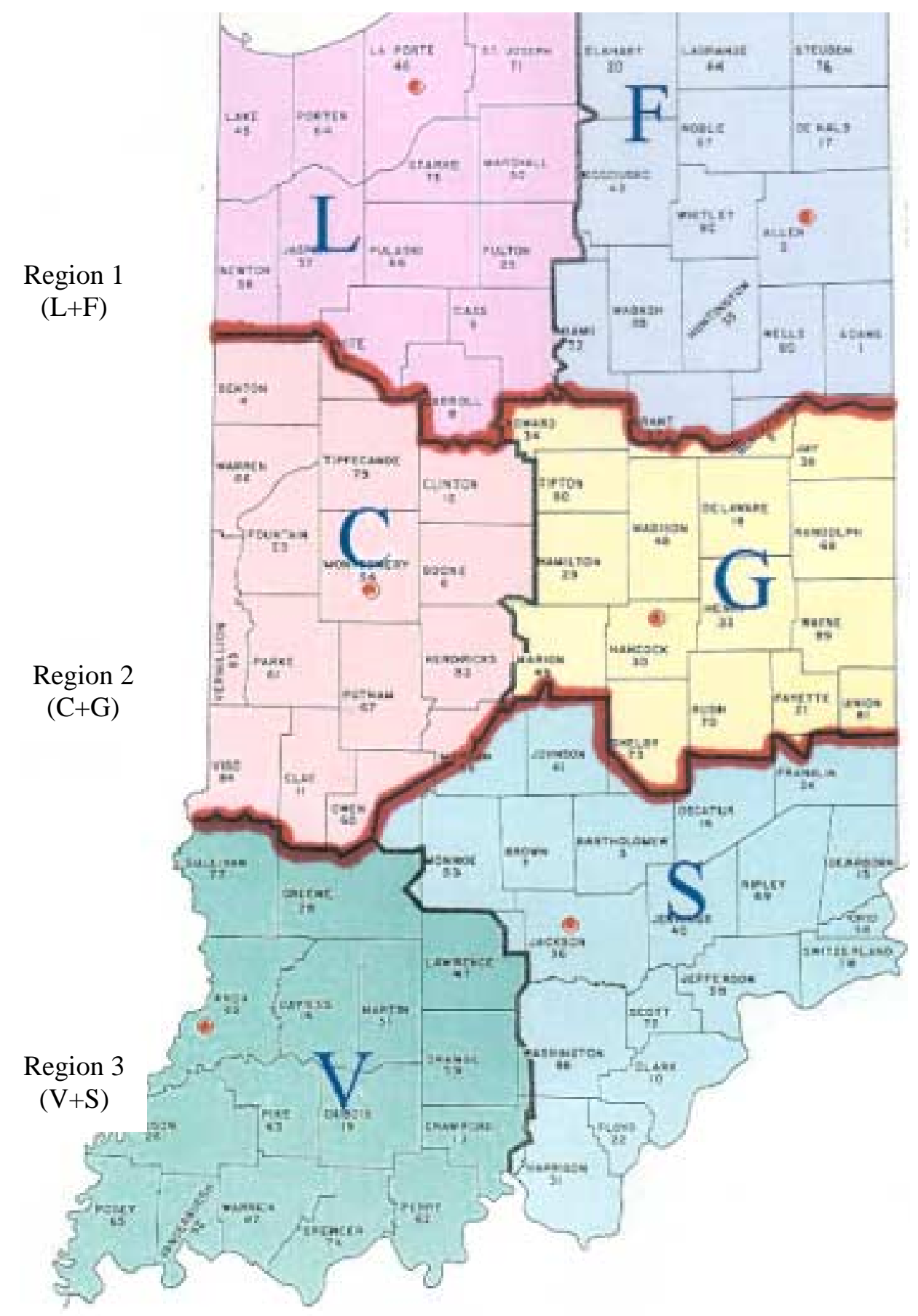

Figure 6. Three Regions Considered in the Present Study 


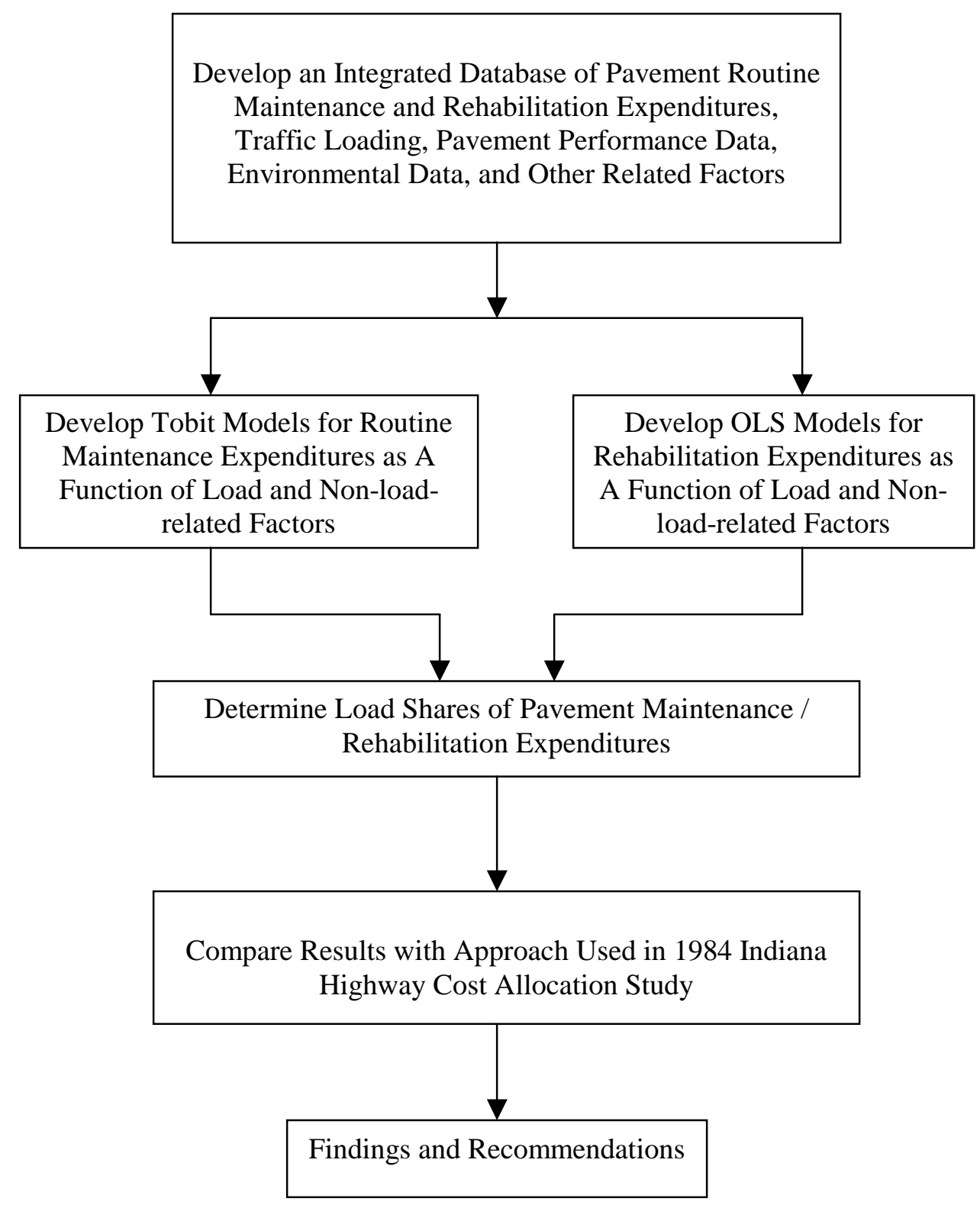

Figure 7. Study Framework 


\subsection{Report Organization}

The report is comprised of five chapters. Chapter 1 discusses the effects of maintenance and rehabilitation, and influence of load and non-load-related factors on pavement deterioration, as well as a literature review of pavement performance models and past studies on allocation of pavement maintenance and rehabilitation expenditures. Chapter 2 describes the problem statement and study objectives. Chapter 3 elaborates on study design, data collection and processing, and methodology used for the study. Chapter 4 mainly concentrates on the model development. For pavement segments on which routine maintenance work occurred, Tobit models were used and justification of the use of those models were provided. Also, Ordinary Least Square (OLS) models were conducted for model development of pavement segments with rehabilitation. Furthermore, the results of applying the proposed method for quantifying the load share of pavement maintenance and rehabilitation expenditures are included in the same chapter. Finally, Chapter 5 presents a summary of study results and compares the results to those of the 1984 Indiana Highway Cost Allocation Study. Areas for future work and research are also identified in this chapter. 


\section{CHAPTER 3 WORK PLAN}

\subsection{Introduction}

It has long been recognized that pavement performance is a manifestation of the aggregated response of a pavement under the combined effects of traffic, environment, age, pavement characteristics and maintenance. In order to establish a theoretically sound and practically usable approach for determining load and non-load shares, a database was developed including maintenance and rehabilitation costs, pavement condition, traffic, region and climatic features, subgrade material characteristics, age, design and construction features focusing on the entire state of Indiana.

\subsection{Study Design}

\subsubsection{Introduction}

Some important aspects about the study design was the manner by which the study was broken down to capture all fine details necessary for the analysis. In particular, highway classification, vehicle classes, pavement types, study period were defined at the onset of the study. A brief description of some preliminary aspects of the study design are provided below:

(a) Highway Classification: Based on the availability of raw data set, three major highway categories were considered in this study: Interstate, State, and U. S. roads.

(b) Vehicle Classification: Traffic data were obtained on the basis of average annual daily traffic survey conducted by Indiana Department of Transportation. In order to facilitate ESAL computations, the vehicle classification used in AASHTO traffic data survey was adopted in the current study as follows: 
Class 1: Motorcycles (axles: 1ST+1S);

Class 2: Passenger Cars (axles: 1ST+1S);

Class 3: Two-axle, 4-tire single units (axles: 1ST+1S);

Class 4: Buses (axles: 1ST+1S);

Class 5: Two-axle, 6-tire single units (axles: 1ST+1S);

Class 6: Three-axle single units (axles: 1ST+1T);

Class 7: Four or more axle single units (axles: 1ST+1TR);

Class 8: Four or less axle single trailers (axles: $1 \mathrm{ST}+2 \mathrm{~S} / 3 \mathrm{~S}$ );

Class 9: Five-axle single trailers (axles: 1ST+2T);

Class 10: Six or more axle single trailers (axles: $1 \mathrm{ST}+1 \mathrm{~T}+1 \mathrm{TR}$ );

Class 11: Five or less axle multiple trailers (axles: $1 \mathrm{ST}+3 \mathrm{~S} / 4 \mathrm{~S})$;

Class 12: Six-axle multiple trailers (axles: $1 \mathrm{ST}+3 \mathrm{~S}+1 \mathrm{~T})$; and

Class 13: Seven or more axle multiple trailers (axles: $1 \mathrm{ST}+2 \mathrm{~S}+2 \mathrm{~T})$.

Note: S-single axle; T-tandem axle; and TR-tridem axle.

(c) Region: Both maintenance and rehabilitation costs and pavement performance vary in different regions of Indiana due mainly to the variation of travel patterns and severity of weather conditions. Therefore, the State of Indiana was divided into three regions: northern, central and southern. Northern region covered Laporte and Fort Wayne districts of Indiana Department of Transportation (INDOT), central region included Crawfordsville and Greenfield districts, and southern region consisted of Vincennes and Seymour districts.

(d) Pavement Type: The data were grouped into three pavement types: flexible, rigid pavement, including jointed concrete pavement (JCP) and continuously reinforced concrete (CRC) pavements, and composite.

(e) Study Period: The data for the analysis were from the 5-year period of 1994-98. 


\subsubsection{Design of Experiment}

The main objective of the design of experiment for the study was to devise an appropriate statistical method of analysis so that the data collected could be adequately used to enable the drawing of valid inferences about the effect of selected independent variables on the response variable. The design of the experiment followed the following basic steps:

- Definition of the problem

- Selection of response variables

- Selection of explanatory variables

- Formulation of the model

\subsubsection{Definition of the Problem}

Highway cost allocation seeks to distribute expenditures of repairing pavement damage among various users of the roadway in an equitable manner. For this objective to be realized, it is important to estimate the shares of pavement damage due to load and non-load factors, not only for each type of pavement, but also for each category of pavement repair. The determination of the relative damage factors was the focal point of the present study. It was assumed that the relative share of pavement damage was directly proportional to the amount of money spent on rehabilitating or maintaining it. 


\subsubsection{Choice of Response Variables}

\subsection{General}

Due to the time and expense involved in the collection of data for the primary response type, and the non-standardization of response variables to indicate structural conditions, the response variable that is typically used for performance modeling are those that describe the functional performance of the road, such as roughness. Roughness is expressed in counts per unit length of road and is measured by equipment mounted on a vehicle at constant speed on the road. This study includes the use of roughness as a measure of pavement performance [Perera et al., 1995] due to the following reasons:

- All states have roughness data for most of their highway sections, over a relatively long period of time,

- Public perception of pavement performance has been found to be directly related to pavement roughness,

- There exists relationships between roughness and other common aggregate measures of pavement performance such as PSI,

- Roughness can be related to the deterioration of pavement structures.

There are many ways of expressing roughness of a pavement surface. These include Root Mean Square Vertical Acceleration (RMSVA), Roughness Number (RN), and International Roughness Index (IRI). Of these, IRI was chosen due to the following reasons:

1. Previous studies have found a high degree of correlation between the overall assessment of pavement surface condition and roughness. For example, in a recent study utilizing the FHWA database, a prediction model for IRI of Jointed Plain Concrete Pavement (JPCP) indicated that roughness could be predicted as a function of visible distress, including joint faulting (mm/mile), spalling (\% of the joints spalled medium-high severity), and transverse cracking (\# of cracks/mile). 
2. Although other assessment of pavement surface condition, such as cracking and rutting, also reflect pavement surface condition and in many cases are responsible for initiating maintenance, IRI data is inexpensive and easy to collect; and,

3. IRI measurements relates directly to road user costs in life cycle costing.

\subsection{Use of Pavement Damage Index as a response variable}

Damage is normalized distress or loss of serviceability index. Damage starts at zero and becomes 1.0 when an unacceptable level of distress of serviceability is reached. The damage equation used at the AASHO Road Test is of the form:

$$
g=\frac{p_{i}-p}{p_{i}-p_{t}}
$$

where

g = "Damage index" after the passage of W standard loads or equivalent standard loads;

$\mathrm{p}_{\mathrm{i}} \quad=$ Initial serviceability index;

$\mathrm{p}_{\mathrm{t}} \quad=$ Terminal or unacceptable level of serviceability index; and

$\mathrm{p} \quad=$ Serviceability index after the passage of $\mathrm{W}$ standard loads.

Using roughness to represent serviceability, the damage index can be expressed in terms of IRI in the following manner:

Damage Index $D I_{t}=\frac{I R I_{I}-I R I_{t}}{I R I_{I}-I R I_{T}}$

where

$\mathrm{DI}_{\mathrm{t}} \quad=$ Damage index at time $\mathrm{t}$;

IRI $_{\mathrm{I}}=$ Initial IRI;

IRI $_{\mathrm{T}}=$ Terminal IRI; and

IRI $_{\mathrm{t}}=$ IRI at time $\mathrm{t}$. 
A pavement's performance over time depends on a number of factors including pavement strength in conjunction with the underlying subgrade strength, cumulative traffic loading on the pavement, environmental effects, pavement maintenance (routine and periodic), rehabilitation (improvement) practices, and existing surface condition of the pavement.

As available records do not include road condition at the time of construction, it is difficult to establish the damage index. Therefore, it is needed to modify the index but retain the concept of damage, in order to obtain a realistic index for which observations are available. In this regard, a Modified Damage Index (MDI) was proposed for pavement segments with routine maintenance and with rehabilitation respectively in this study.

For segments with routine maintenance in a given year $t$, the formula can be written as relative change in IRI between two consecutive years [Al-Suleiman and Sinha, 1988] as below:

$$
\begin{aligned}
& M D I_{t}=\frac{I R I_{t}-I R I_{t-1}}{I R I_{t-1}} \\
& \text { where } \\
& \text { MDI }_{\mathrm{t}}=\text { Modified damage index at year } \mathrm{t} ; \\
& \text { IRI }_{\mathrm{t}-1}=\text { IRI at year } \mathrm{t}-1 \text {; and } \\
& \text { IRI }_{\mathrm{t}}=\text { IRI at year } \mathrm{t} .
\end{aligned}
$$

For segments receiving rehabilitation work during a life cycle of T years, the MDI can be defined as the relative change in IRI between the initial and terminal values during the life cycle, as shown below:

$$
M D I_{T(\text { life cycle })}=\frac{I R I_{T}-I R I_{0}}{I R I_{0}}
$$

where

$$
\begin{array}{ll}
\mathrm{MDI}_{\mathrm{T}(\text { life cycle })} & =\text { Modified damage index in one life cycle of } \mathrm{T} \text { years; } \\
\mathrm{IRI}_{0} & =\text { Initial IRI in the life cycle; } \text { and } \\
\mathrm{IRI}_{\mathrm{T}} & =\text { Terminal IRI in the life cycle. }
\end{array}
$$


The length of one life cycle is determined as the time interval between the completion of the last major work (construction or a subsequent rehabilitation) and the beginning of the next rehabilitation work. Maintenance during the period $\mathrm{T}$ was implicitly considered in the analysis as the pavement section that received rehabilitation also had maintenance activities.

\subsubsection{Choice of Independent Variables}

A number of variables have been found to provide explanation for the amount of pavement damage and subsequently on the amount of money expended on maintenance and rehabilitation. These include the following:

- Environmental region

- Subgrade materials

- $\quad$ Pavement usage

- Structural capacity of the pavement

- Pavement age

- Pavement type

Discussions of these explanatory factors are presented as follows:

(a) Environmental region

Pavements in northern part of Indiana are expected to cold regions have been observed to behave differently from those in the south. The transition from one temperature-state to another, or the freeze-thaw cycle, is largely responsible for most of the pavement damage in such climates. Such transitions cause weakening of bonds in the pavement materials and also causes volume changes in the pavement layer materials and any moisture that occupy the voids of such materials. PCC pavements in particular, are very sensitive to freeze-thaw action. 
Temperature levels and variations are not enough to capture the effects of the environment. Effects of moisture also need to be considered. Wet regions are associated with longer periods of rainfall and greater rainfall intensities. As water is a major factor in pavement deterioration, pavements in wet areas are generally expected to exhibit relatively more rapid rates of deterioration compared to those in drier areas, all other factors being equal. Road sections that suffer from a high water table or that have numerous surface cracks that allow the ingress of surface precipitation are vulnerable to prolonged wetting of their subgrades, with possible subsequent loss of strength and progressive deterioration of the pavement.

(b) Subgrade materials

The subgrade is the structural element upon which the entire pavement is founded, and is an important part of the pavement structure. A subgrade with particles that has a high percentage of fine material is susceptible to reduced strength upon wetting and is more likely to contribute significantly to accelerated deterioration of the overlying pavement. In some areas, the natural ground may be good enough as a subgrade. At other areas, the subgrade consists of special imported fill material either to replace an existing weak natural soil, or to raise the road above the existing ground level.

\section{(c) Pavement usage}

Repeated loading and unloading of a pavement can lead to fatigue failure. Therefore the total amount of traffic loading subjected to pavement section is a critical predicator of the pavement condition and performance. The traffic monitoring units of state, provincial and metropolitan highway agencies currently collect data on traffic volumes, vehicle classifications, and sometimes, vehicle weights. These organizations have devised methods that use these primitive data types to generate annual ESAL values for road sections in their jurisdiction. 
Annual ESAL values summed up over the life of the pavement (period since construction or last rehabilitation) yield the Cumulative ESALs (CESALs).

(d) Structural capacity of pavement (pavement thickness, or structural number)

The condition of a pavement is related to its ability to withstand traffic loading, i.e., its structural capacity. The thicker a pavement, the greater its strength and the lower its susceptibility to load-related pavement distresses. Pavement thickness refers to the total thickness of the surface layer, base and subbase.

(e) Pavement age

All materials experience wear and tear with time, and over time, asphalt in flexible pavements oxidizes and becomes brittle and susceptible to cracking, a process that is accelerated by traffic loading. Also, concrete slabs in rigid pavements are known to suffer from chemical reactions between air and the upper one-third inch of concrete, weakening the concrete and rendering it vulnerable to eventual breakup and erosion.

\section{(f) Pavement type}

The ability of a pavement to resist traffic loading, its deformation patterns in response to traffic and temperature stresses depends on the nature of the pavement material. Pavement type refers to the material type used for the surface layer of the pavement structure. Most pavements generally consist of a subbase and/or base, and the surface layer type is labeled rigid or flexible depending on the type of binder used to cement the top-layer aggregates. If Portland cement is used the pavement is described as a Portland Cement Concrete (PCC) or rigid pavement. If bituminous cement is used, the pavement is a Hot Mix Asphalt (HMA) pavement. Composite pavements refer to as asphalt overlays on PCC. 


\subsubsection{Choice of Model Types}

A model is the representation of a system in which a set of explanatory variables come together to provide a certain response. In the case of statistical experiments, a model is a mathematical relationship that describes the value of an observation in terms of a set of factors and an error component over which there is no control. A statistical model, if correctly specified, is capable of explaining random observation responses for all experimental conditions.

The three important considerations for good models are a good set of explanatory variables, an appropriate response variable, and a performance model type that adequately explains the relationship between the selected independent variables and the response variable. Independent variables and response variables have already been discussed in previous sections. As indicated by Lytton, there are several ways of measuring pavement performance, and therefore there are many types of performance models and these can be broadly classified into two categories: probabilistic models and deterministic [Lytton, 1988]. Probabilistic models typically yield a range of response variables. Examples include survivor curves, and transition process models such as Markov and semi-Markov models. Probabilistic models are particularly useful for network level performance modeling. Deterministic models can be broken down into the following:

- $\quad$ purely mechanistic models (relationship between a response parameter such as stress or strain, and deflection),

- mechanistic empirical models (relationship between a response parameter, such as roughness, cracking, and traffic loading),

A large number of different deterministic-based pavement performance prediction models have been developed for state and local pavement management systems. The models used for the current study were of a deterministic nature. 


\subsubsection{Use of Econometric Methods}

\subsection{General}

Econometrics may be defined as the field of economics in which the tools of mathematical statistics and statistical inference are applied to the empirical analysis of economic phenomena [Goldberger, 1964].

Economic theory is typically concerned with exact functional relationships among economic variables. However, most casual inspection of empirical economic data shows that such exact relationships do not hold in reality. The econometric method provides a linkage between the exact relationships of economic theory and the disturbed relationships of economic reality. In other words, it is the rational method that is grounded in a specification of probabilistic mechanisms that link the economic observations to economic theory.

Recently there has been a trend towards the use of econometric modeling techniques to explain pavement behavior in response to factors that influence pavement damage [Ben-Akiva, 1992] [Gopinath et al., 1996] [Ramaswamy and Ben-Akiva, 1997] [Mohammed et al., 1997]. These techniques have also been used to model and predict the probability or amounts of maintenance as a function of pavement damage and other explanatory factors. The results provided by econometric models have proved to be more consistent with actual observation, compared to those offered by traditional methods. Econometric techniques are also equipped with appropriate tools available to help avoid biases such as selectivity bias, simultaneity bias and endogeneity bias. 


\subsection{Pavement Segments with Routine Maintenance Work}

In this study, econometric methods were used to model damage on pavements that had received maintenance. The main reasons for using these methods for pavement performance modeling based on routine maintenance work, are enumerated and explained as follows:

i) Cause-effect relation between pavement condition and maintenance expenditures with concern of probabilistic mechanisms in selecting pavement segments for the maintenance.

ii) Deal with non-experimental data, which may contain error of measurement, special methods of analysis needed.

Because maintenance work was carried out to only a certain proportion of the one-mile pavement segments that require maintenance in each year due to budget constraint, bias will be introduced if focus is placed only on those pavements with work implemented in that year. Therefore, probabilistic consideration of choosing one segment or not due to maintenance needs in each year should be reflected by using an appropriate econometric model. Conventionally, there are two categories of probabilistic models deal with such situations, namely, the probabilistic models using qualitative dependent variable and those using limited dependent variables.

\section{(a) Probabilistic Models with Qualitative Dependent Variables}

The most commonly used is the linear probability function. The dependent variable can only take two values, 0 (if the event does not occur) and 1 (if the event occurs). Then the classical least-square estimators are generated by treating the dichotomous dependent variable problem as an ordinary linear regression problem. The weakness of this approach is that the assumption of homoskedasticity of the error term is untenable. Also, the absence of negative values of the qualitative dependent variable tends to keep the regression line above the axis over the relevant 
range of the independent variable(s). This will result in an overestimated value in lower end, and an underestimated value in the higher end. Furthermore, the linear probability function allows the expected values of the dependent variable fall outside the interval between 0 and 1 .

Alternatively, the probit analysis model could keep the expected values of the binary dependent variable within the unit interval from the start by using a critical value with standard normal distribution. The dependent variable will be one only if the predictor exceeds the threshold value, it will otherwise take the value of zero. Maximum likelihood estimation was then conducted to obtain maximum likelihood estimators.

(b) Probabilistic Models with Limited Dependent Variables

(i) The 2-stage procedure

One disadvantage of the use of probabilistic models with qualitative dependent variables is that such models are only concerned with whether or not an event occurs, without any information on the extent of occurrence. To incorporate the effect of extent (e.g., amounts spent on maintenance), a two-stage linear probability approach may be used. However, a two-stage procedure considered inferior to the Tobit model (discussed below), as it uses limited information maximum likelihood estimation, which yields less accurate results compare to the latter.

\section{(ii) Tobit Model}

The Tobit (Tobin's probit) model could avoid such bias caused by using reduced information to conduct model development. The basic idea of Tobit model is to create a threshold value for the occurrence of an event, for instance, choosing a segment for maintenance. In our case, the critical value is exactly zero. If the cost is greater than zero, it means work is implemented on the segment; otherwise, no maintenance is carried out on that segment. All pavement segments are then grouped into two categories: those selected for maintenance and 
those not selected for maintenance. The joint maximum likelihood function for the two categories were computed. The point estimators for each independent variable included are obtained by taking the partial derivative of the likelihood function. Naturally, those maximum likelihood estimators are unbiased.

The censored regression (Tobit) model is considered more appropriate in cases where the distribution of a variable is censored by a capacity or in this case, maintenance budget [Greene, 1999]. According to Greene, "when data are censored, the distribution that applies to the sample data is a mixture of discrete and continuous distribution". For this reason, the OLS (which is purely for continuous variables) is not appropriate, and the Tobit model is required.

\subsection{Pavement Segments with Rehabilitation Work}

In the case of rehabilitation, there is no censoring as explained for maintenance. Therefore, the use of OLS analysis suffices. The use of regression techniques assumes that the errors are normally distributed and their variance is homogeneous, i.e., their distribution about the mean error does not systematically vary with the variation of the predicted value of the dependent variable. The assumptions underlying the use of regression need to be verified in the data before it is used.

National Cooperative Highway Research Program (NCHRP) Synthesis (223 Cost Effective Preventive Pavement Maintenance) suggests that the actual performance curve for a section of pavement could be determined by performing a regression analysis of time-condition. Indeed, most past studies on pavement rehabilitation have used this model type. Moreover, regression models have been successfully used by several state pavement management systems for a long time. In current study, regression models were used to establish the relationship of pavement rehabilitation expenditures and load and non-load-related factors. 


\subsubsection{Procedure for Determining Load and Non-load Shares of Maintenance Expenditures}

The steps followed in the procedure to estimate load and non-load shares of maintenance work are discussed below (see Figure 8):

Step 1: Creation of Modified Damage Index -Load and Non-load Factors Function

The Modified Damage Index (MDI)-load and non-load factors functions were developed with the data related to damage index or relative change in IRI between two consecutive years, regional and climatic features, subgrade materials, annual traffic, design and construction specification and pavement age. The relationship is expressed as follows:

$\mathrm{MDI}_{\mathrm{t}}=\mathrm{f}$ [Annual Routine Maintenance Expenditures ${ }_{\mathrm{t}}$, Region \& Climates, Subgrade Materials, Annual ESALs t (18 kips /year/lane-mile), Age (year), Design \& Construction]

Step 2: Expected Annual Routine Maintenance Expenditures -Modified Damage Index Function Based on the per lane-mile Annual Routine Maintenance Expenditures (ARME) and MDI developed at the data preparation stage, the relationship between MDI in year $\mathrm{t}$ and expected ARME in year $\mathrm{t}+1$ for each pavement type was established. The mathematical expression is as follows:

Expected ARME $_{t+1}=\mathrm{f}\left[\mathrm{MDI}_{\mathrm{t}}\right.$, District, Road, Age, etc. $]$

Step 3: Marginal Change in Pavement MDI Caused by Load Factor Marginal change in pavement MDI caused by load factor is defined as percentage change of pavement MDI of providing pavement structure for one additional passage of a unit vehicle load (expressed as one ESAL). From step 1, the marginal change in pavement MDI was then found by partially differentiating the MDI in year $\mathrm{t}, \mathrm{MDI}_{\mathrm{t}}$, with respect to annual traffic loading in year $\mathrm{t},(\mathrm{ESALs})_{\mathrm{t}}$ :

Marginal MDI $_{\mathrm{t} \text { (load) }}=\frac{{\partial \mathrm{MDI}_{\mathrm{t}}}}{{\text { ESALs }(18 \mathrm{kips} / \text { year/lane-mile })_{\mathrm{t}}}_{\mathrm{E}}}$ 
Step 4: Expected Routine Maintenance Expenditures Needed due to Load Factor

From step 2, the marginal expected ARME was obtained by partially differentiating the expected ARME in year $t+1$ with respect to the MDI in year $t$ :

Marginal ARME $_{t+1}=\underline{\text { Change in Expected ARME }}{ }_{t+1}$

Change in $\mathrm{MDI}_{\mathrm{t}}$

At this stage, the expected ARME in a given year due to load factor of the previous year was obtained by simultaneously considering the marginal effects of cost with respect to MDI, and MDI to traffic loading. The relationship is expressed below:

Expected ARME $\mathrm{t}_{\mathrm{t}+1 \text { (Due to load only) }}=\left[\Delta \mathrm{ESAL}_{\mathrm{t}} * \frac{\partial \mathrm{MDL}_{\mathrm{t}}}{\partial \mathrm{ESALs}_{\mathrm{t}}}\right] *\left[\frac{\partial \mathrm{ARME}_{\mathrm{t}+1}}{\partial \mathrm{MDI}_{\mathrm{t}}}\right]$

Step 5: Determining the Load Share of Pavement Routine Maintenance Expenditures

Finally, the expected routine maintenance expenditures in a given year caused by the traffic loading of the previous year was determined. In other words, the calculated amount is the amount required to sustain the existing pavement condition and to prevent it from further load-related deterioration. Because the actual total maintenance expenditures for next year is known, the load share will just be the ratio of the expected maintenance expenditures due to load only and the total maintenance expenditures pledged, as expressed below:

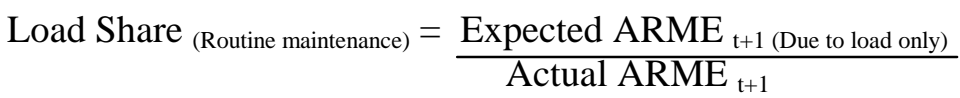

The load shares of routine maintenance expenditures for flexible, rigid and composite pavements for the entire state of Indiana were computed by following this procedure. 


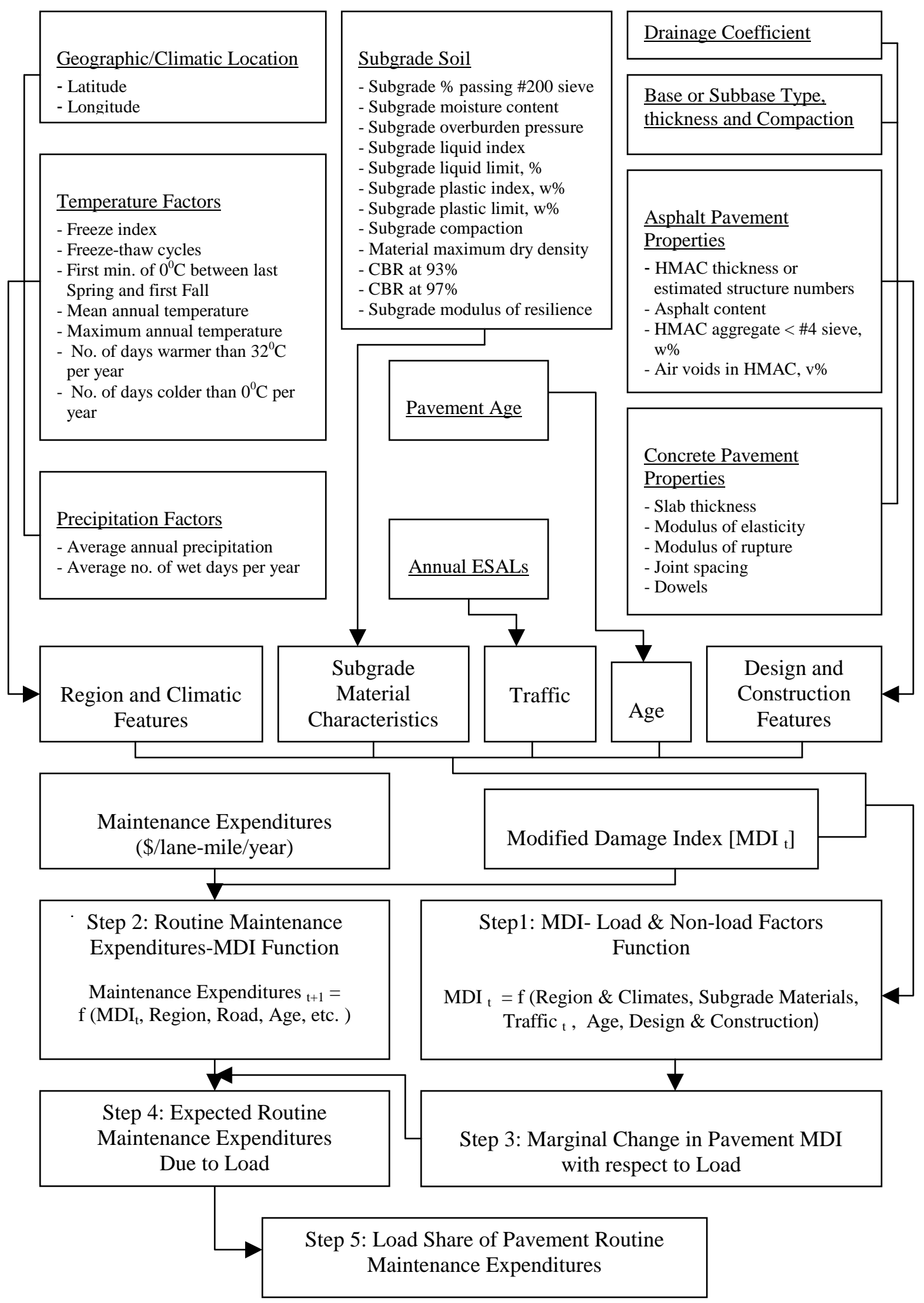

Figure 8. Procedure for Determining the Load Share of Pavement Routine Maintenance Work 


\subsubsection{Procedure for Determining Load and Non-load Shares of Rehabilitation Expenditures}

The steps followed to estimate load and non-load shares of rehabilitation work are discussed below (see Figure 9):

Step 1: Creation of Modified Damage Index -Load \& Non-load Factors Function

The Modified Damage Index (MDI), and load and nonload factor functions were developed with the data of relative change in IRI in one life cycle, regional and climatic features, subgrade materials, cumulative traffic loading in one life cycle, design and construction standards and pavement age. The relationship is listed as follows:

$\mathrm{MDI}_{\mathrm{T} \text { (life cycle) }}=\mathrm{f}\left[\right.$ Region \& Climates, Subgrade Materials, Cumulative ESALs ${ }_{\text {(life cycle) }}$ (18 kips /lane-mile), Age (year), Design \& Construction]

Step 2: Expected Rehabilitation Expenditures-Modified Damage Index Function

Based on the per lane-mile rehabilitation expenditures and MDI in one life cycle prepared in data processing phase, the relationship between MDI in one life cycle and expected rehabilitation cost for each pavement type was established. The relationship is expressed as follows:

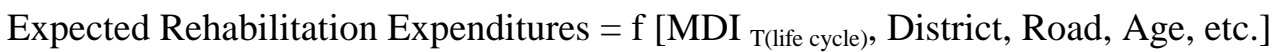

Step 3: Marginal Change in Pavement MDI Caused by Load Factor

Likewise, the marginal change in pavement MDI in one life cycle was then found by

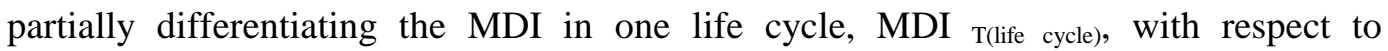
cumulative traffic loading in the same cycle, Cumulative ESALs (life cycle):

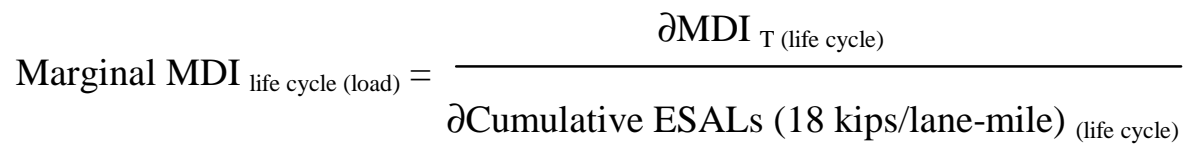


Step 4: Expected Rehabilitation Expenditures Needed due to Load Factor

Based on step 2, the marginal expected rehabilitation expenditures could be obtained by partial differentiating the expected rehabilitation expenditures after the completion of the previous cycle with respect to the MDI in the previous cycle:

\section{Marginal Expenditures $_{(\text {Rehabilitation })}=\underline{\partial \text { Expected Rehabilitation Expenditures }}$ \\ $\partial \mathrm{MDI}_{\mathrm{T} \text { (life cycle) }}$}

Accordingly, by simultaneously considering the marginal effects of rehabilitation expenditures with respect to damage index in previous life cycle, and such MDI to cumulative load in the same cycle, the rehabilitation expenditures needed for the restoration of the pavement damages caused by the effect of cumulative load during the previous cycle could be obtained.

The relationship is shown as follows:

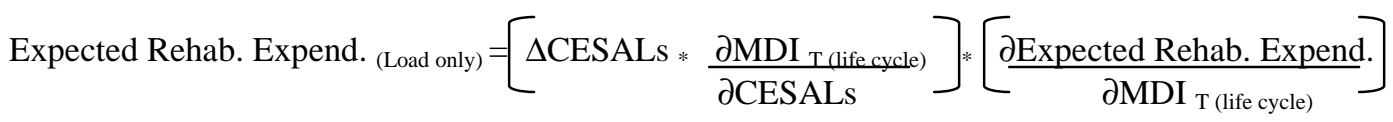

Step 5: Determining the Load Share of Pavement Rehabilitation Expenditures

In previous step, the expected rehabilitation expenditures caused only by the traffic loading of the previous life cycle was determined. Since the actual total rehabilitation expenditures is known, the load share could be determined as the ratio of the expected load-related rehabilitation expenditures and the total rehabilitation expenditures, namely: Load Share $($ Rehabilitation $)=\frac{\text { Expected Rehabilitation Expenditures }}{\text { Actual Total Rehabilitation Expenditures }}$

The life-cycle load shares for damage on flexible, rigid and composite pavements in the entire state of Indiana were found using this method. 


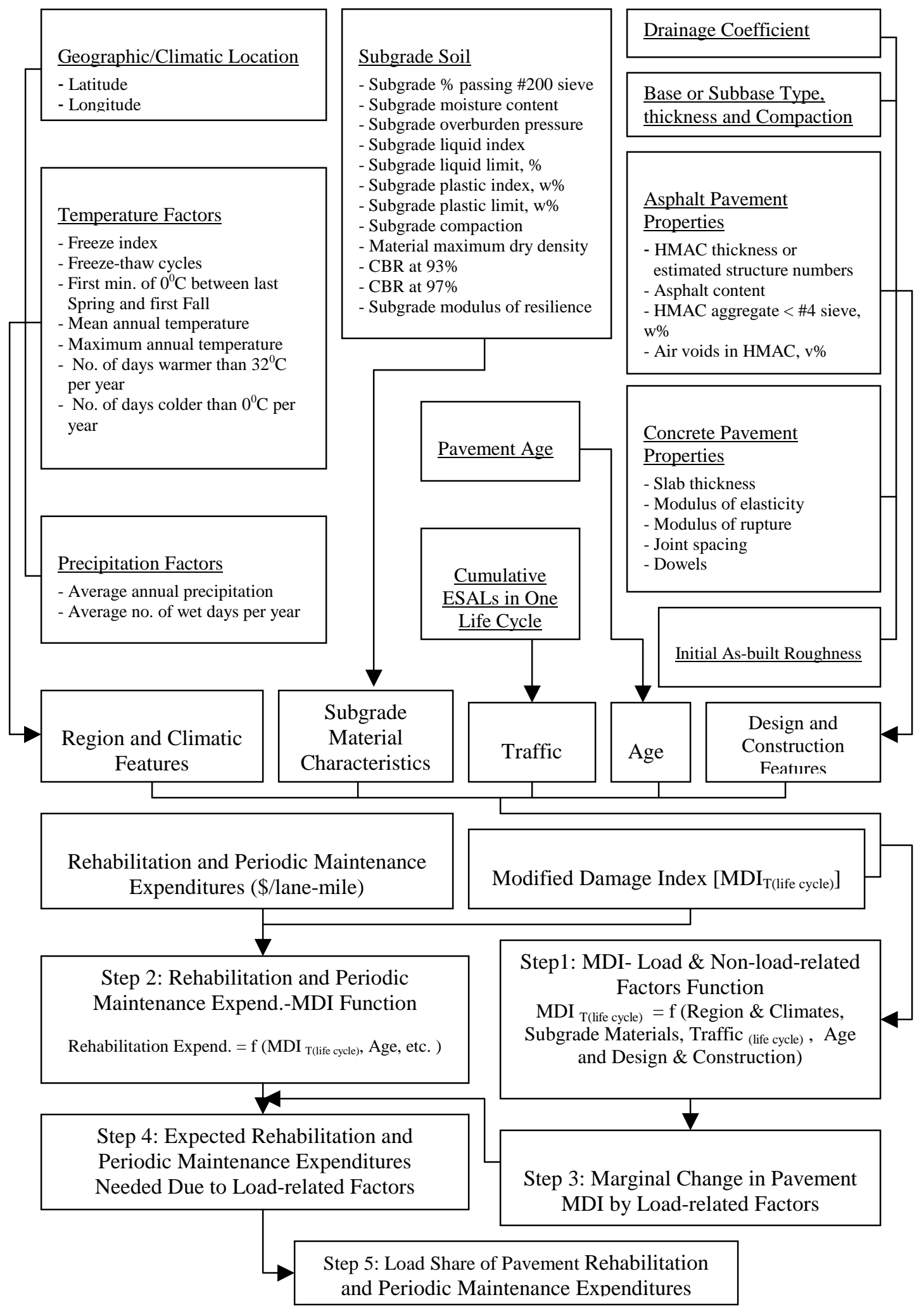

Figure 9. Procedure for Determining the Load Share of Pavement Rehabilitation and Periodic Maintenance Work 


\section{$\underline{\text { 3.3 Data Collection and Processing }}$}

\subsubsection{Data Collection}

Generally, capital expenditure data (including periodic maintenance expenditures by contracting) are available on the basis of individual contracts awarded during the analysis period. Other data items are collected or generated per mile, using the linear referencing milepost system used for pavement condition survey for the Indiana Pavement Management System (IPMS). The details of data items collected are listed in Table 2.

Table 2. Data Items and Sources

\begin{tabular}{|c|c|c|c|c|}
\hline DATA TYPE & CATEGORY & RANGE & PERIOD & SOURCE \\
\hline Expenditures & $\begin{array}{l}\text { i) Maintenance and rehabilitation contracts } \\
\text { ii) Routine maintenance records by force } \\
\text { account in each district }\end{array}$ & Entire state & 1993-98 & $\begin{array}{c}\text { INDOT Planning Division \& } \\
\text { Roadway Management Division }\end{array}$ \\
\hline Pavement Condidtion & International roughness index (IRI) & Entire state & 1994-98 & INDOT Roadway Management Division \\
\hline Climatic Feature & Temperature and precipitation & 92 counties & 1994-98 & Indiana Climatic Center \\
\hline Subgrade Materials & Soil Properties & Entire state & 1994-98 & INDOT Division of Materials and Tests \\
\hline Traffic & $\begin{array}{l}\text { i) Weigh-in-motion (WIM) data } \\
\text { ii) Average annual daily traffic (AADT) }\end{array}$ & $\begin{array}{c}35 \text { WIM stations } \\
\text { Entire state }\end{array}$ & $\begin{array}{l}1993-98 \\
1994-98\end{array}$ & INDOT Roadway Management Division \\
\hline Pavement Age & Pavement age and thickness & Entire state & 1994-98 & INDOT Roadway Management Division \\
\hline $\begin{array}{l}\text { Pavement design } \\
\text { and construction }\end{array}$ & $\begin{array}{l}\text { Drainage coefficient, sub/base thickness, } \\
\text { compaction, asphalt and concrete properties }\end{array}$ & Entire state & 1994-98 & $\begin{array}{l}\text { INDOT Division of Materials and Tests\& } \\
\text { Roadway Management Division }\end{array}$ \\
\hline
\end{tabular}

\subsubsection{Data Processing and Validation}

In view of varying data availability and validity for the various years within the study period originally considered for the study, the analysis period for the study was changed to 1995 97. Some data items were either not directly available from the raw data source and had to be processed. Also, data for certain years within 1995-1997 were not available, efforts were made in generating such data. For example, extrapolation was used in determining the initial pavement condition during one life cycle for pavement segments with capital cost. Likewise, interpolation 
was used to impute missing environmental data. After an in-depth literature review a new approach was introduced to compute the ESAL values from raw traffic data.

\subsubsection{Data processing to obtain initial IRI values during one life cycle for pavement segments} that had undergone rehabilitation

Pavement rehabilitation is carried out when pavement surface condition reaches an unacceptable level, which usually occurs after it has accumulated a certain level of traffic loading. After rehabilitation, the pavement is assumed to revert to its original perfect condition, and a new life cycle is commenced at a time referred to as "age zero". In order to quantify the relationship between change in pavement condition during the life cycle and cumulative load applied in the cycle, the initial pavement condition (i.e., IRI at age zero) needs to be established. Because reliable IRI measurements for only 1994 to 1997 period are available, regression analysis was conducted to interpolate existing IRI data points and age of the individual pavement segments, to impute missing IRI values at age zero.

\subsubsection{Environmental Data}

In order to facilitate the collection of environmental data, the three climatic regions (northern, central and southern) were further divided into nine climatic zones according to Indiana Climatic Center. These zones were northwestern, north-central, northeastern, centralwestern, central, central-eastern, southwestern, south-central and southeastern. In each climatic zone data collected from a historical climatic database included the following: number of days between last spring minimum of $0^{\circ} \mathrm{C}$ and first fall minimum of $0^{\circ} \mathrm{C}$, mean annual temperature, maximum annual temperature, minimum annual temperature, number of days higher than $32^{\circ} \mathrm{C}$, number of days lower than $0^{\circ} \mathrm{C}$, average annual precipitation and average number of wet days. Data was collected for the years 1990, 1997 and 1998. For each climatic zone and for each climate parameter, regression analysis was used to impute missing data from 1995 to 1997. 
Based on the existing temperature data sets for 1990, 1997 and 1998, the freeze index and the number of freeze-thaw cycles for each of the nine climatic zones in those years were developed according to the definition of the two parameters [Yoder, 1975] [Huang, 1993]. Similarly, both freeze index and number of freeze-thaw cycles for 1995 and 1996 were then interpolated in accordance with the derived values. Because the maximum elevation difference in Indiana is only $600 \mathrm{ft}$, the elevation factor was not considered for different milepost within each climatic zone.

\subsubsection{ESAL Computation}

The Strategic Highway Research Program (SHRP) study showed that the mean ratio of predicted to observed traffic in terms of ESALs for 106 observation, when the laboratoryestimated subgrade moduli were used, is 4.48 (9). This indicates that the AASHTO design formula is very conservative, and may not be appropriate for ESAL computation in this study. Therefore, new methods need to be adopted to calculate more accurate ESAL values on the basis of existing traffic volume and configuration attained from the WIM stations. As such, two existing methods being used in practice were investigated and compared. These methods are discussed below:

\subsection{INDOT Proposed Method for ESAL Computation [Gulen et al., 1998]}

The ESAL coefficients of single unit and combination trucks for the design of different pavement types in Indiana are listed below:

Average ESALs/Truck

Single unit Combination

$\begin{array}{lll}\text { Flexible pavement } \quad 0.316 & 0.86\end{array}$

$\begin{array}{lll}\text { Rigid pavement } & 0.23 & 1.115\end{array}$ 


\subsection{Whitford formula}

Whitford [1998] conducted a study on truck weight monitoring using weight-in-motion devices for Alaska Department of Transportation in 1998. The findings of the study suggest the following method for ESAL computation:

$\Sigma$ ESALs $=0.0724 *$ No. of single axle crossings $+0.454 *$ No. of tandem axles crossings

ESALs computations using the two formulas indicated that the latter method always results in a relatively higher value ranging $20-40 \%$ than the former method. However, it is difficult to establish which model is superior because there is yet no basis of comparison. In this regard, a new approach, titled Weighted Load Equivalency Factor method (discussed below) for ESAL computation, was introduced, taking advantage of available detailed traffic information for the entire state of Indiana.

\subsection{Weighted Load Equivalency Factor Method}

The suggested Weighted Load Equivalency Factor (WLEF) method requires that the load equivalency factor for each axle type in each operating weight group of each vehicle class be calculated individually. It is a modification of the AASHTO Load Equivalency Factor (LEF) computation method, but unlike the AASHTO method, the new method disaggregates and stratifies components of the AASHTO method to the smallest possible level, thereby minimizing random variability and improving the prediction of repetitive loading prediction.

For each vehicle class, the total load equivalency factor is calculated as the sum of load equivalency factors of steering, single and tandem or tridem axles (if any) for each of the 20 different operating weight groups within the vehicle class. The final weighted LEF for the entire traffic is the sum of the total weighted LEF for each of the 13 vehicle classes in proportion their respective weighting in the traffic stream. 


$$
\sum_{k=1}^{n} E S A L s=A A D T * 365 * D_{d} * G_{f} * L_{f} * \sum_{i=0}^{13} \sum_{j=1}^{20}\left(\text { LEF }_{i j} * \% \text { Class }_{i} * \% \text { WeightGroup }_{j}\right)
$$

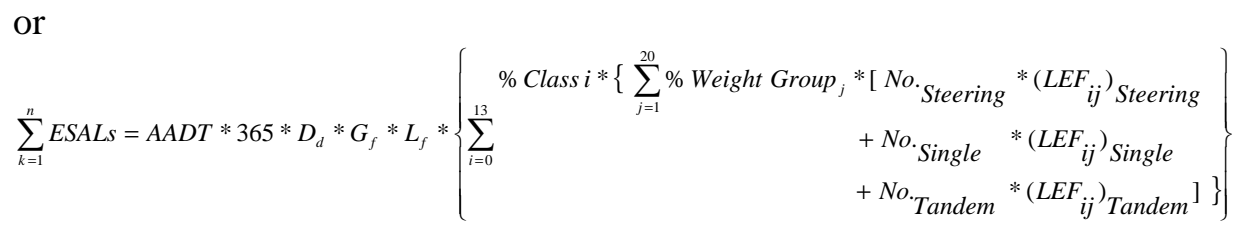

where

$\mathrm{i} \quad=$ Vehicle class $\mathrm{i}(\mathrm{i}=0 \sim 13)$;

$\mathrm{j}=$ Weight group $\mathrm{j}(\mathrm{j}=1 \sim 20)$;

ESALs = Annual equivalent single axle loads during the design period;

$\mathrm{N}=$ = Design period in years;

AADT = Annual average daily traffic;

$\mathrm{D}_{d} \quad=$ Directional distribution factor;

$\mathrm{G}_{f} \quad=$ Growth rate during the analysis period;

$\mathrm{L}_{f} \quad=$ Lane occupancy factor;

No. of lanes in one direction Lane occupancy factor

$\begin{array}{ll}1 & 1.0 \\ 2 & 0.8-1.0 \\ 3 & 0.6-0.8\end{array}$

$\mathrm{LEF}_{\text {class } \mathrm{i}}=$ Weighted load equivalency factor contributed by vehicle class $\mathrm{i}$;

$\% \mathrm{~W}_{\mathrm{j}}=\%$ of vehicles fall in weight group $\mathrm{j}$ within vehicle class $\mathrm{i}$;

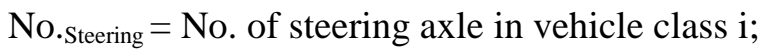

No. Single $^{=}$No. of single axle(s) in vehicle class $i$;

No. Tandem $=$ No. of tandem / tridem axle(s) in vehicle class $\mathrm{i}$; and

$\mathrm{LEF}_{\mathrm{ij}}=$ Load equivalency factor of weight group $\mathrm{j}$ in vehicle class $\mathrm{i}$. 


\subsubsection{Data Preparation}

\subsubsection{Selection of Pavement Segments}

All of the pavement segments to be used for model development are one-mile in length. In order to avoid any bias due to sampling error, all the one-mile segments for which enough and reliable data information, such as IRI measurements over the analysis period of 1995-1997, were modeled. The available data items for the 9,902 one-mile segments on the Interstate, State and U.S. Roads in the entire state of Indiana during 1995-97 are presented in Table 3.

Table 3. Available Data Items for All Interstate, State and U.S. Roads in Indiana during 1995-97

\begin{tabular}{|c|c|c|c|c|}
\hline DATATYPE & DATAITEM & $\overline{\mathrm{UNIT}}$ & $\overline{\text { RANGE }}$ & PERIOD \\
\hline Main. and rehab.expend. & $\begin{array}{l}\text { i) Per lane-mile expend. of routine maintenance by force account (in 98 \$) } \\
\text { ii) Per lane-mile expenditures of rehabilitation by contract (in 97\$) } \\
\text { iii) Per lane-mile expenditures of periodic maintenance by contract (in 97\$) }\end{array}$ & $\begin{array}{l}\text { \$/lane-mile } \\
\text { \$llane-mile } \\
\text { \$/lane-mile }\end{array}$ & Entire state & $1995-97$ \\
\hline Pavement Condidtion & $\begin{array}{l}\text { i) IRI measurements for one-mile segments during 1994-97 } \\
\text { ii) Initial IRI during one life cycle for one-mile segments with rehab. work }\end{array}$ & $\begin{array}{l}\text { inch/mile } \\
\text { inch/mile }\end{array}$ & $\begin{array}{l}\text { 9,902 one-mile segmts } \\
\text { Entire state }\end{array}$ & $\begin{array}{c}1994-97 \\
\text { one life cycle }\end{array}$ \\
\hline Climatic Feature & $\begin{array}{ll}\text { i) } & \text { Freeze index } \\
\text { ii) } & \text { Freeze-thaw cycle } \\
\text { iii) } & \text { No. of days between last Spring and first Fall of minimum of } 0^{\circ} \mathrm{C} \\
\text { iv) } & \text { Mean annual temperature } \\
\text { v) } & \text { Maximum annual temperature } \\
\text { vi) } & \text { Minimum annual temperature } \\
\text { vii) } & \text { No. of days }>32^{\circ} \mathrm{C} \\
\text { viii) No. of days }<0^{\circ} \mathrm{C} \\
\text { ix) } & \text { Average annual precipitation } \\
\text { x) } & \text { Average no. of wet days } \\
\end{array}$ & $\begin{array}{l}\text { Degree-day } \\
\text { No. of days } \\
\text { No. of days } \\
{ }^{\circ} \mathrm{C} \\
{ }^{\circ} \mathrm{C} \\
{ }^{\circ} \mathrm{C} \\
\text { No. of days } \\
\text { No. of days } \\
\text { inches/year } \\
\text { No. of days }\end{array}$ & 92 counties & $1995-97$ \\
\hline Subgrade Materials & 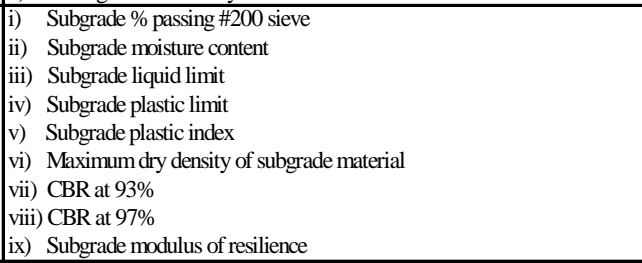 & $\begin{array}{c}\text { weight } \% \\
\% \\
\% \\
\% \\
\% \\
\mathrm{psi} \\
\mathrm{N} / \mathrm{A} \\
\mathrm{N} / \mathrm{A} \\
\mathrm{psi} \\
\end{array}$ & $\begin{array}{l}9,902 \text { one-mile } \\
\text { segments }\end{array}$ & $1995-97$ \\
\hline Traffic & $\begin{array}{ll}\text { i) } & \text { AADT } \\
\text { ii) } & \text { Lane distribution based on WIM data } \\
\text { iii) } & \text { Vehicle composition based on WIM data } \\
\text { iv) } & \text { Vehicle operating weight distribution based on WIM data } \\
\text { v) } & \text { ESALs } \\
\end{array}$ & $\begin{array}{c}\text { vehicles/day } \\
\% \\
\% \\
\% \\
18 \mathrm{kips}\end{array}$ & $\begin{array}{l}9,902 \text { one-mile } \\
\text { segments }\end{array}$ & $1995-97$ \\
\hline Pavement Age & $\begin{array}{ll}\text { i) } & \text { Pavement age } \\
\text { ii) } & \text { Pavement thickness } \\
\end{array}$ & $\begin{array}{c}\text { year } \\
\text { inches }\end{array}$ & $\begin{array}{l}9,902 \text { one-mile } \\
\text { segments }\end{array}$ & $1995-97$ \\
\hline $\begin{array}{l}\text { Pavement design } \\
\text { and construction }\end{array}$ & $\begin{array}{ll}\text { i) } & \text { Drainage coefficient } \\
\text { ii) } & \text { Sub/base thickness and compaction } \\
\text { iii) } & \text { Asphalt content in flexible and overlay pavements } \\
\text { iv) } & \text { Asphalt pavement compaction } \\
\text { v) } & \text { Hot mix asphalt concrete \% aggregate <\#4 sieve } \\
\text { vi) } & \text { Air voids in hot mix asphalt concrete } \\
\text { vii) } & \text { Concrete slab thickness } \\
\text { viii) } & \text { Concrete modulus of elasticity } \\
\text { ix) } & \text { Concrete modulus of rupture } \\
\text { x) } & \text { Joint spacing of concrete pavement } \\
\text { xi) } & \text { Diameter of dowels in concrete pavement } \\
\end{array}$ & $\begin{array}{c}\text { N/A } \\
\text { inches \& \% } \\
\text { Weight \% } \\
\% \\
\text { Weight \% } \\
\text { Volume \% } \\
\text { inches } \\
\text { psi } \\
\text { psi } \\
\text { feet } \\
\text { inches }\end{array}$ & $\begin{array}{l}9,902 \text { one-mile } \\
\text { segments }\end{array}$ & $1995-97$ \\
\hline
\end{tabular}




\subsubsection{Annual Repair Expenditures of Pavement Segments with Routine Maintenance}

For each of the selected pavement segments that has experienced routine maintenance, the annual per lane-mile repair expenditures by force account only for all three pavement types and functional classes were calculated based on information provided by routine maintenance summary reports during the analysis period.

Alternatively, the annual per-lane repair expenditures consisted of both routine maintenance expenditures by force account and periodic maintenance by contract for all three pavement types and functional classes were also separately computed. This facilitated the comparison of impact of periodic maintenance expenditures on the determination of load shares of pavement repair expenditures.

\subsubsection{ESALs for the Analysis}

As relative change in pavement condition was defined differently for segments only with routine maintenance and with rehabilitation, the traffic loading considered for the performance modeling are also different. Annual ESALs were used for the evaluation of pavement condition change between two consecutive years. In contrast, cumulative ESALs in the whole life cycle were adopted for modeling the relative change in pavement condition in that life cycle.

\subsubsection{Region \& Climate, Subgrade Materials, Design \& Construction, and Pavement Age Data}

Data items relevant to climate, subgrade materials, design and construction, and

pavement age for all pavement segments were extracted from the available data source after the completion of data processing. 


\subsection{Chapter Summary}

This chapter provides a summary of the framework used in the present study. First, the effects of routine maintenance and rehabilitation are discussed. Then, highway classification, vehicle class, region division, pavement type, and study period are defined. Finally, a database was developed. This database focuses on routine maintenance and rehabilitation expenditures, pavement condition, and load and non-load-related factors, including, regional and climatic features, subgrade material characteristics, traffic, pavement age, and design and construction standards, for all types of roads throughout the entire state of Indiana. In the course of database development, a new approach for ESALs computation was introduced.

The proposed methodology is based on aggregate performance approach. The concept of "Damage Index" of AASHTO was used as the indicator for quantifying the pavement condition change. Furthermore, the idea of simultaneity was adopted to establish the cause-effect relationship between load factor and pavement damages being represented by routine maintenance and rehabilitation expenditures.

Since the mechanisms of the effect of maintenance and rehabilitation on pavement performance are very different, individual definitions for the two types of treatments were provided. In order to better capture the consecutive or transient and cumulative effects of the two distinctive measures in relation to traffic loading on pavement deterioration, separate procedures, based on the respective definitions on routine maintenance and rehabilitation expenditures, change in pavement condition, traffic under different time frame, were suggested to quantify the load shares of pavement routine maintenance and rehabilitation expenditures. 


\section{CHAPTER 4 DATA ANALYSIS}

The methodologies discussed in Chapter 3 were applied to the appropriate pavement repair categories. As stated before, pavement segments were categorized according to the highest level of pavement repair carried out on a segment. "Pavement segments with routine maintenance work" refers to pavements whose highest repair level was routine maintenance, while "pavement segments with rehabilitation" refers to pavements for which the highest repair level was rehabilitation.

\subsection{Pavement Segments with Routine Maintenance Work}

For reasons stated earlier, the Tobit approach was used to estimate the expenditure function for pavement segments with routine maintenance work. Four different models were estimated, one for each pavement type. Formulation of the models duly recognized the lagged relationship between routine maintenance and pavement damage. That is, the pavement damage at the end of year $\mathrm{t}$ is a function of load and non-load factors in year $\mathrm{t}$; and maintenance decision (and hence, expenditures) in year $t+1$ is influenced by pavement damage in the previous year $t$. The general forms of the routine maintenance expenditure and damage functions for flexible, JCP, CRC and composite pavements are shown below:

$$
\left\{\begin{array}{l}
\mathrm{ARME}_{\mathrm{t}+1}=\alpha_{0}+\sum_{\mathrm{i}=1}^{\mathrm{K}} \alpha_{\mathrm{i}} \mathrm{X}_{\mathrm{i}}+\varepsilon_{1} \\
\mathrm{MDI}_{\mathrm{t}}=\beta_{0}+\sum_{\mathrm{j}=1}^{\mathrm{L}} \beta_{\mathrm{j}} \mathrm{X}_{\mathrm{j}}+\varepsilon_{2}
\end{array}\right.
$$


where

$\mathrm{ARME}_{\mathrm{t}+1}=$ Base 10 logarithm of annual routine maintenance expenditures in year $\mathrm{t}+1$;

MDI $_{\mathrm{t}}=$ Base 10 logarithm of modified damage index in year $\mathrm{t}$;

$\mathrm{X}_{\mathrm{i}} \mathrm{s}^{\mathrm{s}} \quad=$ Dummy variables representing region, road type and pavement age;

$\mathrm{X}_{\mathrm{j}} \mathrm{s}^{\mathrm{s}} \quad=\mathrm{A}$ set of parameters representing climate, subgrade materials, annual ESALs, pavement age, design and construction features;

$\alpha$ 's and $\beta$ 's are model coefficients; $\varepsilon_{1}$ and $\varepsilon_{2}$ are error terms.

For the time-dependent variables, such as annual routine maintenance expenditures, traffic and environment factors, etc, the values used for analysis were those averaged over the year period of study.

\subsubsection{Model Development for All Pavement Types}

LIMDEP software [Econometric Software, 1998] was used to calibrate the models for each of the pavement types considered in the study. This section describes the data provided for each pavement type as well as the calibration and validation of the routine maintenance expenditure and performance models. For model validation, the following standard tests were used:

- Likelihood ratio test;

- Goodness of fit test;

- Conditional moment test; and

- Heteroscedasticity test.

The likelihood ratio test determines whether there is a relationship between the independent variables and the dependent variable, while the goodness of fit test, by utilizing the McFadden Likelihood Ratio Index ( $\left.\mathrm{LRI}_{\mathrm{McFadden}}\right)$, proves the estimated data points have a good fit 
with the observed data. The conditional moment test examines the third and fourth moments of the error distribution. If the distribution is normal, these moments are zero and $3 \sigma^{4}$, respectively. The heterocedasticity test involves an assessment of the consistency or inconsistency of the maximum likelihood estimators. If heterocedasticity is present, the maximum likelihood function shows inconsistency.

\subsubsection{Model Development for Flexible Pavements}

From the total number of pavement segments in the state, only those with consistent information were used for model development. For flexible pavements, the data include 828 onemile segments. The descriptive statistics of mean, standard deviation, minimum and maximum values for all variables initially considered are presented in Appendix 3.

The calibrated coefficients of maintenance expenditure and performance models for flexible pavements are listed in Tables 4(a) and 4(b). The significant variables for the expenditure function were \%IRI change and road type $\left(\mathrm{DM}_{1}\right.$ and $\left.\mathrm{DM}_{2}\right)$, while for the damage index function the significant variables were annual ESALs per unit thickness (Annual ESALs / THICKNESS), freeze-thaw cycles (FZTHAW) and number of days of minimum $0^{\circ} \mathrm{C}$ between successive springfall periods (DAYS0 $\left.{ }^{0} \mathrm{CSF}\right)$.

The model coefficients obtained for flexible pavement routine maintenance are as expected. A large increase in pavement condition (reflected by a large change in IRI) is expected to result in a high level of routine maintenance activity causing increased expenditures for routine maintenance. This is explained by the positive sign and large magnitude of the t-statistic in the cost model. Also, the expenditure model has a positive coefficient of $\mathrm{DM}_{1}$ (dummy variable for Interstate highways). This means that all other factors being equal, a higher maintenance expenditure is predicted for Interstate pavements compared to non-Interstate pavements. This result is expected, as Interstate roads have higher routine maintenance standards. 
The performance model for flexible pavements shows that traffic loading, pavement thickness, the number of freeze-thaw cycles and the number of days a pavement experiences a temperature higher than $0^{\circ} \mathrm{C}$ between successive spring-fall periods are significant predictors of pavement performance. The model obtained suggests that greater loading of the pavement annual ESALs and smaller pavement thickness result in a greater deterioration in pavement condition. Also, the magnitude and the direction of the t-statistic for number of freeze-thaw cycles (FZTHAW) are indicative of the significant adverse impact of freezing and thawing on pavement condition. Furthermore, the larger the number of days of minimum $0^{0} \mathrm{C}$ between successive spring-fall periods, the smaller is the rate of damage, which suggests that flexible pavements perform relatively better in "above-zero" conditions.

Table 4(a). Model Calibration for Flexible Pavements with Routine Maintenance Work Stage 1: Maintenance Expenditure Function for Flexible Pavements

\begin{tabular}{|c|c|c|}
\hline Variable & Value of Coefficient & t-Statistic \\
\hline Constant term & 0.3770 & 3.477 \\
\hline $\begin{array}{c}\text { \% IRI Change } \\
\text { (based on 10 logarithm) }\end{array}$ & 46.0201 & 7.595 \\
\hline $\begin{array}{c}\text { Dummy variable 1 } \\
\text { (for Interstate) }\end{array}$ & 0.8864 & 11.855 \\
\hline $\begin{array}{c}\text { Dummy variable 2 } \\
\text { (for State roads) }\end{array}$ & 0.2537 & 3.802 \\
\hline
\end{tabular}

Stage 2: Damage Index Function for Flexible Pavements

\begin{tabular}{|c|c|c|}
\hline Pariable & Value of Coefficient & t-Statistic \\
\hline$\left[\frac{\text { AnnualESALs }}{\text { THICKNESS }}\right]$ & 0.0052 & 5.792 \\
\hline FZTHAW & 0.0003 & 7.254 \\
\hline DAYS0 ${ }^{\circ} \mathrm{CSF}$ & -0.0002 & -6.823 \\
\hline
\end{tabular}


Table 4(b). Tests for Model Validity for Flexible Pavements with Routine Maintenance Work

\begin{tabular}{|c|c|c|}
\hline Test & Outcome & Inference \\
\hline Likelihood Ratio Test & $\begin{array}{c}-2 \ln \left(\mathrm{L}_{\mathrm{R}}^{\wedge} / \mathrm{L}_{\mathrm{U}}^{\wedge}\right)=329.7366 \\
>>\chi_{(0.99,3)}^{2}=11.34, \text { reject } \mathrm{H}_{0}\end{array}$ & $\begin{array}{c}\text { Significant relationship } \\
\text { between maintenance cost and } \\
\text { the independent variables }\end{array}$ \\
\hline Goodness of fit & $\mathrm{LRI}_{\text {McFadden }}=0.177$ & Fair fit \\
\hline $\begin{array}{c}\text { Conditional moment test for } \\
\text { normality of error terms }\end{array}$ & $\begin{array}{c}\chi_{(\mathrm{LMSTAT})}^{2}=4.3445< \\
\chi_{(0.99,2)}^{2}=9.21, \text { conclude } \mathrm{H}_{0}\end{array}$ & Normal error terms \\
\hline $\begin{array}{c}\text { Heteroscedasticity test for } \\
\text { constancy of error variance }\end{array}$ & $\begin{array}{c}-2 \ln \left(\mathrm{L}_{\mathrm{R}}^{\wedge} / \mathrm{L}_{\mathrm{U}}\right)=9.3302< \\
\chi_{(0.99,3)}^{2}=11.34, \text { conclude } \mathrm{H}_{0}\end{array}$ & Constancy of error variance \\
\hline
\end{tabular}

\subsubsection{Model Development for Jointed Concrete Pavements (JCP)}

Data from 141 one-mile JCP pavement segments were used for model development. The descriptive statistics of mean, standard deviation, minimum and maximum values for all variables initially considered are presented in Appendix 6. The details of maintenance expenditure and performance models for JCP segments followed the same form as given in Tables 5(a) and 5(b).

For the routine maintenance expenditure function, the significant variables were change in road condition (\% IRI change) and road type (DM, dummy variable for Interstate versus Noninterstate). The significant variables for the damage index function included loading (Annual ESALs), number of days of minimum $0^{\circ} \mathrm{C}$ between successive spring-fall periods (DAYS0 ${ }^{\circ} \mathrm{CSF}$ ), and regional location of the pavement segment $\left(\mathrm{DM}_{1}\right.$ and $\mathrm{DM}_{2}$, dummy variables for Northern and Central Indiana).

From Table 5(a) it can be seen that the model coefficients are intuitive. The greater the pavement damage (relative change in IRI), the greater the maintenance expenditures in the following year. Interstate JCP pavements are more likely to receive higher levels of maintenance. 
For JCP pavements, the performance model has significant and positive coefficients for traffic loading, but has significant and negative coefficients for number days of $0^{\circ} \mathrm{C}$ between successive spring-fall period and northern Indiana. This means that the higher the traffic loading, the greater the pavement damage. The model also infers that JCP pavements in regions with less freeze-thaw cycles and less precipitation suffer less deterioration (and therefore lower maintenance expenditures). This is consistent with reasoning. Northern Indiana has less freezethaw cycles and precipitation, the JCP pavements perform better than those in southern Indiana. JCP pavements do not necessarily perform worse in colder regions. Rather, they are more sensitive to temperature variation and amount of precipitation.

The tests for model validation showed that there is statistically significant relationship between maintenance expenditures and the independent variables. The goodness of fit test showed a fairly good fit, and both assumptions of normality error terms and constant variance of the error terms were found to be satisfied.

Table 5(a). Model Calibration for JCP Pavements with Routine Maintenance Work Stage 1: Routine Maintenance Expenditure Function for JCP Pavements

\begin{tabular}{|c|c|c|}
\hline Variable & Palue of Coefficient & t-Statistic \\
\hline Constant term & 0.7924 & 3.374 \\
\hline $\begin{array}{c}\text { \% IRI Change } \\
\text { (based on 10 logarithm) }\end{array}$ & 37.7325 & 2.795 \\
\hline $\begin{array}{c}\text { DM, dummy variable } \\
(1 \text { for Interstate })\end{array}$ & 0.2627 & 1.806 \\
\hline
\end{tabular}


Stage 2: Damage-index Function

\begin{tabular}{|c|c|c|}
\hline Pariable & Value of Coefficient & t-Statistic \\
\hline Constant term & 0.0756 & 1.993 \\
\hline Annual ESALs & 0.0081 & 3.624 \\
\hline DAYS0 ${ }^{\circ}$ CSF & -0.0006 & -3.126 \\
\hline $\begin{array}{c}\text { DM }_{1} \text {, dummy variable } 1 \\
(1 \text { for Northern Indiana })\end{array}$ & -0.0087 & -1.728 \\
\hline $\begin{array}{c}\text { DM } \\
(1 \text { for Central Indiana })\end{array}$ & -0.0116 & -2.140 \\
\hline
\end{tabular}

Table 5(b). Tests for Model Validity for JCP Pavements with Routine Maintenance Work

\begin{tabular}{|c|c|c|}
\hline Test & Outcome & Inference \\
\hline Likelihood ratio test & $\begin{array}{c}-2 \ln \left(\mathrm{L}_{\mathrm{R}}^{\wedge} / \mathrm{L}_{\mathrm{U}}^{\wedge}\right)=20.6604> \\
\chi_{(0.99,2)}=9.21, \text { reject } \mathrm{H}_{0}\end{array}$ & $\begin{array}{c}\text { Significant relationship } \\
\text { between maintenance cost and } \\
\text { the independent variables }\end{array}$ \\
\hline Goodness of fit & $\mathrm{LRI}_{\mathrm{McFadden}}=0.06$ & Fair fit \\
\hline $\begin{array}{c}\text { Conditional moment test for } \\
\text { normality of error terms }\end{array}$ & $\chi_{(\mathrm{LMSTAT})}=1.163<$ \\
$\chi_{(0.99,2)}^{2}=9.21$, conclude $\mathrm{H}_{0}$ & Normal error terms \\
\hline $\begin{array}{c}\text { Heteroscedasticity test for } \\
\text { constancy of error variance }\end{array}$ & $\begin{array}{c}-2 \ln \left(\mathrm{L}_{\mathrm{R}} / \mathrm{L}_{\mathrm{U}}{ }_{\mathrm{U}}\right)=9.20< \\
\chi_{(0.99,2)}=9.21, \text { conclude } \mathrm{H}_{0}\end{array}$ & Constancy of error variance \\
\hline
\end{tabular}

\subsubsection{Model Development for Continuous Reinforced Concrete (CRC) Pavements}

Data from 29 one-mile CRC pavement segments were used for model development. The descriptive statistics of mean, standard deviation, minimum and maximum values for all variables initially considered are presented in Appendix 9. The model for CRC segments was of the same general form as those formulated for flexible and JCP pavements, except that only one-stage (i.e., 
determination of the expenditure function) was carried out because of the small size of the data set for this pavement type.

For CRC pavements that received routine maintenance, the calibrated coefficients and corresponding $t$ statistics are shown in Tables 6(a) and 6(b). It was found that the interaction between traffic loading (Annual ESALs) and pavement thickness (THICKNESS) was significant, and these variables were coined as a ratio. The large magnitude and positive sign of the coefficients of these variables suggests that greater loading, less pavement thickness and greater age lead to faster rate of deterioration. This is consistent with real life situation. Pavement age (AGE) was also found to be significant, and it shows that pavement age has an effect on routine maintenance expenditures, even through the effect on CRC pavements was less than those on other pavement types. This suggests, quite reasonably, that CRC pavement deterioration is more vulnerable for non-age factors, and this could be attributed to the very rigid composition of such pavements. The results of all the validity tests (shown in Table 9(b)) indicate that the models are statistically valid.

Table 6(a). Model Calibration for CRC Pavements with Routine Maintenance Work

\begin{tabular}{|c|c|c|}
\hline Pariable & Value of Coefficient & t-Statistic \\
\hline $\begin{array}{c}{\left[\frac{\text { Annual ESALs }}{\text { Thickness }} \text { (based on 10 logarithm) }\right.} \\
\text { (AGE-8)*DM } \\
\begin{array}{c}\text { DM, dummy variable } \\
(1 \text { for pavement age } \geq 8,0 \\
\text { otherwise) }\end{array}\end{array}$ & 0.4449 & 17.644 \\
\hline
\end{tabular}


Table 6(b). Tests for Model Validity for CRC Pavement with Routine Maintenance Work

\begin{tabular}{|c|c|c|}
\hline Test & Outcome & Inference \\
\hline Likelihood ratio test & $\begin{array}{c}-2 \ln \left(\mathrm{L}_{\mathrm{R}} / \mathrm{L}_{\mathrm{U}}\right)=23.6682> \\
\chi_{(0.99,2)}^{2}=9.21, \text { reject } \mathrm{H}_{0}\end{array}$ & $\begin{array}{c}\text { Significant relationship } \\
\text { between maintenance cost and } \\
\text { the independent variables }\end{array}$ \\
\hline Goodness of fit & $\mathrm{LRI}_{\text {McFadden }}=0.39$ & Good fit \\
\hline $\begin{array}{c}\text { Conditional moment test for } \\
\text { normality of error terms }\end{array}$ & $\begin{array}{c}\chi_{(\mathrm{LMSTAT})}^{2}=1.943< \\
\chi_{(0.99,2)}=9.21, \text { conclude } \mathrm{H}_{0}\end{array}$ & Normal error terms \\
\hline $\begin{array}{c}\text { Heteroscedasticity test for } \\
\text { constancy of error variance }\end{array}$ & $\begin{array}{c}-2 \ln \left(\mathrm{L}_{\mathrm{R}} / \mathrm{L}_{\mathrm{U}}\right)=7.974< \\
\chi_{(0.99,2)}=9.21, \text { conclude } \mathrm{H}_{0}\end{array}$ & Constancy of error variance \\
\hline
\end{tabular}

\subsubsection{Model Development for Composite Pavements}

For developing a cost model for composite pavements, data from 1,961 one-mile composite pavement segments were used. The descriptive statistics, including mean, standard deviation, minimum and maximum values, for all variables initially considered are presented in Appendix 12. The calibrated coefficients for maintenance expenditure and performance models for composite pavements are listed in Tables 7(a) and 7(b).

The calibrated model showed that pavement condition (\%IRI Change) and road type were significant variables for the maintenance expenditure function. For the damage index function the Annual ESALs per unit thickness (Annual ESALs / THICKNESS), maximum temperature (MAXTEM), minimum temperature (MINTEM) and pavement age (AGE) were significant. Deterioration of pavement condition is expected to cause increased expenditures for routine maintenance. Also, the cost model has a positive coefficient of $\mathrm{DM}_{1}$, this means that a higher maintenance expenditure is expected for Interstate roads compare with non-Interstate roads. The performance model for composite pavements shows that traffic loading and maximum 
temperature all have a significant and positive influence on routine maintenance expenditures. Also, the sensitivity of composite pavements to low temperature is reflected in the significant and negative signs of the coefficients, "MINTEM". Other variable that showed a significant positive impact on routine maintenance expenditures of composite pavements includes pavement age. The tests of model validity indicated justification of a statistically significant relationship between routine maintenance expenditures and the independent variables, a fairly good fit, and the normality assumption and constant variance of the error terms.

Table 7(a). Model Calibration for Composite Pavements with Routine Maintenance Work Stage 1: Routine Maintenance Expenditure Function for Composite Pavements

\begin{tabular}{|c|c|c|}
\hline Pariable & Value of Coefficient & t-Statistic \\
\hline Constant term & -114.4843 & -8.468 \\
\hline $\begin{array}{c}\text { \% IRI Change } \\
\text { (based on 10 logarithm) }\end{array}$ & 8061.9762 & 13.969 \\
\hline $\begin{array}{c}\mathrm{DM}_{1} \text {, dummy variable } \\
(1 \text { for Interstate, 0 otherwise) }\end{array}$ & 373.6397 & 20.055 \\
\hline
\end{tabular}

Stage 2: Damage Index Function for Composite Pavements

\begin{tabular}{|c|c|c|}
\hline Pariable & Value of Coefficient & t-Statistic \\
\hline$\left[\begin{array}{c}\text { AnnualESALs } \\
\text { THICKNESS }\end{array}\right.$ & 0.0062 & 7.744 \\
\hline MAXTEM & 0.00035 & 24.834 \\
\hline MINTEM & -0.0007 & -12.410 \\
\hline $\begin{array}{c}\text { (AGE-8)*DM } \text { DM }_{2}, \text { dummy variable } \\
(1 \text { for pavement age } \geq 8, \\
0 \text { otherwise })\end{array}$ & 0.0012 & 3.525 \\
\hline
\end{tabular}


Table 7 (b). Tests for Model Validity for Composite Pavements with Routine Maintenance Work

\begin{tabular}{|c|c|c|}
\hline Test & Outcome & Inference \\
\hline Likelihood ratio test & $\begin{array}{c}-2 \ln \left(\mathrm{L}_{\mathrm{R}} / \mathrm{L}_{\mathrm{U}}\right)=1,451.2934> \\
\chi^{2}(0.99,2)\end{array}=9.21$, reject $\mathrm{H}_{0}$ & $\begin{array}{c}\text { Significant relationship } \\
\text { between maintenance cost and } \\
\text { the independent variables }\end{array}$ \\
\hline Goodness of fit & $\mathrm{LRI}_{\mathrm{McFadden}}=0.12$ & Fair fit \\
\hline $\begin{array}{c}\text { Conditional moment test for } \\
\text { normality of error terms }\end{array}$ & $\begin{array}{c}\chi_{(\mathrm{LMSTAT})}^{2}=6.322< \\
\chi_{(0.99,2)}=9.21, \text { conclude } \mathrm{H}_{0}\end{array}$ & Normal error terms \\
\hline $\begin{array}{c}\text { Heteroscedasticity test for } \\
\text { constancy of error variance }\end{array}$ & $\begin{array}{c}-2 \ln \left(\mathrm{L}_{\mathrm{R}} / \mathrm{L}_{\mathrm{U}}\right)=0.583< \\
\chi_{(0.99,2)}^{2}=9.21, \text { conclude } \mathrm{H}_{0}\end{array}$ & Constancy of error variance \\
\hline
\end{tabular}

\subsubsection{Estimation of Load and Non-load Shares of Pavement Routine Maintenance Expenditures}

\subsubsection{Introduction}

After the appropriate cost and performance models have been developed, calibrated and tested, the next step was to use these models to determine the load and non-load shares of pavement damage and subsequently, routine maintenance expenditures of such pavement damage. Table 8 shows the summary of the average annual routine maintenance expenditures, IRI change, annual ESALs, and thickness for all pavement types.

Table 8. Summary of the Average Annual Routine Maintenance Expenditures, IRI Change, Annual ESALs, and Thickness for All Pavement Types

\begin{tabular}{|c|c|c|c|c|c|c|}
\hline \multicolumn{2}{|c|}{ Pavement Type } & & & Annual ESALs & Ave. \% IRI Change & Thickness \\
\hline \multirow{4}{*}{ Total } & Flexible & $141,007.77$ & $146,275.91$ & $394,627,263.81$ & & \\
\hline & JCP & $63,908.41$ & $46,470.98$ & $184,817,968.58$ & - & \\
\hline & CRC & $8,408.43$ & $9,303.27$ & $20,849,066.11$ & - & \\
\hline & Composite & $420,776.73$ & $399,132.38$ & $1,424,372,148.00$ & & \\
\hline \multirow{4}{*}{ Average } & Flexible & 66.47 & 77.58 & 193,206.95 & $4.10 \%$ & 14.16 \\
\hline & $\mathrm{JCP}$ & 125.76 & 116.36 & $396,660.31$ & $3.03 \%$ & 21.59 \\
\hline & CRC & 155.37 & 188.93 & $298,125.47$ & $2.7 \%$ & 20.98 \\
\hline & Composite & 87.05 & 99.29 & $278,692.08$ & $2.28 \%$ & 14.69 \\
\hline
\end{tabular}




\subsubsection{Analysis of Load Share of Routine Maintenance Expenditures for Flexible, JCP, CRC} and Composite Pavements

(a) Load Share of Routine Maintenance Expenditures for Flexible Pavements

Based on the maintenance expenditure and performance models developed for flexible pavements, we have

$$
\begin{aligned}
& \frac{\partial A R M E_{t+1}}{\partial A n n u a l E S A L s_{t}}=\frac{\partial A R M E_{t+1}}{\partial\left(\% \text { IRI Change } e_{t}\right)} * \frac{\partial(\% \text { IRI Change })}{\partial A \text { nnualESAL } s_{t}}=\alpha_{1} * \alpha_{2} * \frac{\overline{\text { ARME }_{t+1}}}{\overline{\text { AnnualESAL }_{t}}}=46.0201 * 0.005158^{*} * \frac{77.58}{193,206.95}=9.53 \times 10^{-5} \\
& \text { ExpectedARME } E_{\text {load-relatedonly) }}=\frac{\partial A R M E_{t+1}}{\partial A n n u a l E S A L s_{t}} * \Delta \text { AnnualESALs } s_{t}=\left(9.53 \times 10^{-5}\right) * 394,627,263.81=37,610.3375 \\
& \text { Load Share }=\frac{\text { Expected ARME }_{\text {load-relatedonly) }}}{{\text { Total } A R M E_{t+1}}_{t^{\prime}}}=\frac{37,610.3375}{146,275.91}=25.7 \%
\end{aligned}
$$

Note: "ARME" refers to the annual routine maintenance expenditures

(b) Load Share of Routine Maintenance Expenditures for JCP Pavements

Based on the maintenance expenditure and performance models developed for JCP pavements, we have

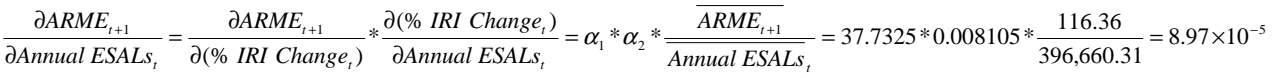

$$
\begin{aligned}
& \text { Expected ARME } E_{(\text {load-related only) }}=\frac{\partial A R M E_{t+1}}{\partial A \text { Annual ESALs }} * \Delta \text { Annual ESALs } s_{t}=\left(8.97 \times 10^{-5}\right) * 184,817,968.58=16,578.1718 \\
& \text { Load Share }=\frac{\text { Expected }^{A R M E_{(\text {load }} \text {-related only) }}}{\text { Total } A R M E_{t+1}}=\frac{16578.1718}{46,470.98}=35.7 \%
\end{aligned}
$$

(c) Load Share of Routine Maintenance Expenditures for CRC Pavements

Based on the maintenance expenditure model developed for CRC pavements, we have

$$
\begin{aligned}
& \frac{\partial \text { ARME }_{+1}}{\partial \text { AnnualESALs }_{t}}=\alpha * \frac{\overline{\text { ARME }}_{+1}}{\overline{\text { AnnualESALs }}}=0.4449 * \frac{188.93}{298,125.47}=2.82 \times 10^{-4} \\
& \text { ExpectedARME }_{\text {load-relatedonly) }}=\frac{\partial A R M E_{t+1}}{\partial A n n u a l E S A L s_{t}} * \Delta \text { AnnualESALs } s_{t}=\left(2.82 \times 10^{-4}\right) * 20,849,066.11=5,879.4366 \\
& \text { Load } \text { Share }=\frac{\text { Expected } A R M E_{\text {load }- \text { relatedonly) }}}{\text { Total ARME } E_{t+1}}=\frac{5,879.4366}{9,303.27}=63.2 \%
\end{aligned}
$$


(d) Load Share of Routine Maintenance Expenditures for Composite Pavements

Based on the maintenance expenditure and performance models developed for composite pavements, we have

$$
\begin{aligned}
& \frac{\partial A R M E_{l_{1+1}}}{\partial \text { AnnualESALs }_{i}}=\alpha_{1} * \alpha_{2} * \frac{1}{\ln 10} * \frac{1}{\text { AnnualESALs }}=8,016.9762 * 0.0062 * \frac{1}{\ln 10} * \frac{1}{278,692.08}=7.8 \times 10^{-5} \\
& \text { ExpectedARME } E_{\text {load-relatedonly) }}=\frac{\partial A R M E_{+1}}{\partial A n n u a l E S A L s} * \Delta \text { AnnualESALs }=\left(7.8 \times 10^{-5}\right) * 1,424,372,148.00=111,101.0275 \\
& \text { Load Share }=\frac{\text { ExpectedARME }_{\text {load-relatedonly) }}}{\text { TotalARME } E_{+1}}=\frac{111,101.0275}{399,132.38}=27.8 \%
\end{aligned}
$$

\subsubsection{Summary of Load Shares of Pavement Routine Maintenance Expenditures for Flexible, JCP, CRC, and Composite Pavements}

Load shares of pavement routine maintenance expenditures for flexible, JCP, CRC, and composite pavements are summarized in Table 9.

Table 9. Summary of Load Shares of Routine Maintenance Expenditures for Flexible, JCP, CRC and Composite Pavements

\begin{tabular}{|c|c|c|c|c|}
\hline Pavement Type & Flexible & JCP & CRC & Composite \\
\hline $\begin{array}{c}\text { Load share } \\
\text { (routine maintenance only) }\end{array}$ & $25.7 \%$ & $35.7 \%$ & $63.2 \%$ & $27.8 \%$ \\
\hline
\end{tabular}




\subsection{Pavement Segments with Rehabilitation Work}

In order to estimate the load share of pavement rehabilitation expenditures, it is necessary to define the service life of a pavement segment, and to obtain reliable measures of pavement performance over the analysis period. For a pavement segment that has received rehabilitation, its service life is considered to be the time interval between the last rehabilitation work and the start of rehabilitation activity that falls in our analysis period (1995 to 1997). For all the pavement segments for which rehabilitation was commenced in 1996 and 1997, the condition of the pavement was considered as the terminal condition. This provided a data point with which extrapolation of roughness trends was carried out. Model development for estimating the load and non-load shares of pavement rehabilitation expenditures was conducted separately for flexible, JCP and composite pavements. The general form of the OLS models is shown below:

$$
\operatorname{EXPEND}_{(\text {rehab. })}=\alpha_{0}+\sum_{\mathrm{i}=1}^{\mathrm{K}} \alpha_{\mathrm{i}} \mathrm{X}_{\mathrm{i}}+\varepsilon
$$

where

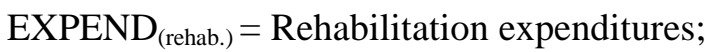

$\alpha$ 's are model coefficients;

$\mathrm{X}_{\mathrm{i}}$ 's are a set of independent variables representing climatic and regional features, cumulative ESALs, subgrade materials, pavement age, design and construction standards; and $\varepsilon$ 's are error terms.

\subsubsection{Model Development for All Pavement Types}

This section describes each aspect of the data for each pavement type. SAS software [SAS Institute, 1996] was used to develop the rehabilitation expenditure models. The calibrated models 
were then examined for their validity using four standard tests available in the SAS package. Regression model validity was checked using the following criteria:

- ANOVA hypothesis test;

- Goodness of fit test;

- Correlation test; and

- Modified Levene test.

The ANOVA hypothesis test gives evidence of any relationship between independent variables and the dependent variable. Goodness of fit test using coefficient of determination (adjusted $\mathrm{R}^{2}$ ) showing whether the estimated data points have a good fit with the observed data. The correlation test was conducted by calculating the coefficient of correlation between the residuals and their expected values under normality. If the observed coefficient of correlation is at least as large as the critical value for a given level of significance, it is concluded that the error terms are reasonably normally distributed. The Modified Levene test is based on the variability of the residuals. The larger the error variance, the larger the variability of the residuals will tend to be. To conduct the test, the data set is divided into two groups. Then two sample t-tests based on the test statistic are carried out to determine whether the mean of the absolute deviations for one group differs significantly from the mean absolute deviation for the second group. Large absolute values of $\mathrm{t}$-statistic indicate that the error terms do not have constant variance. 


\subsubsection{Model Development for Flexible Pavements}

Data from 202 one-mile flexible pavement segments were used for model development. The descriptive statistics of mean, standard deviation, minimum and maximum values for the variables initially considered are presented in Appendix 16. As shown in Table 10(a)(i), the calibrated expenditure model for flexible pavements that received rehabilitation was of the general form stated in previous section. The significant variables were Cumulative ESALs per unit thickness (Cumulative ESALs / THICKNESS), interaction term of subgrade materials, subgrade moisture content and freeze index (P200*MOIST*FZI), drainage coefficient (DRAINCO) and pavement age (AGE).

The positive sign and high t-statistic value for the cumulative loading per unit thickness correctly indicates that higher level of traffic loading and smaller pavement thickness are associated with increased rehabilitation expenditures. Also, clayey subgrade, coupled with a higher moisture content and a higher freeze index, together constitutes favorable conditions for increased pavement failure and therefore rehabilitation expenditures. Additionally, the greater the pavement age, the higher the expenditure for rehabilitation work. The negative sign of the tstatistic for drainage features indicates that lack of pavement drainage leads to greater levels of pavement damage.

A summary of test results is given in Table 10(a)(ii). The test results for model validity provided evidence to the existence of statistically significant relationship between rehabilitation expenditures and the selected independent variables. Also, the goodness of fit test showed a good fit, and the correlation test and Modified Levene test indicated that the error terms are normally distributed and with constant variance.

The model for flexible pavements with rehabilitation and periodic maintenance expenditures gave similar results for only rehabilitation work. The model coefficients and test 
results were presented in Tables 10(b)(i) and 10(b)(ii). In both cases, the models did not implicitly include expenditures for routine maintenance activities carried out during the life cycle of the pavements.

Table 10 (a)(i). Model Calibration for Flexible Pavements with Rehabilitation Work

\begin{tabular}{|c|c|c|}
\hline Variable & Value of Coefficient & t-Statistic \\
\hline Constant Term & 172,431 & 5.4454 \\
\hline$\left[\begin{array}{c}\text { Cumulative ESALS } \\
\text { THICKNESS }\end{array}\right.$ & 0.3113 & 50.6584 \\
\hline P200*MOIST*FZI & 300.83 & 5.4255 \\
\hline $\begin{array}{c}\text { DRAINCO } \\
\text { DM is a dummy variable } \\
(1 \text { for pavement age } \geq 10, \\
0 \text { otherwise })\end{array}$ & $-145,378$ & -4.6671 \\
\hline
\end{tabular}

Table 10 (a)(ii). Tests for Model Validity for Flexible Pavements with Rehabilitation Work

\begin{tabular}{|c|c|c|}
\hline Test & Outcome & Inference \\
\hline ANOVA hypothesis & $\begin{array}{c}\text { From ANOVA table, } \\
\text { P-value }=0.0001<0.01, \\
\text { reject } \mathrm{H}_{0}\end{array}$ & $\begin{array}{c}\text { Significant relationship } \\
\text { between rehabilitation cost } \\
\text { and the independent } \\
\text { variables }\end{array}$ \\
\hline Goodness of fit & Adjusted $\mathrm{R}^{2}=0.96$ & Good fit \\
\hline $\begin{array}{c}\text { Correlation test for } \\
\text { normality of error terms }\end{array}$ & $\begin{array}{c}\text { Correlation coefficient } \\
\mathrm{r}=0.984>0.98(\text { critical value), } \\
\text { conclude } \mathrm{H}_{0}\end{array}$ & Normal error terms \\
\hline $\begin{array}{c}\text { Modified Levene test for } \\
\text { constancy of error variance }\end{array}$ & $\begin{array}{c}\text { Levene P-value }=0.13175 \\
>0.01, \text { conclude } \mathrm{H}_{0}\end{array}$ & Constancy of error variance \\
\hline
\end{tabular}


Table 10(b)(i). Model Calibration for Flexible Pavements with Rehabilitation and Periodic Maintenance Work

\begin{tabular}{|c|c|c|}
\hline Pariable & Value of Coefficient & t-Statistic \\
\hline Constant Term & 170,305 & 5.3898 \\
\hline$\left[\frac{\text { Cumulative ESALs }}{\text { THICKNESS }}\right.$ & 0.3110 & 50.7293 \\
\hline P200*MOIST*FZI & 300.687 & 5.4348 \\
\hline DRAINCO & $-143,243$ & -4.6086 \\
\hline $\begin{array}{c}\text { DM is a dummy variable } \\
(1 \text { for pavement age } \geq 10, \\
0 \text { otherwise })\end{array}$ & 700.426 & 3.3796 \\
\hline
\end{tabular}

Table 10(b)(ii). Tests for Model Validity for Flexible Pavements with Rehabilitation and Periodic Maintenance Work

\begin{tabular}{|c|c|c|}
\hline Test & Outcome & Inference \\
\hline ANOVA hypothesis & $\begin{array}{c}\text { From ANOVA table, } \\
\text { P-value }=0.0001<0.01, \\
\text { reject } \mathrm{H}_{0}\end{array}$ & $\begin{array}{c}\text { Significant relationship } \\
\text { between rehabilitation } \\
\text { cost and the independent } \\
\text { variables }\end{array}$ \\
\hline Goodness of fit & Adjusted $\mathrm{R}^{2}=0.96$ & Good fit \\
\hline $\begin{array}{c}\text { Correlation test for } \\
\text { normality of error terms }\end{array}$ & $\begin{array}{c}\text { Correlation coefficient } \\
\mathrm{r}=0.984>0.98(\text { critical value) } \\
\text { conclude } \mathrm{H}_{0}\end{array}$ & Normal error terms \\
\hline $\begin{array}{c}\text { Modified Levene test for } \\
\text { constancy of error variance }\end{array}$ & $\begin{array}{c}\text { Levene P-value }=0.12563 \\
>0.01, \text { conclude } \mathrm{H}_{0}\end{array}$ & $\begin{array}{c}\text { Constancy of error } \\
\text { variance }\end{array}$ \\
\hline
\end{tabular}




\subsubsection{Model Calibration for Jointed Concrete Pavements (JCP)}

For the development of rehabilitation expenditure models for JCP pavements, data from 49 one-mile segments were used. The descriptive statistics of variables initially considered are presented in Appendix 19. As presented in Table 11(a)(i), the significant variables for the rehabilitation expenditure model were cumulative traffic loading (Cumulative ESALs), JCP slab thickness (SLABTH), number of days with $32^{\circ} \mathrm{C}$ or more and pavement age.

For JCP pavements with rehabilitation, it was found that traffic loading, number of hot days with $32^{\circ} \mathrm{C}$ or more and age had direct and significant relationship with pavement rehabilitation expenditures. This is intuitive. Higher traffic loading, excessive temperatures and older pavements are expected to result in higher levels of rehabilitation expenditures. The sign of the coefficient for concrete slab thickness was found to be negative. Again, this is reasonable. Higher pavement thickness means greater resistance to failure and consequently, less rehabilitation expenditures.

The test results for model validation were summarized in Table 11(a)(ii). These tests showed that there was a statistically strong relationship between rehabilitation expenditures of JCP pavements with the four explanatory variables indicated above, and a good fit was obtained. Also, the assumptions of normality and constant variance of the error terms were found to be true. Similar model and test results were obtained for JCP segments that received both periodic maintenance and rehabilitation as shown in Tables 11(b)(i) and 11(b)(ii). 
Table 11(a)(i). Model Calibration for JCP Pavement with Rehabilitation Work

\begin{tabular}{|c|c|c|}
\hline Pariable & Value of Coefficient & t-Statistic \\
\hline Constant Term & $-628,986$ & -3.0901 \\
\hline Cumulative ESALs & 0.038 & 12.5278 \\
\hline SLABTH & $-40,020.6$ & -3.6617 \\
\hline DAYS $>32^{\circ} \mathrm{C}$ & $13,274.1$ & 3.7592 \\
\hline AGE & $34,759.9$ & 3.9709 \\
\hline
\end{tabular}

Table 11(a)(ii). Tests for Model Validity for JCP Pavement with Rehabilitation Work

\begin{tabular}{|c|c|c|}
\hline Test & Outcome & Inference \\
\hline ANOVA hypothesis & $\begin{array}{c}\text { From ANOVA table, } \\
\text { P-value }=0.0001<0.01, \\
\text { Reject } \mathrm{H}_{0}\end{array}$ & $\begin{array}{c}\text { Significant relationship } \\
\text { between rehabilitation cost } \\
\text { and the independent } \\
\text { variables }\end{array}$ \\
\hline Goodness of fit & Adjusted $\mathrm{R}^{2}=0.96$ & Good fit \\
\hline $\begin{array}{c}\text { Correlation test for } \\
\text { normality of error terms }\end{array}$ & $\begin{array}{c}\text { Correlation coefficient } \\
\mathrm{r}=0.9473>0.94(\text { critical value }), \\
\text { conclude } \mathrm{H}_{0}\end{array}$ & Normal error terms \\
\hline $\begin{array}{c}\text { Modified Levene test for } \\
\text { constancy of error } \\
\text { variance }\end{array}$ & $\begin{array}{c}\text { Levene P-value }=0.08 \\
>0.01, \text { conclude } \mathrm{H}_{0}\end{array}$ & Constancy of error variance \\
\hline
\end{tabular}


Table 11(b)(i). Model Calibration for JCP Pavements with Rehabilitation and Periodic Maintenance Work

\begin{tabular}{|c|c|c|}
\hline Variable & Value of Coefficient & t-Statistic \\
\hline Constant Term & $-665,863$ & -3.4230 \\
\hline Cumulative ESALs & 0.0374 & 12.9107 \\
\hline SLABTH & $-38,797.5$ & -3.7144 \\
\hline DAYS $>32^{\circ} \mathrm{C}$ & $13,409.3$ & 3.9737 \\
\hline AGE & $37,613.1$ & 4.4961 \\
\hline
\end{tabular}

Table 11(b)(ii). Tests for Model Validity for JCP Pavements with Rehabilitation and Periodic Maintenance Work

\begin{tabular}{|c|c|c|}
\hline Test & Outcome & Inference \\
\hline ANOVA hypothesis & $\begin{array}{c}\text { From ANOVA table, } \\
\text { P-value }=0.0001<0.01, \\
\text { Reject } \mathrm{H}_{0}\end{array}$ & $\begin{array}{c}\text { Significant relationship } \\
\text { between rehabilitation cost } \\
\text { and the independent } \\
\text { variables }\end{array}$ \\
\hline Goodness of fit & Adjusted $\mathrm{R}^{2}=0.96$ & Good fit \\
\hline $\begin{array}{c}\text { Correlation test for } \\
\text { normality of error terms }\end{array}$ & $\begin{array}{c}\text { Correlation coefficient } \\
\mathrm{r}=0.9513>0.94(\text { critical value) } \\
\text { conclude } \mathrm{H}_{0}\end{array}$ & Normal error terms \\
\hline $\begin{array}{c}\text { Modified Levene test for } \\
\text { constancy of error } \\
\text { variance }\end{array}$ & $\begin{array}{c}\text { Levene } \mathrm{P} \text {-value }=0.063 \\
>0.01, \text { conclude } \mathrm{H}_{0}\end{array}$ & Constancy of error variance \\
\hline
\end{tabular}




\subsubsection{Model Development for Composite Pavements}

621 one-mile composite pavement segments provided data for model development. The descriptive statistics of mean, standard deviation, minimum and maximum values for variables initially considered are presented in Appendix 22. From Table 12(a)(i), it is seen that the cumulative traffic loading per unit thickness of composite pavements (Cumulative ESALs / THICKNESS), product of subgrade moisture and freeze index (MOIST*FZI), minimum temperature (MINTEM) and pavement age (AGE) were variables found to have direct and significant impacts on rehabilitation expenditures for composite pavements. This is an expected inference, because higher levels of pavement loading/thickness ratio, greater levels of moisture content in subgrade soil, higher freeze levels and pavement age all contribute significantly to increased pavement deterioration and thus pavement rehabilitation expenditures. The sign of the coefficient for minimum temperature was found to be negative. This is reasonable. Given other factors equal, higher minimum temperature provides a better whether condition, relatively less pavement damage and consequently, lower rehabilitation expenditures.

Table 12(a)(ii) summarized the test results for model validation, the ANOVA hypothesis test, which typically examines the existence of significant relationship between a dependent variable and multiple independent variables, indicated that composite pavement rehabilitation expenditures were strongly dependent on the identified independent variables. The goodness of fit test showed that the model provided a good fit to the data. Furthermore, the Modified Levene test showed that the error terms have constant variance. As shown in Tables 12(b)(i) and 12(b)(ii), similar model and test results were obtained for composite segments that received both periodic maintenance and rehabilitation. 
Table 12(a)(i). Model Calibration for Cost Model for Composite Pavements with Rehabilitation Work

\begin{tabular}{|c|c|c|}
\hline Pariable & Value of Coefficient & t-Statistic \\
\hline Constant Term & 540,918 & 7.4095 \\
\hline$\left[\begin{array}{c}\text { Cumulative ESALs } \\
\hline \text { THICKNESS }\end{array}\right.$ & 0.2409 & 29.3913 \\
\hline MOIST*FZI & 71.0328 & 39.5450 \\
\hline MINTEM & $-10,392.8$ & -6.8227 \\
\hline $\begin{array}{c}\text { (AGE-10)*DM } \\
\text { (1 for a dummy variable } \\
0 \text { otherwise) }\end{array}$ & $10,593.2$ & 8.8256 \\
\hline
\end{tabular}

Table 12(a)(ii). Tests for Model Validity for Composite Pavements with Rehabilitation Work

\begin{tabular}{|c|c|c|}
\hline Test & Outcome & Inference \\
\hline ANOVA hypothesis & $\begin{array}{c}\text { From ANOVA table, } \\
\text { P-value }=0.0001<0.01, \\
\text { reject } \mathrm{H}_{0}\end{array}$ & $\begin{array}{c}\text { Significant relationship } \\
\text { between rehabilitation cost } \\
\text { and the independent } \\
\text { variables }\end{array}$ \\
\hline $\begin{array}{c}\text { Goodness of fit } \\
\text { Correlation test for } \\
\text { normality of error terms }\end{array}$ & $\begin{array}{c}\text { Adjusted } \mathrm{R}^{2}=0.899 \\
\mathrm{r}=0.95<0.97(\text { critical value) }\end{array}$ & $\begin{array}{c}\text { Geod fit } \\
\text { error terms are normally } \\
\text { distributed }\end{array}$ \\
\hline $\begin{array}{c}\text { Modified Levene test for } \\
\text { constancy of error } \\
\text { variance }\end{array}$ & $\begin{array}{c}\text { Levene P-value }=0.362 \\
>0.01, \text { conclude } \mathrm{H}_{0}\end{array}$ & \begin{tabular}{c} 
Constancy of error variance \\
\hline
\end{tabular} \\
\hline
\end{tabular}


Table 12(b)(i). Model Calibration for Cost Model for Composite Pavements with Rehabilitation and Periodic Maintenance Work

\begin{tabular}{|c|c|c|}
\hline Properties & Value of Coefficient & t-Statistic \\
\hline Variable & 448,354 & 5.7782 \\
\hline$\left[\frac{\text { Cumulative ESALs }}{\text { THICKNESS }}\right]$ & 0.2327 & 26.7081 \\
\hline MOIST*FZI & 71.0545 & 37.2170 \\
\hline MINTEM & $-8,337.28$ & -5.1495 \\
\hline $\begin{array}{c}\text { (AGE-10)*DM } \\
\text { (1 for pavement age } \geq 10, \\
0 \text { otherwise) }\end{array}$ & $8,961.62$ & 7.0246 \\
\hline
\end{tabular}

Table 12(b)(ii). Tests for Model Validity for Composite Pavements with Rehabilitation and Periodic Maintenance Work

\begin{tabular}{|c|c|c|}
\hline Test & Outcome & Inference \\
\hline ANOVA hypothesis & $\begin{array}{c}\text { From ANOVA table, } \\
\text { P-value }=0.0001<0.01, \\
\text { Reject } \mathrm{H}_{0}\end{array}$ & $\begin{array}{c}\text { Significant relationship } \\
\text { between rehabilitation cost } \\
\text { and the independent variables }\end{array}$ \\
\hline Goodness of fit & Adjusted $\mathrm{R}^{2}=0.885$ & Good fit \\
\hline $\begin{array}{c}\text { Correlation test for } \\
\text { normality of error terms }\end{array}$ & $\begin{array}{c}\text { Correlation coefficient } \\
\mathrm{r}=0.941<0.97(\text { critical value) }\end{array}$ & $\begin{array}{c}\text { Residue plot shows that error } \\
\text { terms are normally distributed }\end{array}$ \\
\hline $\begin{array}{c}\text { Modified Levene test for } \\
\text { constancy of error } \\
\text { variance }\end{array}$ & $\begin{array}{c}\text { Levene P-value }=0.16752 \\
>0.01, \text { conclude } \mathrm{H}_{0}\end{array}$ & Constancy of error variance \\
\hline \multicolumn{2}{|c}{} \\
\hline
\end{tabular}




\subsubsection{Estimation of Load and Non-load Shares of Pavement Rehabilitation Expenditures}

\subsubsection{Introduction}

After the required expenditure models have been developed, the next step was to use these models to determine the load and non-load shares of pavement damage and subsequently, cost of rehabilitation of such pavement damage. Table 13 shows the summary of the rehabilitation /and periodic maintenance expenditures, IRI change, cumulative ESALs, and thickness for all pavement types.

Table 13. Summary of Capital Costs, IRI Change, Cumulative ESALs, and Thickness for Pavement Segments with Work Commenced in 1996 and 1997

\begin{tabular}{|c|c|c|c|c|c|}
\hline \multicolumn{2}{|c|}{ Pavement Type } & $\begin{array}{c}\text { Rehabilitation } \\
(97 \$)\end{array}$ & $\begin{array}{c}\text { Rehab. \& } \\
\text { Periodic Main. } \\
(97 \$)\end{array}$ & $\begin{array}{c}\text { Cumulative ESALs } \\
(18 \text { kips) }\end{array}$ & $\begin{array}{c}\text { Thickness } \\
\text { (inch) }\end{array}$ \\
\hline \multirow{3}{*}{ Total } & Flexible & $64,581,572.73$ & $64,590,919.00$ & $795,747,416.33$ & - \\
\cline { 2 - 6 } & JCP & $54,097,100.48$ & $54,142,150.01$ & $1,119,342,543.19$ & - \\
\cline { 2 - 6 } Average & Composite & $248,424,282.36$ & $250,946,494.49$ & $4,679,865,437.28$ & - \\
\cline { 2 - 6 } & Flexible & $186,890.83$ & $186,916.89$ & $2,197,968.69$ & 13.76 \\
\cline { 2 - 6 } & JCP & $461,637.03$ & $461,859.62$ & $9,469,896.86$ & 22.04 \\
\hline
\end{tabular}

\subsubsection{Analysis of Load Share of Rehabilitation /and Periodic Maintenance Expenditures for}

\section{Flexible, JCP and Composite Pavements}

(a) Load Shares of Rehabilitation /and Periodic Maintenance Expenditures for Flexible Pavements

(i) Based on Rehabilitation Expenditures

$$
\begin{aligned}
& \frac{\partial \text { EXPEND }_{\text {(rehab.) }}}{\partial \text { CumulativeESALs }}=\frac{\alpha}{\overline{\text { THICKNESS }}}=\frac{0.3113}{13.76}=0.022623546 \\
& \text { Expected EXPEND }_{(\text {rehab.) }}=\frac{\partial \text { EXPEND }_{(\text {rehab. })}}{\partial \text { CumulativeESALs }} * \Delta \text { CumulativeESALs }=0.022623546 * 795,747,416.33=18,002,628.68 \\
& \text { Load Share }=\frac{\text { Expected } E X P E N D_{(\text {rehab. })}}{{\text { Total } E X P E N D_{(\text {rehab } .)}}_{E}}=\frac{18,002,628.68}{64,581,572.73}=27.8 \%
\end{aligned}
$$


(ii) Based on Rehabilitation and Periodic Maintenance Expenditures

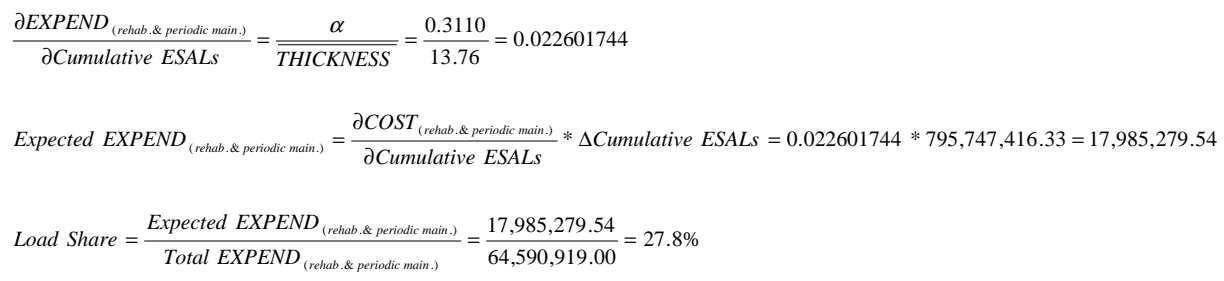

(b)Load Share of Rehabilitation /and Periodic Maintenance Expenditures for JCP Pavements

\section{(i) Based on Rehabilitation Expenditures}

$$
\begin{aligned}
& \frac{\partial \operatorname{EXPEND}_{(\text {rehab. })}}{\partial \text { Cumulative ESALs }}=\alpha=0.038 \\
& \text { Expected EXPEND } \\
& \text { Load Shar. }) \\
& \text { Lexe }=\frac{\text { Expected EXPENDIative ESALs }_{(\text {rehab. })}}{\text { Total EXPEND }}=\frac{42,535,016.63}{54,097,100.48}=78.6 \%
\end{aligned}
$$

\section{(ii) Based on Rehabilitation and Periodic Maintenance Expenditures}

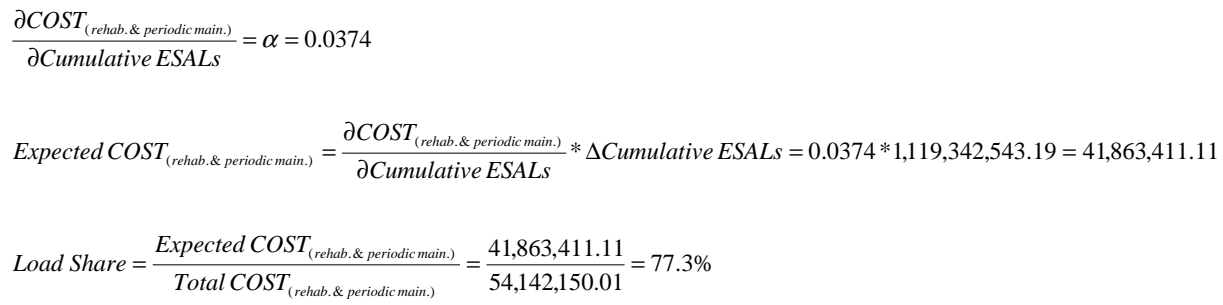


(c) Load Share of Load Share of Rehabilitation /and Periodic Maintenance Expenditures for Composite Pavements

(i) Based on Rehabilitation Expenditures

$$
\begin{aligned}
& \frac{\partial \operatorname{COST}_{(\text {rehab.) }}}{\text { dCumulative ESALs }}=\frac{\alpha}{\overline{\text { THICKNESS }}}=\frac{0.2409}{14.12}=0.02 \\
& \text { Expected } \operatorname{COST}_{(\text {rehab.) }}=\frac{\partial \operatorname{COST}_{(\text {rehab.) }}}{\partial \text { Cumulative ESALs }} * \Delta \text { Cumulative ESALs }=0.02 * 4,679,865,437.28=93,597,308.74 \\
& \text { Load Share }=\frac{\text { Expected } \operatorname{COST} T_{(\text {rehab } .)}}{\text { Total } \operatorname{COST} T_{(\text {rehab. })}}=\frac{93,597,308.74}{248,424,282.36}=38 \%
\end{aligned}
$$

(ii) Based on Rehabilitation and Periodic Maintenance Expenditures

$$
\begin{aligned}
& \frac{\partial \operatorname{COST}_{\text {(rehab.\& periodicmain. })}}{\partial \text { Cumulative ESALs }}=\frac{\alpha}{\overline{T H I C K N E S S}}=\frac{0.2327}{14.12}=0.02 \\
& \text { Expected } \operatorname{COST}_{(\text {rehab.\& periodic main.) }}=\frac{\partial \operatorname{COS} T_{\text {(rehab.\& periodic main.) }}}{\partial \text { Cumulative ESALs }} * \Delta \text { Cumulative ESALs }=0.02 * 4,679,865,437.28=93,597,308.74 \\
& \text { Load Share }=\frac{\text { Expected COST }}{\text { (rehab.\& periodic main. })}=\frac{93,597,308.74}{250,946,494.49}=38 \%
\end{aligned}
$$

\subsubsection{Summary of Load Shares of Rehabilitation /and Periodic Maintenance Expenditures for}

\section{$\underline{\text { Flexible, JCP and Composite Pavements }}$}

Load shares of rehabilitation and periodic maintenance expenditures for flexible, JCP and composite pavements are summarized in Table 14.

Table 14. Summary of Load Shares of Rehabilitation /and Periodic Maintenance Expenditures for Flexible, JCP and Composite Pavements

\begin{tabular}{|c|c|c|c|}
\hline Load Share Pavement Type & Flexible & JCP & Composite \\
\hline Rehabilitation & $27.8 \%$ & $78.6 \%$ & $38.0 \%$ \\
\hline Rehab. \& Periodic Maintenance & $27.8 \%$ & $77.3 \%$ & $38.0 \%$ \\
\hline
\end{tabular}




\subsection{Chapter Summary}

Different approaches were used to establish the load share of pavement damage for pavement segments that had received maintenance and those that had received rehabilitation. The development of models that relate maintenance expenditures and pavement condition, and pavement condition and traffic loading, were readily established Tobit models. However, for rehabilitation expenditures and traffic loading ordinary least square (OLS) models were used. The Tobit model, which is described as censored regression model, was used for modeling routine maintenance expenditures because annual routine maintenance levels are censored by budgetary constraints. Econometric theory states that in such cases, OLS is not appropriate and censored regression models yield more consistent estimates.

The rate of change in pavement roughness was found to be a useful response variable for modeling the influence of traffic, environmental factors as well as pavement age on pavement damage and maintenance/ rehabilitation expenditures. Both Tobit and OLS models revealed that load shares of maintenance and rehabilitation expenditures for flexible and composite pavements were lower than those for rigid pavements. Moreover, for the same type of pavement, the portion of load share for rehabilitation expenditures was higher than that calculated according to the maintenance expenditures. This result is as expected because rehabilitation and periodic maintenance provide added structural capacity. 


\section{CHAPTER 5 SUMMARY, CONCLUSIONS AND RECOMMENDATIONS}

\subsection{Summary of Findings}

This study utilized a comprehensive database that contains a wide range of data types relevant to highway pavement performance and expenditures in the State of Indiana. This was accompanied by definition of appropriate measures of pavement maintenance and rehabilitation, and pavement condition. Also, the various load and non-load related factors of pavement deterioration were defined. Three pavement types were considered, and the study period, which was constrained by data availability and reliability, ranged from 1995 to 1997.

Tobit models were used to explain the variation of routine maintenance expenditures in response to various load and non-load factors of pavement deterioration, while OLS models were employed to develop a function relating costs of pavement rehabilitation to pavement deterioration. From these models, the load shares of pavement maintenance and rehabilitation expenditures for each pavement type and under each category of pavement repair was determined.

In order to draw useful conclusions from the results of the current study, it was necessary to synthesize the findings in four ways:

- Findings by repair category

- Findings by pavement type

- Findings by approach used

- Findings by year of study 


\subsubsection{Findings by Repair Category}

For each pavement type, repair category consists of routine maintenance, rehabilitation, and a combination of periodic maintenance and rehabilitation. As periodic maintenance is relatively very little, interpretation of the study results has been carried out mainly using routine maintenance and rehabilitation, respectively. For each of these pavement repair categories, the distribution of load and non-load shares for each pavement type was assessed to determine how load shares varied across pavement types for that repair category, and attempts were made to explain the reasons for any observed trends. It was found that regardless of repair category, nonload effects account for greater repair expenditures for flexible pavements, but that share diminishes in the case of composite, JCP, and CRC pavements.

\subsubsection{Findings for Pavements That Had Received Only Routine Maintenance}

Figure 10 shows the distribution of load and non-load shares of routine maintenance expenditures for all four-pavement types. This figure shows that the load share of routine maintenance expenditures is lowest for flexible pavements (about 26\%), increases to $28 \%$ and $36 \%$ for composite and JCP pavements respectively, and is greatest for CRC pavements (63\%). From this it is inferred that the cost of repairing load-related damage to flexible pavements is less than that for repairing non-load damage on such pavement. This is an important consideration for any cost allocation study. A possible explanation for this inference is that the interaction effects of materials used for flexible pavement construction and environmental factors are more pronounced than for materials and traffic loading. The results further suggest that as pavement composition is more and more dominated by reinforced concrete and steel content, the load share of pavement damage increases, and the pavement becomes relatively less vulnerable to non-load factors of pavement deterioration such as the environment. 


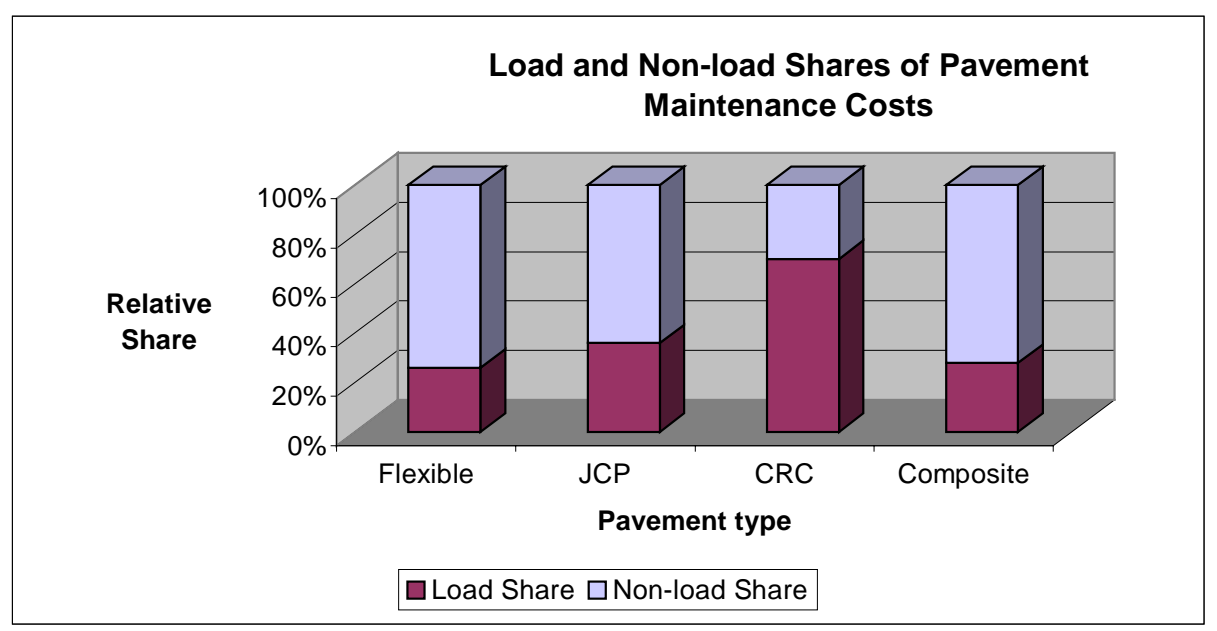

Figure 10. Load and Non-load Shares of Pavement Routine Maintenance Expenditures (Current Study)

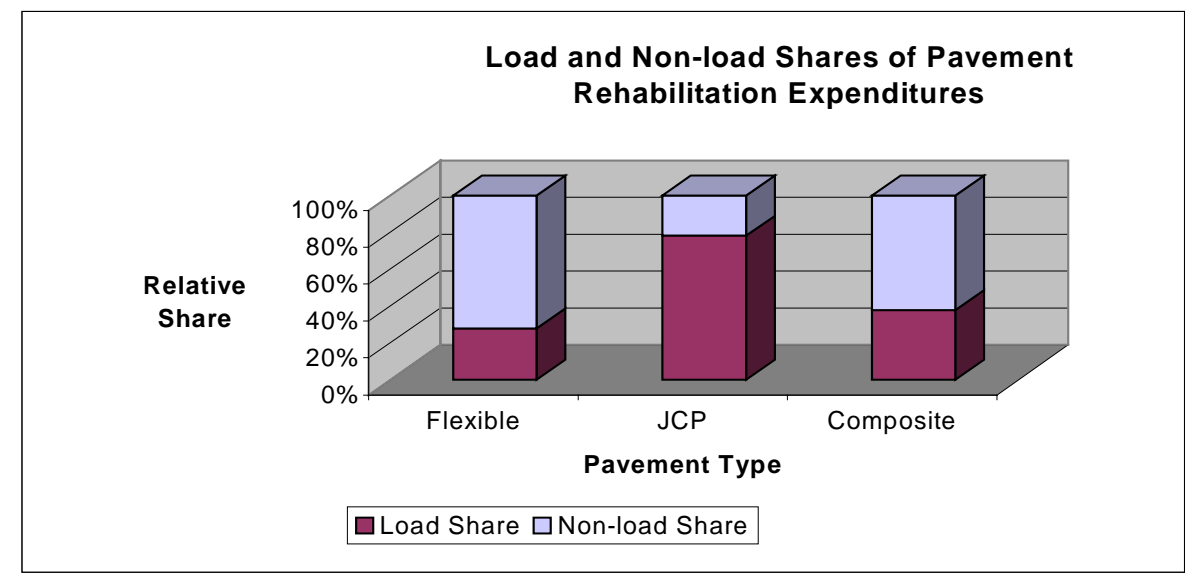

Figure 11. Load and Non-load Shares of Pavement Rehabilitation Expenditures (Current Study)

\subsubsection{Findings for Pavements That Had Undergone Rehabilitation}

As shown in Figure 11, of the three pavement types that had undergone rehabilitation, flexible pavements had the lowest load share of pavement rehabilitation expenditures (28\%), while JCP pavements had the highest share (78\%). This suggests that rehabilitation of flexible pavements, though a structural activity, corrects pavement damage a greater share of which is induced by environment and other non-load related factors. On the other hand, a greater share of 
damage on JCP pavements that are repaired by rehabilitation is caused by traffic loading. The situation for composite pavements is somewhat in between, at 38\%. This result is intuitive because most of composite pavements in Indiana consist of flexible overlays on rigid pavements.

\subsubsection{Findings by Pavement Type}

It was necessary to analyze the results for each pavement type, so that differences in load and non-load shares for each repair category applied to the given pavement type can be explained without bias to pavement materials. An interesting observation is that across all pavement types, load shares were smaller for sections that had received only routine maintenance than it was for sections that had received rehabilitation. This result is not unexpected, because routine maintenance is generally carried out by highway agencies in response to functional defects, while rehabilitation is done to correct structural deficiencies and to restore load-bearing capacity. A discussion for each pavement type is presented below.

\subsubsection{Flexible Pavements}

Figure 12(a), the load share of flexible pavement repair expenditures is substantially lower than non-load share, regardless of repair category. The load share is about $26 \%$ for routine maintenance and is only slightly higher $(28 \%)$ for rehabilitation. While the higher load share for rehabilitation is reasonable within the context of intended objective of repair (structural versus functional), the closeness of the two values reflects the fact that the load share of flexible pavement repair is not sensitive to repair category. 

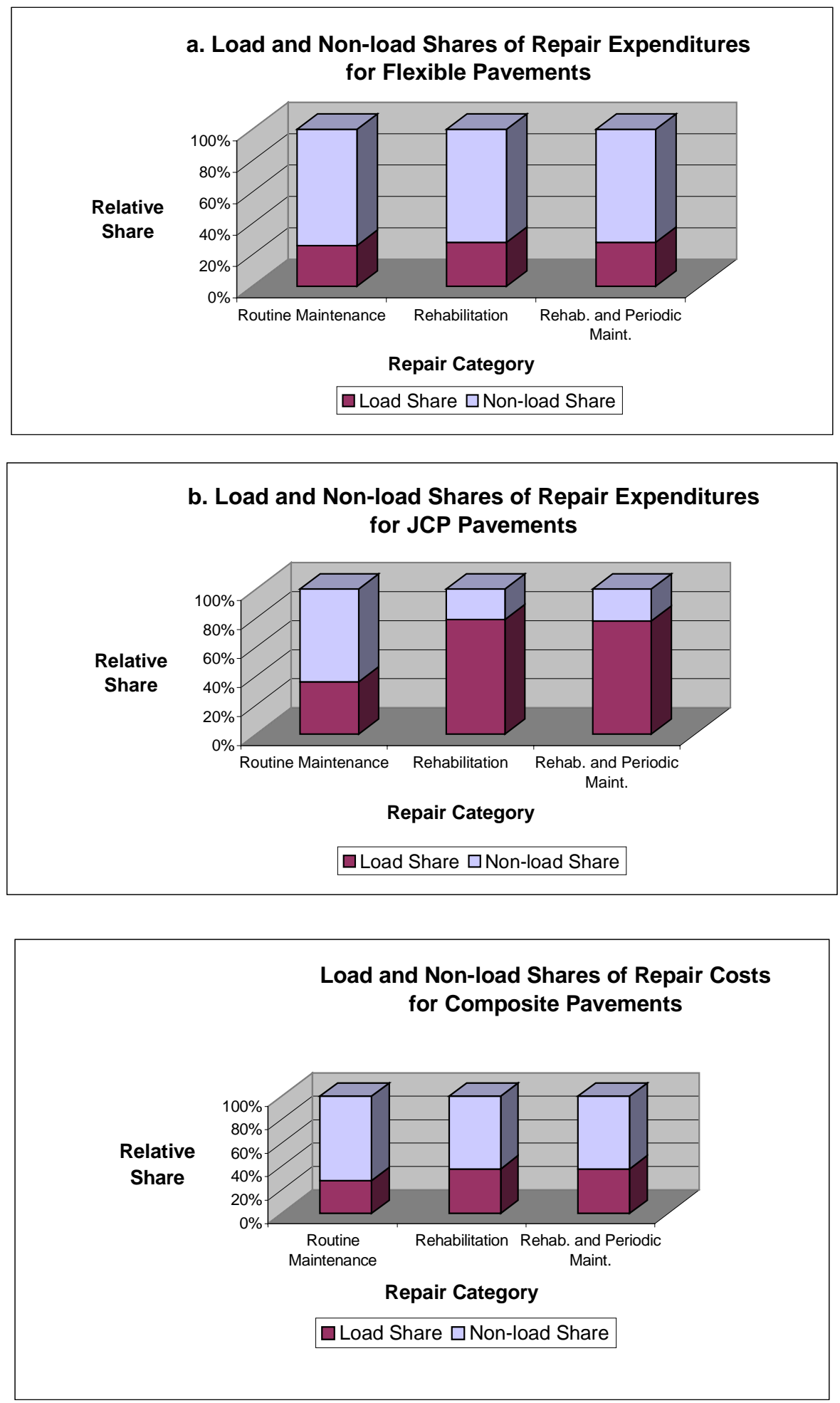

Figure 12. Load and Non-load Shares of Repair Expenditures for Various Pavement Types 


\subsubsection{JCP Pavements}

As illustrated in Figure 12(b), the load share of JCP pavement repair expenditures is very sensitive to repair category. For routine maintenance, only $36 \%$ of pavement damage repair is attributable to load, while for rehabilitation, $78 \%$ is attributable to load. This finding suggests that for JCP pavement repair activities that involve structural capacity improvement, the load share of repair be over twice the load share for activities that do not improve structural capacity. Therefore it would be unfair to allocate JCP pavement repair expenditures without due cognizance to the type of pavement repair.

\subsubsection{Composite Pavements}

Figure 12(c) shows that the load share of composite pavement repair expenditures is not very sensitive to repair category, as the range of values is $28-38 \%$ for routine maintenance and rehabilitation respectively. The higher load share for rehabilitation compared to that for routine maintenance is defensible given the fact that routine maintenance activities are mostly carried out to correct non-structural defects.

\subsubsection{Findings by Approach Used}

Table 15 shows the comparison of the results of using the current approach and the 1984 Indiana Highway Cost Allocation approach using current data (1995-1997). This table, as well as Figure 12, shows the distribution of load and non-load shares across pavement types and pavement repair categories.

As seen from Table 15 and Figure 13, the results obtained in the current study was generally consistent with those using the 1984 Indiana HCAS approach, with a few exceptions where differences in results can be considered significant. Both studies found that the impact of 
load-related factors on pavement repair expenditures was higher for rigid pavements compared to that for

Table 15. Comparison of Results between Current Study and 1984 Indiana HCAS Approaches

\begin{tabular}{|c|c|c|c|c|c|c|}
\hline \multirow{2}{*}{$\begin{array}{l}\text { Pavement } \\
\text { Type }\end{array}$} & \multirow[t]{2}{*}{ Repair Type } & \multirow[t]{2}{*}{ Repair Details } & \multicolumn{2}{|c|}{ Current Approach } & \multicolumn{2}{|c|}{$\begin{array}{l}1984 \text { HCAS } \\
\text { Approach }\end{array}$} \\
\hline & & & Load & Non-load & Load & Non-load \\
\hline \multirow{3}{*}{ Flexible } & $\begin{array}{l}\text { Pavement with } \\
\text { maintenance }\end{array}$ & $\begin{array}{l}\text { Models based only on } \\
\text { routine maintenance }\end{array}$ & $26 \%$ & $(74 \%)^{* 3}$ & $21 \%$ & $(79 \%)$ \\
\hline & \multirow{2}{*}{$\begin{array}{l}\text { Pavement with } \\
\text { rehabilitation }\end{array}$} & $\begin{array}{l}\text { Models based on } \\
\text { rehabilitation only }\end{array}$ & $28 \%$ & $(72 \%)$ & \multirow[b]{2}{*}{$42 \%$} & \multirow[b]{2}{*}{$(58 \%)$} \\
\hline & & $\begin{array}{l}\text { Models based on } \\
\text { rehabilitation and } \\
\text { periodic maintenance }\end{array}$ & $28 \%$ & $(72 \%)$ & & \\
\hline \multirow{3}{*}{$\mathrm{JCP}$} & $\begin{array}{l}\text { Pavement with } \\
\text { maintenance }\end{array}$ & $\begin{array}{l}\text { Models based only on } \\
\text { routine maintenance }\end{array}$ & $36 \%$ & $(64 \%)$ & $54 \%$ & $(46 \%)$ \\
\hline & \multirow{2}{*}{$\begin{array}{l}\text { Pavement with } \\
\text { rehabilitation }\end{array}$} & $\begin{array}{l}\text { Models based on } \\
\text { rehabilitation only }\end{array}$ & $79 \%$ & $(21 \%)$ & \multirow[b]{2}{*}{$85 \%$} & \multirow[b]{2}{*}{$(15 \%)$} \\
\hline & & $\begin{array}{l}\text { Models based on } \\
\text { rehabilitation and } \\
\text { periodic maintenance }\end{array}$ & $78 \%$ & $(22 \%)$ & & \\
\hline $\mathrm{CRC}^{* 1}$ & $\begin{array}{l}\text { Pavement with } \\
\text { maintenance }\end{array}$ & $\begin{array}{l}\text { Models based only on } \\
\text { routine maintenance }\end{array}$ & $63 \%$ & $(37 \%)$ & $100 \%{ }^{* 2}$ & (0) \\
\hline \multirow{3}{*}{ Composite } & $\begin{array}{l}\text { Pavement with } \\
\text { maintenance }\end{array}$ & $\begin{array}{l}\text { Models based only on } \\
\text { routine maintenance }\end{array}$ & $28 \%$ & $(72 \%)$ & $29 \%$ & $(71 \%)$ \\
\hline & \multirow{2}{*}{$\begin{array}{l}\text { Pavement with } \\
\text { rehabilitation }\end{array}$} & $\begin{array}{l}\text { Models based on } \\
\text { rehabilitation only }\end{array}$ & $38 \%$ & $(62 \%)$ & \multirow{2}{*}{$56 \%$} & \multirow{2}{*}{$(44 \%)$} \\
\hline & & $\begin{array}{l}\text { Models based on } \\
\text { rehabilitation and } \\
\text { periodic maintenance }\end{array}$ & $38 \%$ & $(62 \%)$ & & \\
\hline
\end{tabular}

Note: 1) For CRC pavement, no analysis was conducted for segments with rehabilitation due to lack of data.

2) For CRC pavement, only one route was used when conducting analysis by using earlier Indiana approach. The result may not be representative of all pavement types in this category.

3) Numbers in parenthesis indicate non-load shares. 

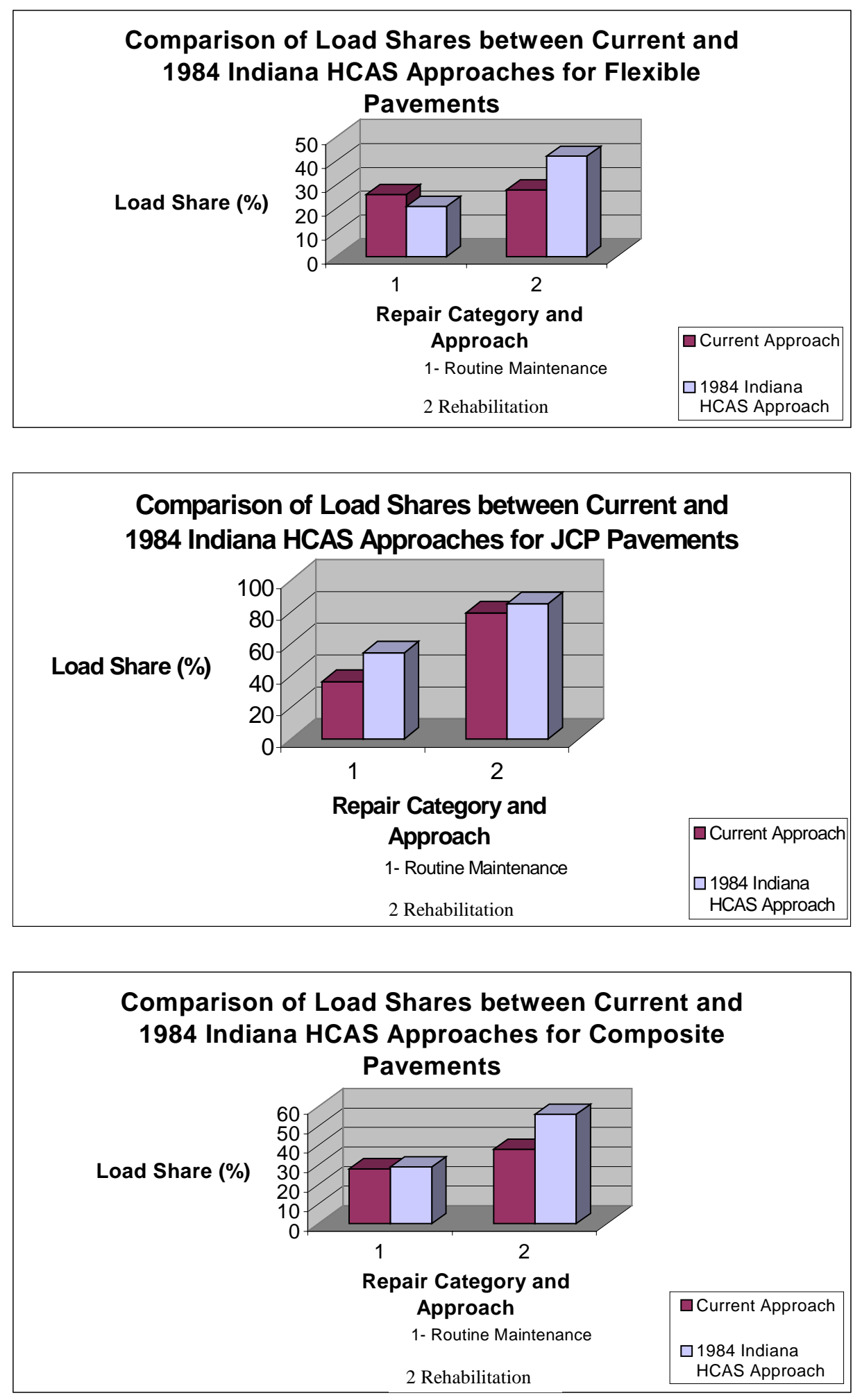

Figure 13. Comparison of Load and Non-load Shares of Pavement Repair Expenditures 
flexible and composite pavements. A summary of the results obtained using the 1984 Indiana HCAS approach on the basis of current data set was provided in Appendix 24.

For flexible pavement sections that had received only routine maintenance, the 1984 Indiana HCAS approach found that approximately $21 \%$ of damage is attributed to pure load factor. This was quite similar to the results obtained from the current study (26\%). From the standpoint of rehabilitation and periodic maintenance, the 1984 Indiana HCAS approach found that $42 \%$ of flexible pavement damage is due to pure load factor while the current study found this value to be $28 \%$. As expected, both studies attribute to flexible pavements with rehabilitation a greater share of load share of pavement repair expenditures as compared to flexible pavements with routine maintenance. This is because rehabilitation activities are generally carried out by highway agencies to address structural deficiencies.

For JCP pavement with maintenance, the 1984 Indiana HCAS approach found that $54 \%$ of pavement damage is due to pure load factors while the current study found that this figure was in the region of $36 \%$. The value obtained in this study is deemed more realistic because routine maintenance activities correct only functional deficiencies and do not improve the structural capacity of the road. Therefore, the load share of pavement repair expenditures from the standpoint of routine maintenance is expected to be relatively little. The picture for rehabilitated JCP pavements is similar. The current study finds that for such pavements with rehabilitation, $78 \%$ of flexible pavement damage is attributable to load, while the 1984 Indiana HCAS approach finds that value as $85 \%$.

For CRC pavements, the current study found that about $63 \%$ of pavement damage can be attributed to load-related factors for pavements that had received only routine maintenance. The 1984 Indiana HCAS approach found this value to be $100 \%$, but it is pertinent to note that only 
one route was used for the analysis in that study, and the result is not expected to be representative of all routes in that category.

For composite pavements that had received only routine maintenance, the results from the current study and the 1984 Indiana HCAS approach were somewhat similar, with load shares of $28 \%$ and $29 \%$, respectively. However, for composite pavements that had undergone rehabilitation, the load share was $38 \%$ and $56 \%$, respectively. The difference in these two sets of values is rather large, and can probably be explained by the difference in the two approaches.

\subsubsection{Findings by Year of Study}

Finally, a comparison was made on the results of the current approach applied to current data to the results of the 1984 Indiana HCA approach applied to data at that time. The comparison revealed differences in the ratio of pavement repair expenditures attributed to load and non-load factors. The load shares obtained from the current study were consistently lower than those of the 1984 study, for all pavement types. This finding is not unexpected. Over the past 15 years, travel patterns have changed considerably. Also, vehicle axle configurations, tire pressures, and other vehicle-related features have also changed. Furthermore, design procedures, material types and construction techniques have been improved to maximize the structural capacity of a pavement for a given set of conditions. All these changes have occurred as a result of efforts to improve the load-bearing capacity of the pavement, increase pavement durability, and to reduce the effective loading from heavy vehicles.

The obvious reduction in load related effects, coupled with no significant change in nonload related effects, over the past 15 years, means that the current load shares of repair expenditures are expected to be lower than those of 15 years ago. The study results are consistent with this explanation. 


\section{$\underline{5.2 \text { Conclusions }}$}

It is clear from the current study that the load share of pavement repair expenditures is highest (over 60\%) for CRC pavements, followed by JCP and composite pavements, and is least for flexible pavements. This is true for all the pavement sections regardless of road repair category.

Generally, it was revealed that the load shares of pavement repair expenditures for flexible and composite pavements were lower than those for rigid pavements, regardless of pavement repair category. Furthermore, for each pavement type, it was found that pavement sections that had received non-structural pavement repairs (i.e., routine maintenance) had a relatively smaller load share of repair expenditures as compared to those sections that had received structure-enhancing repairs (rehabilitation).

Finally, the following conclusions can be made about load shares of pavement repair expenditures:

- It is sensitive to pavement type

- It is sensitive to pavement repair category

- It is sensitive to the year of study

- For a given pavement type, load share sensitivity differs across pavement repair categories (most sensitive for JCP, least sensitive for flexible pavements)

In light of the discussion of results, it is imperative that any meaningful and reliable cost allocation study be preceded by determination of the load and non-load shares of pavement repair expenditures. This should be carried out with respect to the type of pavements in the network in question and the various categories of past pavement repair activities, and should utilize, as much as possible, current data on the network usage, condition and maintenance expenditures. 


\subsection{Recommendations and Directions for Future Work and Research}

The observations and results from this study can be salient inputs for the update of the highway cost allocation study for Indiana. This way, a fair and equitable distribution of highway costs allocation can be revised to ensure that pavement maintenance and rehabilitation expenditures are distributed in an equitable and efficient manner. This study can be extended further to examine the load and non-load shares of expenditures used for different activities of maintenance, such as pothole patching, resealing, etc. Another area of further study is the implicit consideration of routine maintenance in the rehabilitation expenditure models. 


\section{REFERENCES}

AASHTO [1976], AASHTO Maintenance Manual, American Association of State Highway and Transportation Officials, Washington, D. C.

AASHTO [1993], AASHTO Interim Guide for Design of Pavement Structures, American Association of State Highway and Transportation Officials, Washington, D.C.

Al-Suleiman, T., and Sinha, K. C. [1988], "An Evaluation of Effects of Routine Maintenance on Pavement Surface Condition”, School of Civil Engineering, Purdue University, West Lafayette, Indiana.

Ben-Akiva, M., Humplick, F., Madanat, S. and Ramaswamy, R. [1992], "Latent Performance Approach to Infrastructure Management", Transportation Research Record 1311, Transportation Research Board, National Research Council, Washington, D.C.

Butler, B. C., Charmichael, R. F., and Flanagan, P. R. [1985], “Impact of Pavement Maintenance on Damage Rate", Volume 1, Final Report, ARE, Inc., Consultants, DTFH61-83-C-00125, Federal Highway Administration, Washington, D. C.

Econometric Software [1998], “LIMDEP User's Manual”, Econometric Software, Plainview, New York.

Fwa, T. F. and Sinha, K. C. [1986], "Study of the Effects of Routine Pavement Maintenance", Transportation Research Record 1102, Transportation Research Board, National Research Council, Washington, D.C.

Fwa, T. F. and Sinha, K. C. [1987], "Estimation of Environmental and Traffic Loading Effects on Highway Pavements", Australian Road Research 17(4), Australian Road Research Board Ltd, Victoria, Australia.

Goldberger, A. S. [1964], Econometric Theory, New York: John Wiley \& Sons, Inc., New York, N.Y.

Gopinath, D., Ben-Akiva, M. and Ramaswamy, M. [1996], "Modeling Performance of Highway Pavements", Transportation Research Record 1449, Transportation Research Board, National Research Council, Washington, D.C.

Greene, W. H. [1999], Econometric Analysis, Prentice Hall, Upper Saddle River, New Jersey.

Gulen, S., Nagle, J., Zhu, K., MacArthur, S., and Hooker, G. [1998], "Determination of Practical ESALs on Indiana Roads", Indiana Department of Transportation, Indiana. 
Hajek, J. J., Tighe, S. L., and Hutchinson, B. G. [1998], “ Allocation of Pavement Damage Due to Truck Using a Marginal Cost Method”, Transportation Research Record 1613, Transportation Research Board, National Research Council, Washington, D. C.

Huang, Y. H. [1993], Pavement Analysis and Design, Prentice Hall, Englewood Cliffs, New Jersey.

Lytton, R. L. [1988], "Concepts of Pavement Performance Prediction and Modeling”, Department of Civil Engineering, Texas A \& M University, College Station, Texas.

Mannering, F. L., and Kilareski, W. P. [1998], Principle of Highway Engineering and Traffic Analysis, John Wiley \& Sons, Inc., New York, N. Y.

Mohammed, D., McCarthy, P. and Sinha, K. C. [1997], "The Mixed Logit Approach", Transportation Research Record 1597, Transportation Research Board, National Research Council, Washington, D.C.

Martin, T. [1994], "Pavement Behavior Prediction for Life-cycle Costing", Australian Road Research 255, Australian Road Research Board Ltd, Victoria, Australia.

Oregon Department of Transportation (Oregon DOT) [1987], "1986 Oregon Highway Cost Allocation Study", Salem, Oregon.

Oregon Department of Transportation (Oregon DOT) [1995], "1994 Oregon Highway Cost Allocation Study", Salem, Oregon.

Paterson, W. D. O. [1987], Road Deterioration and Maintenance Effects: Models for Planning and Management, Johns Hopkins University Press, Baltimore, Maryland.

Perera, R. W., Byrum, C., and Kohn, S. D. [1995], "Investigation of Pavement Roughness", Final Report, Report No. FHWA-RD-97-147, Federal Highway Administration, Washington, D. C.

Ramaswamy, R. and Ben-Akiva, M. [1997], "Estimation of Highway Pavement Deterioration from In-Service Pavement Data", Transportation Research Record 1570, Transportation Research Board, National Research Council, Washington, D.C.

Rilett, L. R., Hutchinson, B. G., and Hass R. C. G. [1990], "Cost Allocation Implications of Flexible Pavement Deterioration Models", Transportation Research Record 1215, Transportation Research Board, National Research Council, Washington, D. C.

SAS Institute. [1996], "SAS/INSIGHT User's Guide”, SAS Institute Inc., Cary, North Carolina.

Sinha, K. C., Fwa, T. F., Ting, E. C., Shanteau, R. M., Saito, M. and Michael, H. L. [1984], "Indiana Highway Cost Allocation Study", School of Civil Engineering, Purdue University, West Lafayette, Indiana.

Small, K. A., Winston, C., and Evans, C. [1989], Road Work: A New Highway Pricing and Investment Policy, The Brookings Institution, Washington, D. C. 
Strategic Highway Research Program (SHRP) [1994], "Evaluation of the AASHTO Design Equations and Recommended Improvements", Washington, D.C.

United States Department of Transportation (U.S. DOT) [1998], "1997 Federal Highway Cost Allocation Study", Washington, D.C.

Virginia Department of Transportation (VIDOT) [1983], "1982 Virginia Highway Cost Allocation Study", Richmond, Virginia.

Whitford, R. K. [1998], "State of Alaska: Truck Weight Monitoring Plan Using Weigh-in-Motion Devices”, Final Report, Project No. 76095, Purdue University, West Lafayette, Indiana.

Yoder, E. J. [1975], Principles of Pavement Design, New York: John Wiley \& Sons, New York City, New York. 


\section{LIST OF ABBREVIATIONS}

\begin{tabular}{|c|c|}
\hline AADT & Average Annual Daily Traffic \\
\hline AASHO & American Association of State Highway Officials \\
\hline AASHTO & American Association of State Highway and Transportation Officials \\
\hline ANOVA & Analysis of Variance \\
\hline ARE & Austin Research Engineers \\
\hline ARME & Annual Routine Maintenance Expenditures \\
\hline ARRB & Australia Road Research Board \\
\hline CBR & California Bearing Ratio \\
\hline CESALs & Cumulative Equivalent Single Axle Loads \\
\hline $\mathrm{CRC}$ & Continuously Reinforced Concrete \\
\hline DI & Damage Index \\
\hline DOT & Department of Transportation \\
\hline $\mathrm{DM}$ & Dummy Variable \\
\hline ESALs & Equivalent Single Axle Loads \\
\hline EUAC & Equivalent Uniform Annual Cost \\
\hline FHWA & Federal Highway Administration \\
\hline FZI & Freeze Index \\
\hline FZTHAW & Freeze-thaw Cycles \\
\hline GPS & General Pavement Study \\
\hline HCAS & Highway Cost Allocation Study \\
\hline
\end{tabular}




\begin{tabular}{|c|c|}
\hline HMAC & Hot Mix Asphalt Concrete \\
\hline INDOT & Indiana Department of Transportation \\
\hline IPMS & Indiana Pavement Management Systems \\
\hline IRI & International Roughness Index \\
\hline $\mathrm{JCP}$ & Jointed Concrete Pavement \\
\hline JPCP & Jointed Plain Concrete Pavement \\
\hline JTRP & Joint Transportation Research Program \\
\hline LEF & Load Equivalency Factor \\
\hline LIMDEP & Limited Dependent Variable (Software Package) \\
\hline LRI & Likelihood Ratio Index \\
\hline LTPP & Long Term Pavement Performance \\
\hline MAXTEM & Maximum Temperature \\
\hline MDI & Modified Damage Index \\
\hline MINTEM & Minimum Temperature \\
\hline NCHRP & National Cooperative Highway Research Program \\
\hline OLS & Ordinary Least Square \\
\hline PCC & Portland Cement Concrete \\
\hline PMS & Pavement Management Systems \\
\hline PSI & Present Serviceability Index \\
\hline $\mathrm{RCI}$ & Ride Comfort Index \\
\hline RMSVA & Root Mean Square Vertical Acceleration \\
\hline $\mathrm{RN}$ & Roughness Number \\
\hline SAS & Statistical Analysis System (Software Package) \\
\hline SHRP & Strategic Highway Research Program \\
\hline SN & Structural Number \\
\hline
\end{tabular}


TSI Terminal Serviceability Index

VMT Vehicle Miles of Travel

WIM Weigh-in-Motion

WLEF Weighted Load Equivalency Factor 
APPENDICES 
Appendix 1. Definition of General Model Parameters For Routine Maintenance 
PARAMETER

94TFA

95TFA

96TFA

97TFA

98TFA

94FA

95FA

96FA

97FA

98FA

94IRI

95IRI

96IRI

97IRI

95IRICH

96IRICH

97IRICH

95LIRI1

96LIRI1

97LIRI1

$\mathrm{IRI}_{0}$

ALPHA

$\mathrm{R}_{\text {IRI }}^{2}$

$\mathrm{IRI}_{\mathrm{T}}$

$\mathrm{PSI}_{0}$

$\mathrm{PSI}_{\mathrm{T}}$

AVE456T

AVE567T

AVE678T

AVE9456

AVE9567

AVE9678

567IRI

567IRI1

FZI

FZTHAW

DAYOSF

MEANTEM

MAXTEM

MINTEM

DAY32

DAY0

PRECIP

LPRE

WETDAY

WET

P200

P200LPR

MOIST

LL

PL

PI

SUBDEN

CBR93

REMOD

LREMOD

95AADT

96AADT

97AADT

95TRUCK

96TRUCK

97TRUCK

95LANE

96LANE

\section{DEFINITION}

Expenditures of routine maint. by force account and periodic maint. by contract in 1994

Expenditures of routine maint. by force account and periodic maint. by contract in 1995

Expenditures of routine maint. by force account and periodic maint. by contract in 1996

Expenditures of routine maint. by force account and periodic maint. by contract in 1997

Expenditures of routine maint. by force account and periodic maint. by contract in 1998

Routine maintenance Expenditures only by force account in 1994

Routine maintenance Expenditures only by force account in 1995

Routine maintenance Expenditures only by force account in 1996

Routine maintenance Expenditures only by force account in 1997

Routine maintenance Expenditures only by force account in 1998

IRI measurement in 1994

IRI measurement in 1995

IRI measurement in 1996

IRI measurement in 1997

$\%$ change in IRI between 1994 and 95

$\%$ change in IRI between 1995 and 96

$\%$ change in IRI between 1996 and 97

$\log _{10}(\%$ change in IRI between 1994 and $95+100 \%)$

$\log _{10}(\%$ change in IRI between 1995 and $96+100 \%)$

$\log _{10}(\%$ change in IRI between 1996 and $97+100 \%)$

Initial IRI

Predicted annual IRI increment rate

$\mathrm{R}^{2}$ of the regression model for the extrapolation of initial IRI

Terminal IRI

Initial pavement serviceability index

Terminal pavement serviceability index

Average annual routine and periodic maintenance Expenditures during 1994-96

Average annual routine and periodic maintenance Expenditures during 1995-97

Average annual routine and periodic maintenance Expenditures during 1996-98

Average annual routine maintenance Expenditures during 1994-96

Average annual routine maintenance Expenditures during 1995-97

Average annual routine maintenance Expenditures during 1996-98

Average \% change in IRI during 1995, 96 and 97

Average \% change in IRI during 1995, 96 and $97+100 \%$

Freeze index

Freeze thaw cycle

No. of days between first minimum of $0^{\circ} \mathrm{C}$ between Spring and Fall

Average annual temperature

Maximum annual temperature

Minimum annual temperature

No. of days $>32^{\circ} \mathrm{C}$

No. of days $<0^{\circ} \mathrm{C}$

Annual precipitation

$\log _{10}$ (annual precipitation)

Annual no. of wet days

Annual no. of wet days

Subgrade percent passing \#200 sieve

Subgrade percent passing \#200 sieve $* \log _{10}$ (annual precipitation)

Subgrade moisture content

Subgrade liquid limit

Subgrade plastic limit

Subgrade plasticity index

Maximum dry density of subgrade materials

California bearing capacity at $93 \%$

Subgrade resilient modulus

$\log _{10}$ (subgrade resilient modulus)

Average annual daily traffic in 1995

Average annual daily traffic in 1996

Average annual daily traffic in 1997

Truck percentage in traffic stream in 1995

Truck percentage in traffic stream in 1996

Truck percentage in traffic stream in 1997

Lane traffic in 1995

Lane traffic in 1996

\section{UNIT}

\$/lane-mile/year (98\$)

\$/lane-mile/year (98\$)

\$lane-mile/year (98\$)

\$/lane-mile/year (98\$)

\$lane-mile/year (98\$)

\$/lane-mile/year (98\$)

\$/lane-mile/year (98\$)

\$/lane-mile/year (98\$)

\$/lane-mile/year (98\$)

\$/lane-mile/year $(98 \$)$

inch/mile

inch/mile

inch/mile

inch/mile

inch/mile

inch/mile

inch/mile

\$lan-mile/year (98\$)

\$/lan-mile/year (98\$)

$\$$ /lan-mile/year (98\$)

$\$ /$ lan-mile/year (98\$)

\$/lan-mile/year (98\$)

\$/lan-mile/year (98\$)

degree-day no. of cycles

$$
{ }^{0} \mathrm{~F}
$$

${ }^{0} \mathrm{~F}$

${ }^{0} \mathrm{~F}$

day

day

inch/year

day

day

weight $\%$

weight $\% *$ inch/year

$\%$

$\%$

lb/inch ${ }^{3}$

$\%$

psi

vehicle/day

vehicle/day

vehicle/day

$\%$

vehicle/day

vehicle/day 
97LANE Lane traffic in 1997

567AADT Average of AADT during 1995-97

AADT2 (Average of AADT during 1995-97-5,000) $*$ alpha $_{1} \quad\left[\right.$ alpha $_{1}=1$, if AADT >5,000

AADT3 (Average of AADT during 1995-97-50,000) $* \mathrm{alpha}_{2}\left[\mathrm{alpha}_{2}=1\right.$, if AADT > 50,000]

567TRUC Average truck percentage in traffic stream during 1995-97

567LANE Average lane traffic during 1995-97

INESAL Equivalent single axle loads computed by INDOT method

WHESAL Equivalent single axle loads computed by Whitford method

95ESAL Equivalent single axle loads in 1995 computed by Weighted-LEF method

96ESAL Equivalent single axle loads in 1996 computed by Weighted-LEF method

97ESAL Equivalent single axle loads in 1997computed by Weighted-LEF method

AVEESAL Average equivalent single axle loads during 1995-97 by Weighted-LEF method

LAVESAL $\quad \log _{10}$ (average equivalent single axle loads during 1995-97)

CESAL Cumulative equivalent single axle loads during one life cycle

LCESAL $\quad \log _{10}$ (cumulative equivalent single axle loads during one life cycle)

LESALAB $\quad \log _{10[}$ cumulative equivalent single axle loads /(sub/base + HMAC thickness)]

PSIESAL PSI-cumulative ESALs loss during one life cycle

94AGE Pavement age in 1994

95AGE Pavement age in 1995

96AGE Pavement age in 1996

97AGE Pavement age in 1997

AGE Pavement age

AGE2 (Pavement age-5 or 8$) *$ beta $_{1} \quad\left[\right.$ beta $_{1}=1$, if age $>5$ for flexible or $>8$ for rigid)

AGE3

DRAINCO

(Pavement age-10 or 15$) *$ beta $_{2}\left[\right.$ beta $_{2}=1$, if age $>10$ for flexible or $>15$ for rigid)

Drainage coefficient

BASETH Sub/base thickness

BLPRE Sub/base thickness * $\log _{10}$ (precipitation)

BASECOM Sub/base compaction

HMACTH Hot mix asphalt concrete (HMAC) thickness

SLABTH Slab thickness

THICK Sub/base thickness + HMAC thickness or slab thickness

ESAL/TH Equvalent single axle loads / (sub/base + HMAC thickness or slab thickness)

LESALTH $\quad \log _{10}$ [equvalent single axle loads / (sub/base + HMAC thickness or slab thickness)]

AC32

SLAB32

HMAC thickness * no. of days $>32^{\circ} \mathrm{C}$

Slab thickness * no. of days $>32^{\circ} \mathrm{C}$

LACBASE $\quad \log _{10}$ (sub/base thickness + HMAC thickness)

LSLBASE $\quad \log _{10}$ (subbase thickness + slab thickness)

ASPHCON Asphalt content

AGG4 Percent of aggregate in HMAC passing \#4 sieve

LAGG4 $\quad \log _{10}$ (percent of aggregate in HMAC passing \#4 sieve)

AIRVOID Air voids in HMAC

LAV $\quad \log _{10}$ (air voids in HMAC)

D32AV No. of days $>32^{\circ} \mathrm{C} *$ Air voids in HMAC

ELASMOD Modulus of elasticity of concrete pavement

RUPMOD Modulus of rupture of concrete pavement

JOINT Joint spacing between concrete slabs

vehicle/day

vehicle/day

vehicle/day

vehicle/day

vehicle/day

18kips

18kips

18kips

18kips

18kips

18kips

18kips

DOWEL

Diameter of dowel 
Appendix 2. Variables Considered for the Model Development of Flexible Pavements with Routine Maintenance 
Equation 1: Tobit Model

Dependent Variable

Unit

Average annual routine maintenance Expenditures during 1996-98 (in 98 \$) \$/lane-mile/year

Independent Variables

Average \% change in IRI of flexible pavement during 1995-97

Region: Dummy variables

District: Dummy variables

Road Type: Dummy variables

Pavement Age: Average of 1995-97

year

Age2: Dummy variable (for age group of 6-10 years)

Age3: Dummy variable (for age group of 10 years up)

Equation 2: Simultaneous Regression Equation

Dependent Variable

Average \% change in IRI of flexible pavement during 1995-97

Independent Variables

Average annual routine maintenance Expenditures during 1995-97 (in 98 \$) \$/lane-mile/year

Region: Dummy variables

District: Dummy variables

Road Type: Dummy variables

Freeze index

Freeze-thaw cycle

No. of days between last Spring and first Fall of minimum of $0^{\circ} \mathrm{C}$

Mean annual temperature

Maximum annual temperature

Minimum annual temperature

No. of days $>32^{\circ} \mathrm{C}$

No. of days $<0^{\circ} \mathrm{C}$

Average annual precipitation

Average no. of wet days

Subgrade \% passing \#200 sieve

Subgrade moisture content

Subgrade plastic index

Maximum dry density of subgrade material

Subgrade modulus of resilience

AADT

AADT2: Dummy variable

degree-day no. of days

no. of days

no. of days

no. of days

inches/year

no. of days

weight $\%$

$\%$

$\%$

psi

psi

vehicles/day

AADT3: Dummy variable

$\%$ Truck in traffic stream

Lane distribution based on WIM data

Vehicle composition based on WIM data

Vehicle operating weight distribution based on WIM data

ESALs 
Pavement age

year

Age2: Dummy variable (for age group of 6-10 years)

Age3: Dummy variable (for age group of 10 years up)

Drainage coefficient

Sub/base thickness

Base thickness * precipitation

Base compaction

Hot mix asphalt concrete (HMAC) thickness

HMAC thickness $*$ no. of days $>32^{\circ} \mathrm{C}$

ESALs/ (sub/base thickness + HMAC thickness)

Asphalt content in HMAC

Hot mix asphalt concrete \% aggregate < \#4 sieve

Air voids in hot mix asphalt concrete

No. of days $>32^{\circ} \mathrm{C} *$ air voids

inches
inches
$\%$
inches
inches $*$ days
$18 \mathrm{kips} /$ inch
$\%$
weight \%
volume \%
days * volume \%


Appendix 3. Descriptive Statistics of All Variables Initially Considered for Flexible Pavement Modeling Based on Routine Maintenance 


\begin{tabular}{|c|c|c|c|c|c|}
\hline Flexible pavements & Mean & Std. Deviation & Minimum & Maximum & Unit \\
\hline AVE9456 & 63.13 & 39.40 & 0.00 & 911.23 & \$/lane-mile/year (98\$) \\
\hline AVE9567 & 66.47 & 39.40 & 0.00 & 911.23 & \$/lane-mile/year (98\$) \\
\hline AVE9678 & 77.58 & 12.23 & 0.00 & $1,736.90$ & \$/lane-mile/year (98\$) \\
\hline 567IRI & 0.04 & 0.00 & -0.34 & 0.33 & \\
\hline 567IRI1 & 0.02 & 0.00 & -0.18 & 0.12 & \\
\hline FZI & 280.49 & 81.37 & 74.62 & $1,483.80$ & degree-day \\
\hline FZTHAW & 95.40 & 5.19 & 65.33 & 115.95 & no.of cycles \\
\hline DAYOSF & 177.46 & 1.61 & 87.88 & 265.85 & day \\
\hline MEANTEM & 51.35 & 1.45 & 48.60 & 54.81 & ${ }^{0} \mathrm{~F}$ \\
\hline MAXTEM & 54.66 & 1.75 & 52.30 & 57.82 & ${ }^{0} \mathrm{~F}$ \\
\hline MINTEM & 48.13 & 1.31 & 46.29 & 51.98 & ${ }^{0} \mathrm{~F}$ \\
\hline DAY32 & 23.98 & 1.41 & 13.00 & 49.00 & day \\
\hline DAYO & 113.35 & 11.31 & 96.00 & 124.00 & day \\
\hline PRECIP & 41.01 & 5.46 & 7.29 & 70.93 & inch/year \\
\hline LPRE & 1.61 & 0.07 & 0.86 & 1.85 & \\
\hline WETDAY & 117.16 & 7.78 & 95.00 & 134.00 & day \\
\hline P200 & 0.72 & 0.14 & 0.14 & 1.00 & weight $\%$ \\
\hline P200LPR & 84.31 & 21.95 & 18.18 & 133.46 & weight $\%$ * inch/year \\
\hline MOIST & 0.17 & 0.06 & 0.08 & 0.33 & $\%$ \\
\hline PI & 12.94 & 7.35 & 0.00 & 38.50 & $\%$ \\
\hline SUBDEN & 108.55 & 0.00 & 95.60 & 136.90 & $\mathrm{lb} / \mathrm{inch}^{3}$ \\
\hline REMOD & $6,164.86$ & 106.07 & $2,700.00$ & $17,400.00$ & psi \\
\hline LREMOD & 3.77 & 0.01 & 3.43 & 4.24 & \\
\hline 567AADT & $9,016.85$ & $3,340.49$ & 214.21 & $76,397.33$ & vehicle/day \\
\hline AADT2 & $3,992.13$ & $1,605.10$ & 0.00 & $37,139.00$ & vehicle/day \\
\hline AADT3 & 167.88 & 0.00 & 0.00 & $26,397.33$ & vehicle/day \\
\hline AVEESAL & $193,206.95$ & $52,490.26$ & 482.09 & $2,961,015.91$ & 18kips \\
\hline LAVESAL & 4.77 & 0.39 & 2.68 & 6.47 & \\
\hline AGE & 10.04 & 4.95 & 2.67 & 25.00 & year \\
\hline AGE2 & 1.25 & 3.54 & 0.00 & 5.00 & year \\
\hline AGE3 & 1.92 & 0.00 & 0.00 & 15.00 & year \\
\hline DRAINCO & 1.06 & 0.07 & 1.00 & 1.10 & \\
\hline BASETH & 12.04 & 2.12 & 2.25 & 20.00 & inch \\
\hline BLPRE & 19.57 & 3.51 & 2.50 & 45.97 & inch * (inch/year) \\
\hline BASECOM & 0.95 & 0.00 & 0.95 & 0.95 & \\
\hline HМАCTH & 2.11 & 0.18 & 0.60 & 16.00 & inch \\
\hline THICK & 14.16 & 2.30 & 4.70 & 28.00 & inch \\
\hline ESAL/TH & $14,826.43$ & $4,844.41$ & 37.81 & $569,597.18$ & 18kips/inch \\
\hline LESALTH & 3.63 & 0.47 & 1.58 & 5.76 & \\
\hline AC32 & 53.96 & 1.77 & 8.13 & 784.00 & inch * day \\
\hline LACBASE & 1.13 & 0.07 & 0.67 & 1.45 & \\
\hline ASPHCON & 0.06 & 0.00 & 0.06 & 0.07 & weight $\%$ \\
\hline AGG4 & 0.35 & 0.00 & 0.35 & 0.35 & weight \% \\
\hline LAGG4 & -0.46 & 0.00 & -0.46 & -0.46 & \\
\hline AIRVOID & 0.06 & 0.00 & 0.06 & 0.06 & volume \% \\
\hline LAV & -1.22 & 0.00 & -1.22 & -1.22 & \\
\hline D32AV & 1.44 & 0.08 & 0.78 & 2.94 & day * volume $\%$ \\
\hline
\end{tabular}

Note: The detailed explanations of the variables listed above are given in Appendix 1. 
Appendix 4. Details of Model Validation for Cost and Performance Models Developed for Flexible Pavements Based on Routine Maintenance 


\section{Model Validation}

(1) Likelihood Ratio Test

Null hypothesis $\quad \mathrm{H}_{0}: \quad$ All the $\beta_{\mathrm{i}} \quad=0$

Alternative hypothesis $\quad \mathrm{H}_{1}$ : At least one $\beta \neq 0$

Let $\mathrm{L}_{\mathrm{U}}=$ the Likelihood function of the Tobit model without constraints

Let $\mathrm{L}_{\mathrm{R}}=$ the Likelihood function of the Tobit model with constraints

From the LIMDEP output, the following is obtained:

The null hypothesis is rejected. This means that there is a relationship between the dependent

$$
-2 \ln \left(\frac{\hat{L}_{R}}{\hat{L}_{U}}\right)=-2 * \ln \left(\frac{e^{(-929.786)}}{e^{(-764.9177)}}\right)=329.7366>>\chi^{2}(0.99,3)=11.34 \text { (criticalvalue) }
$$

variable (expected maintenance expenditures) and the dependent variables (pavement condition change, age, and road type).

(2) Goodness of Fit

$$
L R I_{\text {McFadden }}=1-\left(\frac{\ln \hat{L}_{U}}{\ln \hat{L}_{R}}\right)=1-\frac{(-764.9177)}{(-929.786)}=0.177
$$

(3) Conditional Moment Test for Normality Assumption of Error Terms
Null hypothesis
$\mathrm{H}_{0}$ : $\quad$ The error term is normal

Alternative hypothesis

$\mathrm{H}_{1}$ : The error term is not normal

From LIMDEP output, we have

$$
\begin{array}{lll}
\text { LMSTAT } & = & .43445396835470370 \mathrm{D}+01 \\
\mathrm{Q} & = & .20000000000000000 \mathrm{D}+01 \\
\text { Result } & = & .88608125423125720 \mathrm{D}+00 \\
\chi_{(\text {LMSTAT) }}^{2} & =4.3445<\chi_{(0.99,2)}^{2}=9.21 \text { (critical value) }
\end{array}
$$

The null hypothesis is not rejected.

(4) Heteroscedasticity Test

Null hypothesis $\quad \mathrm{H}_{0}: \quad$ The error term is homoscedastic

Alternative hypothesis $\mathrm{H}_{1}$ : The error term is heteroscedastic

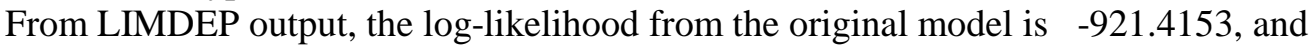
the log-likelihood from the expanded model is -916.7502

$$
\left.-2 \ln \left(\frac{\hat{L}_{\text {original }}}{\hat{L}_{\text {exp anded }}}\right)=-2 *[-921.4153-(-916.7502)]=9.3302<\chi^{2}(0.99,4)=13.28 \text { (critical value }\right)
$$

Fail to reject null hypothesis. The error term is homoscedastic. 
Appendix 5. Variables Considered for the Model Development of JCP Pavements with Routine Maintenance 
Equation 1: Tobit Model

Dependent Variable

Average annual routine maintenance expenditures during 1996-98 (in 98 \$)

\$/lane-mile/year

Independent Variables

Average \% change in IRI of PCC pavement during 1995-97

Region: Dummy variables

District: Dummy variables

Road Type: Dummy variables

Pavement Age: Average of 1995-97

Age2: Dummy variable (for age group of 9-15 years)

Age3: Dummy variable (for age group of 15 years up)

Equation 2: Simultaneous Regression Equation

Dependent Variable

Average \% change in IRI of PCC pavement during 1995-97

Independent Variables

Average annual routine maintenance expenditures during 1995-97 (in 98 \$)

\$/lane-mile/year

Region: Dummy variables

District: Dummy variables

Road Type: Dummy variables

Freeze index

degree-day

Freeze-thaw cycle

No. of days between last Spring and first Fall of minimum of $0^{\circ} \mathrm{C}$

Mean annual temperature

Maximum annual temperature

Minimum annual temperature

No. of days $>32^{\circ} \mathrm{C}$

No. of days $<0^{0} \mathrm{C}$

Average annual precipitation

Average no. of wet days

Subgrade \% passing \#200 sieve

Subgrade moisture content

Subgrade plastic index

Maximum dry density of subgrade material

no. of days

no. of days

Subgrade modulus of resilience

AADT

AADT2: Dummy variable

AADT3: Dummy variable

$\%$ Truck in traffic stream

year

ESALs

Pavement age

Age2: Dummy variable (for age group of 9-15 years)

${ }^{0} \mathrm{~F}$
${ }^{0} \mathrm{~F}$
${ }^{0} \mathrm{~F}$

no. of days

no. of days

inches/year

no. of days

weight $\%$

Age3: Dummy variable (for age group of 15 years up)

Drainage coefficient 
Subbase thickness

inches

Base thickness * precipitation

inches $^{2}$

Base compaction

Slab thickness

Slab thickness $*$ no. of days $>32^{\circ} \mathrm{C}$

inches

ESALs/ (sub/base thickness + slab thickness)

inches $*$ days

Concrete modulus of elasticity

18kips/inch

Concrete modulus of rupture

psi

Joint spacing of concrete pavement

psi

Diameter of dowels in concrete pavement

feet

inches 
Appendix 6. Descriptive Statistics of All Variables Initially Considered for JCP Pavement Modeling Based on Routine Maintenance 


\begin{tabular}{|c|c|c|c|c|c|}
\hline JCP pavements & Mean & Std. Deviation & Minimum & Maximum & Unit \\
\hline AVE9456 & 149.75 & 321.00 & 0.00 & $1,611.19$ & \$/lane-mile/year (98\$) \\
\hline AVE9567 & 125.76 & 121.97 & 0.00 & $1,457.27$ & $\$$ /lane-mile/year (98\$) \\
\hline AVE9678 & 116.36 & 128.44 & 0.00 & $1,469.18$ & $\$$ /lane-mile/year (98\$) \\
\hline 567IRI & 0.03 & 0.08 & -0.17 & 0.16 & \\
\hline 567IRI1 & 0.01 & 0.03 & -0.08 & 0.06 & \\
\hline FZI & 247.81 & 38.81 & 74.68 & 399.93 & degree-day \\
\hline FZTHAW & 85.98 & 5.79 & 65.33 & 114.33 & no. of cycles \\
\hline DAYOSF & 180.16 & 25.62 & 162.72 & 255.51 & day \\
\hline MEANTEM & 52.01 & 1.18 & 48.60 & 56.05 & ${ }^{0} \mathrm{~F}$ \\
\hline MAXTEM & 55.00 & 1.75 & 52.30 & 57.82 & ${ }^{0} \mathrm{~F}$ \\
\hline MINTEM & 48.81 & 3.11 & 46.58 & 52.38 & ${ }^{0} \mathrm{~F}$ \\
\hline DAY32 & 26.62 & 15.56 & 13.00 & 49.00 & day \\
\hline DAYO & 111.37 & 13.44 & 96.00 & 124.00 & day \\
\hline PRECIP & 41.35 & 11.10 & 23.13 & 84.13 & inch/year \\
\hline LPRE & 1.61 & 0.16 & 1.36 & 1.92 & \\
\hline WETDAYS & 115.91 & 7.07 & 95.00 & 134.00 & day \\
\hline P200 & 0.74 & 0.07 & 0.25 & 1.00 & weight $\%$ \\
\hline P200LPRE & 84.85 & 13.03 & 31.62 & 124.00 & \\
\hline MOIST & 0.17 & 0.05 & 0.11 & 0.24 & $\%$ \\
\hline PI & 12.31 & 1.34 & 2.00 & 32.00 & $\%$ \\
\hline SUBDEN & 108.88 & 9.62 & 94.10 & 127.43 & $\mathrm{lb} / \mathrm{inch}^{3}$ \\
\hline REMOD & $6,580.85$ & $1,909.19$ & $2,100.00$ & $12,300.00$ & psi \\
\hline LREMOD & 3.79 & 0.19 & 3.32 & 4.09 & \\
\hline 567AADT & $22,463.08$ & $16,155.61$ & 960.14 & $126,067.28$ & vehicle/day \\
\hline AADT2 & $8,532.98$ & $16,155.61$ & 0.00 & $37,239.26$ & vehicle/day \\
\hline AADT3 & $4,361.40$ & 0.00 & 0.00 & $76,067.28$ & vehicle/day \\
\hline AVEESALS & $396,660.31$ & $712,845.37$ & $9,876.44$ & $4,448,972.89$ & 18kips \\
\hline LAVESAL & 5.23 & 0.59 & 3.99 & 6.65 & \\
\hline AGE & 14.29 & 8.01 & 5.33 & 29.00 & year \\
\hline AGE2 & 2.12 & 0.00 & 0.00 & 6.00 & year \\
\hline AGE3 & 2.24 & 2.36 & 0.00 & 14.00 & year \\
\hline DRAINCO & 1.08 & 0.00 & 1.00 & 1.10 & \\
\hline BASETH & 11.52 & 5.66 & 1.00 & 20.00 & inch \\
\hline BASELPRE & 18.71 & 7.56 & 1.59 & 33.17 & \\
\hline BASECOM & 0.95 & 0.00 & 0.95 & 0.95 & $\%$ \\
\hline SLABTH & 10.07 & 3.54 & 0.60 & 16.00 & inch \\
\hline THICK & 21.59 & 2.12 & 5.50 & 36.00 & inch \\
\hline ESAL/TH & $20,710.51$ & $38,177.91$ & 456.72 & $222,448.64$ & 18kips/inch \\
\hline LESALTH & 3.93 & 0.57 & 2.66 & 5.35 & \\
\hline SLAB32 & 299.55 & 94.05 & 8.13 & 784.00 & inch * day \\
\hline LSLBASE & 1.30 & 0.06 & 0.74 & 1.56 & \\
\hline ELASMOD & $3,990,543.74$ & 0.00 & $2,666,666.67$ & $4,000,000.00$ & psi \\
\hline RUPMOD & 660.93 & 0.00 & 441.67 & 662.50 & psi \\
\hline JOINT & 19.95 & 0.00 & 13.33 & 20.00 & $\mathrm{ft}$ \\
\hline DOWEL & 1.20 & 0.18 & 0.00 & 1.50 & inch \\
\hline
\end{tabular}

Note: The detailed explanations of the variables listed above are given in Appendix 1. 
Appendix 7. Details of Model Validation for Cost and Performance Models Developed for JCP Pavements Based on Routine Maintenance 


\section{Model Validation}

\section{(1) Likelihood Ratio Test}

Null hypothesis $\quad \mathrm{H}_{0}: \quad$ All the $\beta_{\mathrm{i}} \quad=0$

Alternative hypothesis $\quad \mathrm{H}_{1}$ : At least one $\beta \neq 0$

Let $\mathrm{L}_{\mathrm{U}}=$ the Likelihood function of the Tobit model without constraints

Let $\mathrm{L}_{\mathrm{R}}=$ the Likelihood function of the Tobit model with constraints

From the LIMPED output, the following is obtained:

$$
-2 \ln \left(\frac{\hat{L}_{R}}{\hat{L}_{U}}\right)=-2 * \ln \left(\frac{e^{(-176.5892)}}{e^{(-166.2590)}}\right)=20.6604>\chi^{2}(0.99,2)=9.21(\text { critical value })
$$

The null hypothesis is rejected. There is relationship between the dependent variable (expected maintenance expenditures) and the dependent variables (pavement condition change and region).

(2) Goodness of Fit

$$
L R I_{\text {McFadden }}=1-\left(\frac{\ln \hat{L}_{U}}{\ln \hat{L}_{R}}\right)=1-\frac{(-166.2590)}{(-176.5892)}=0.06
$$

(3) Conditional Moment Test for Normality Assumption of Error Terms

From LIMDEP output, we have

$$
\begin{array}{ll}
\text { LMSTAT } & =.11627380972778710 \mathrm{D}+01 \\
Q & =.20000000000000000 \mathrm{D}+01 \\
\text { Result } & =.44086763662819650 \mathrm{D}+00 \\
\chi_{(\text {LMSTAT) }}^{2} & =1.163<\chi_{(0.99,2)}^{2}=9.21 \text { (critical value) }
\end{array}
$$

The hypothesis of normality is not rejected.

(4) Heteroscedasticity Test

Null hypothesis

Alternative hypothesis

From LIMPED output, the log-likelihood from the original model is -189.3097, and the log-likelihood from the expanded model is -184.7047

$-2 \ln \left(\frac{\hat{L}_{\text {original }}}{\hat{L}_{\text {expanded }}}\right)=-2 *[-189.3097-(-184.7047)]=9.2096<\chi^{2}(0.99,2)=9.21$ (critical value $)$

Fail to reject null hypothesis. The error term is homoscedastic. 
Appendix 8. Variables Considered for the Model Development of CRC Pavements with Routine Maintenance 


\section{Tobit Model}

Dependent Variable

Average annual routine maintenance expenditures during 1996-98 (in 98 \$) \$/lane-mile/year

Independent Variables

Average annual routine maintenance expenditures during 1995-97 (in 98 \$)

\$/lane-mile/year

Average \% change in IRI of CRC pavement during 1995-97

Region: Dummy variables

District: Dummy variables

Road Type: Dummy variables

Freeze index

degree-day

Freeze-thaw cycle

No. of days between last Spring and first Fall of minimum of $0^{\circ} \mathrm{C}$

Mean annual temperature

Maximum annual temperature

Minimum annual temperature

No. of days $>32^{\circ} \mathrm{C}$

No. of days $<0^{\circ} \mathrm{C}$

Average annual precipitation

Average no. of wet days

Subgrade \% passing \#200 sieve

Subgrade moisture content

Subgrade plastic index

Maximum dry density of subgrade material

no. of days

no. of days

${ }^{0} \mathrm{~F}$

${ }^{0} \mathrm{~F}$

${ }^{0} \mathrm{~F}$

no. of days

no. of days

inches/year

no. of days

weight $\%$

$\%$

$\%$

psi

psi

Subgrade modulus of resilience

AADT

AADT2: Dummy variable

vehicles/day

AADT3: Dummy variable

$\%$ Truck in traffic stream

$\%$

ESALs

18 kips

Pavement age

Age2: Dummy variable (for age group of 9-15 years)

year

Age3: Dummy variable (for age group of 15 years up)

Drainage coefficient

Subbase thickness

Base thickness $*$ precipitation

Base compaction

Slab thickness

Slab thickness $*$ no. of days $>32^{\circ} \mathrm{C}$

ESALs/ (sub/base thickness + slab thickness)

Concrete modulus of elasticity

Concrete modulus of rupture

Joint spacing of concrete pavement 
Appendix 9. Descriptive Statistics of All Variables Initially Considered for CRC Pavement Modeling Based on Routine Maintenance 


\begin{tabular}{|c|c|c|c|c|c|}
\hline CRC pavements & Mean & Std. Deviation & Minimum & Maximum & Unit \\
\hline AVE9456 & 108.08 & 215.52 & 0.00 & 813.75 & \$/lane-mile/year (98\$) \\
\hline AVE9567 & 155.37 & 371.48 & 0.00 & $1,457.27$ & \$/lane-mile/year (98\$) \\
\hline AVE9678 & 188.93 & 386.01 & 0.00 & $1,469.18$ & \$/lane-mile/year (98\$) \\
\hline 567IRI & 0.03 & 0.03 & 0.00 & 0.11 & \\
\hline 567IRI1 & 0.01 & 0.01 & 0.00 & 0.05 & \\
\hline FZI & 168.92 & 82.96 & 108.74 & 399.93 & degree-day \\
\hline FZTHAW & 74.66 & 12.63 & 65.33 & 99.00 & no. of cycles \\
\hline DAYOSF & 174.23 & 1.63 & 171.89 & 177.00 & day \\
\hline MEANTEM & 52.84 & 1.50 & 49.79 & 53.95 & ${ }^{0} \mathrm{~F}$ \\
\hline MAXTEM & 56.40 & 1.94 & 52.30 & 57.82 & ${ }^{0} \mathrm{~F}$ \\
\hline MINTEM & 49.85 & 1.50 & 46.58 & 50.97 & ${ }^{0} \mathrm{~F}$ \\
\hline DAY32 & 29.31 & 10.07 & 13.00 & 37.00 & day \\
\hline DAYO & 114.97 & 6.06 & 104.00 & 124.00 & day \\
\hline PRECIP & 44.72 & 4.24 & 38.16 & 47.95 & inch/year \\
\hline LPRE & 1.65 & 0.04 & 1.58 & 1.68 & \\
\hline WETDAYS & 116.69 & 5.73 & 113.00 & 134.00 & day \\
\hline P200 & 0.83 & 0.16 & 0.49 & 0.99 & weight $\%$ \\
\hline P200LPRE & 96.77 & 18.70 & 62.38 & 122.39 & \\
\hline MOIST & 0.19 & 0.01 & 0.17 & 0.21 & $\%$ \\
\hline PI & 15.95 & 9.88 & 4.50 & 37.70 & $\%$ \\
\hline SUBDEN & 104.64 & 2.45 & 99.90 & 109.10 & $\mathrm{lb} / \mathrm{inch}^{3}$ \\
\hline REMOD & $6,191.38$ & $1,858.81$ & $4,050.00$ & $11,400.00$ & psi \\
\hline LREMOD & 3.78 & 0.11 & 3.61 & 4.06 & \\
\hline 567AADT & $22,864.95$ & $18,324.54$ & $3,367.63$ & $83,800.91$ & vehicle/day \\
\hline AADT2 & $12,542.98$ & $7,724.41$ & 0.00 & $28,404.60$ & vehicle/day \\
\hline AADT3 & $2,331.10$ & $8,716.60$ & 0.00 & $33,800.91$ & vehicle/day \\
\hline AVEESALS & $298,125.47$ & $500,388.96$ & $27,052.64$ & $1,658,345.35$ & 18kips \\
\hline LAVESAL & 5.03 & 0.57 & 4.43 & 6.22 & \\
\hline AGE & 16.90 & 8.64 & 3.00 & 24.00 & year \\
\hline AGE2 & 0.21 & 0.62 & 0.00 & 2.00 & year \\
\hline AGE3 & 5.21 & 4.16 & 0.00 & 9.00 & year \\
\hline DRAINCO & 1.03 & 0.05 & 1.00 & 1.10 & \\
\hline BASETH & 13.62 & 2.40 & 8.00 & 16.00 & inch \\
\hline BASELPRE & 22.47 & 4.05 & 12.65 & 26.89 & \\
\hline BASECOM & 0.95 & 0.00 & 0.95 & 0.95 & $\%$ \\
\hline SLABTH & 7.36 & 2.86 & 1.00 & 11.00 & inch \\
\hline THICK & 20.98 & 3.63 & 12.00 & 24.00 & inch \\
\hline ESAL/TH & $15,327.25$ & $27,059.83$ & $1,978.93$ & $99,747.69$ & 18kips/inch \\
\hline LESALTH & 3.71 & 0.58 & 3.30 & 5.00 & \\
\hline SLAB32 & 224.26 & 117.18 & 15.00 & 407.00 & inch * day \\
\hline LSLBASE & 1.31 & 0.09 & 1.08 & 1.38 & \\
\hline ELASMOD & $4,000,000.00$ & 0.00 & $4,000,000.00$ & $4,000,000.00$ & psi \\
\hline RUPMOD & 662.50 & 0.00 & 662.50 & 662.50 & psi \\
\hline JOINT & 20.00 & 0.00 & 20.00 & 20.00 & $\mathrm{ft}$ \\
\hline DOWEL & 1.17 & 0.42 & 0.00 & 1.50 & ch \\
\hline
\end{tabular}

Note: The detailed explanations of the variables listed above are given in Appendix 1. 
Appendix 10. Details of Model Validation for Cost Model Developed for CRC Pavements Based on Routine Maintenance 


\section{Model Validation}

\section{(1) Likelihood Ratio Test}

Null hypothesis

$\mathrm{H}_{0}: \quad$ All the $\beta_{\mathrm{i}} \quad=0$

Alternative hypothesis

$\mathrm{H}_{1}$ : $\quad$ At least one $B \neq 0$

Let $\mathrm{L}_{\mathrm{U}}=$ the Likelihood function of the Tobit model without constraints

Let $\mathrm{L}_{\mathrm{R}}=$ the Likelihood function of the Tobit model with constraints

From the LIMPED output, the following is obtained:

$$
-2 \ln \left(\frac{\hat{L_{R}}}{\hat{L}_{U}}\right)=-2 * \ln \left(\frac{e^{((-29.9799)}}{e^{(-18.1458)}}\right)=23.6682>\chi^{2}(0.99,2)=9.21(\text { critical value })
$$

The null hypothesis is rejected. There is relationship between the dependent variable (expected maintenance expenditures) and the dependent variables (pavement condition change and region).

(2) Goodness of Fit

$$
L R I_{\text {McFadden }}=1-\left(\frac{\ln \hat{L}_{U}}{\ln \hat{L}_{R}}\right)=1-\frac{(-18.1458)}{(-29.9799)}=0.39
$$

(3) Conditional Moment Test for Normality Assumption of Error Terms

From LIMDEP output, we have

$$
\begin{aligned}
& \text { LMSTAT }=.19429845215490040 \mathrm{D}+01 \\
& \mathrm{Q}=.2000000000000000 \mathrm{D}+01 \\
& \text { Result }=.62148222367106650 \mathrm{D}+00 \\
& \chi_{\text {(LMSTAT) }}^{2}=1.943<\chi_{(0.99,2)}^{2}=9.21 \text { (critical value) }
\end{aligned}
$$

The hypothesis of normality is not rejected.

(4) Heteroscedasticity Test

Null hypothesis $\quad \mathrm{H}_{0}: \quad$ The error term is homoscedastic

Alternative hypothesis $\quad \mathrm{H}_{1}$ : The error term is heteroscedastic

From LIMPED output, the log-likelihood from the original model is -20.2308 , and the log-likelihood from the expanded model is -16.2438

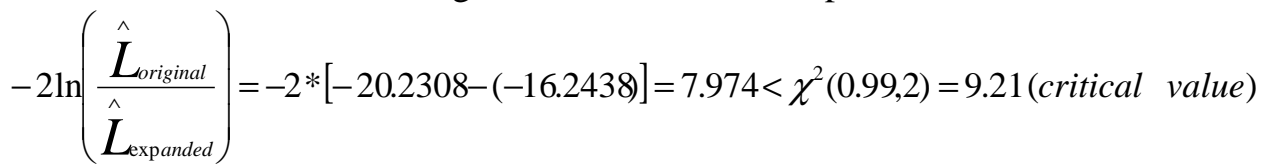

Fail to reject null hypothesis. The error term is homoscedastic. 
Appendix 11. Variables Considered for the Model Development of Composite Pavements With Routine Maintenance 
Tobit Model

Dependent Variable

Average annual routine maintenance expenditures during 1996-98 (in 98 \$)

Independent Variables

Average annual routine maintenance expenditures during 1995-97 (in 98 \$)

Average \% change in IRI of overlay pavement during 1995-97

Region: Dummy variables

District: Dummy variables

Road Type: Dummy variables

Freeze index

degree-day

Freeze-thaw cycle

No. of days between last Spring and first Fall of minimum of $0^{\circ} \mathrm{C}$

Mean annual temperature

Maximum annual temperature

Minimum annual temperature

No. of days $>32^{\circ} \mathrm{C}$

No. of days $<0^{\circ} \mathrm{C}$

Average annual precipitation

Average no. of wet days

Subgrade \% passing \#200 sieve

Subgrade moisture content

Subgrade plastic index

no. of days

no. of days

${ }^{0} \mathrm{~F}$

${ }^{0} \mathrm{~F}$

${ }^{0} \mathrm{~F}$

no. of days

no. of days

inches/year

no. of days

weight $\%$

$\%$

$\%$

psi

psi

Subgrade modulus of resilience

AADT

AADT2: Dummy variable

vehicles/day

AADT3: Dummy variable

$\%$ Truck in traffic stream

Lane distribution based on WIM data

Vehicle composition based on WIM data

Vehicle operating weight distribution based on WIM data

ESALs

Pavement age

Age2: Dummy variable (for age group of 6-10 years)

Age3: Dummy variable (for age group of 10 years up)

Drainage coefficient

Sub/base thickness

Base thickness * precipitation

Base compaction

Hot mix asphalt concrete (HMAC) thickness

HMAC thickness $*$ no. of days $>32^{\circ} \mathrm{C}$

ESALs/ (sub/base thickness + HMAC thickness)

Asphalt content in HMAC

Hot mix asphalt concrete \% aggregate $<\# 4$ sieve

Air voids in hot mix asphalt concrete

$$
\begin{array}{r}
\text { inches } \\
\text { inches }{ }^{2} \\
\% \\
\text { inches } \\
\text { inches } * \text { days } \\
\text { 18kips/inch } \\
\% \\
\text { weight \% } \\
\text { volume \% }
\end{array}
$$


Appendix 12. Descriptive Statistics of All Variables Initially Considered for Composite Pavement Modeling Based on Routine Maintenance 


\begin{tabular}{|c|c|c|c|c|c|}
\hline Composite pavements & Mean & Std. Deviation & Minimum & Maximum & Unit \\
\hline AVE9456 & 91.49 & 211.47 & 0.00 & $1,708.66$ & $\$$ /lane-mile/year (98\$) \\
\hline AVE9567 & 87.05 & 187.66 & 0.00 & $1,457.27$ & \$/lane-mile/year (98\$) \\
\hline AVE9678 & 99.29 & 247.94 & 0.00 & $1,736.90$ & \$/lane-mile/year (98\$) \\
\hline 567IRI & 0.02 & 0.06 & -0.34 & 0.30 & \\
\hline 567IRI1 & 0.01 & 0.03 & -0.18 & 0.11 & \\
\hline FZI & 296.22 & 108.26 & 74.68 & 851.54 & degree-day \\
\hline FZTHAW & 89.92 & 8.67 & 49.32 & 116.06 & no. of cycles \\
\hline DAYOSF & 175.22 & 7.75 & 111.26 & 240.43 & day \\
\hline MEANTEM & 50.85 & 1.50 & 46.99 & 55.38 & ${ }^{0} \mathrm{~F}$ \\
\hline MAXTEM & 54.00 & 1.54 & 49.54 & 57.82 & ${ }^{0} \mathrm{~F}$ \\
\hline MINTEM & 47.79 & 1.37 & 44.01 & 54.66 & ${ }^{0} \mathrm{~F}$ \\
\hline DAY32 & 19.23 & 8.05 & 13.00 & 49.00 & day \\
\hline DAYO & 113.97 & 7.97 & 96.00 & 124.00 & day \\
\hline PRECIP & 41.95 & 7.97 & 17.97 & 89.33 & inch/year \\
\hline LPRE & 1.62 & 0.07 & 1.25 & 1.95 & \\
\hline WETDAYS & 122.07 & 8.85 & 95.00 & 134.00 & day \\
\hline P200 & 0.70 & 0.20 & 0.10 & 1.00 & weight $\%$ \\
\hline P200LPRE & 85.59 & 24.93 & 12.06 & 133.73 & weight $\% *$ inch/year \\
\hline MOIST & 0.37 & 2.87 & 0.08 & 47.10 & $\%$ \\
\hline $\mathrm{PI}$ & 14.44 & 10.97 & 1.90 & 125.10 & $\%$ \\
\hline SUBDEN & 109.48 & 12.57 & 1.60 & 139.70 & $\mathrm{lb} / \mathrm{inch}^{3}$ \\
\hline REMOD & $6,374.58$ & $2,094.02$ & 0.00 & $22,050.00$ & psi \\
\hline LREMOD & 3.80 & 3.32 & 0.00 & 4.34 & \\
\hline 567AADT & $13,873.01$ & $17,997.50$ & 886.83 & $179,319.88$ & vehicle/day \\
\hline AADT2 & $6,569.00$ & $8,972.63$ & 0.00 & $41,307.28$ & vehicle/day \\
\hline AADT3 & $1,362.80$ & $9,331.92$ & 0.00 & $129,319.88$ & vehicle/day \\
\hline AVEESALs & $278,692.08$ & $589,834.54$ & $1,807.61$ & $6,445,080.17$ & 18kips \\
\hline LAVESAL & 4.98 & 0.65 & 3.26 & 6.81 & \\
\hline AGE & 8.59 & 3.62 & 1.67 & 25.00 & year \\
\hline AGE2 & 1.80 & 1.83 & 0.00 & 5.33 & year \\
\hline AGE3 & 0.83 & 2.12 & 0.00 & 15.00 & year \\
\hline DRAINCO & 1.25 & 2.90 & 1.00 & 51.36 & \\
\hline BASETH & 12.21 & 3.49 & 2.50 & 21.00 & inch \\
\hline BASELPRE & 19.73 & 5.71 & 3.91 & 33.66 & inch * (inch/year) \\
\hline BASECOM & 0.95 & 0.00 & 0.95 & 1.00 & \\
\hline HMACTH & 2.49 & 2.14 & 0.27 & 16.00 & inch \\
\hline THICK & 14.69 & 3.48 & 5.00 & 28.00 & inch \\
\hline ESAL/TH & $24,005.09$ & $64,678.70$ & 112.98 & $745,302.83$ & 18kips/inch \\
\hline LESALTH & 3.83 & 0.68 & 2.05 & 5.87 & \\
\hline AC32 & 47.75 & 63.66 & 4.05 & 784.00 & inch * day \\
\hline LACBASE & 1.15 & 0.12 & 0.70 & 1.45 & \\
\hline ASPHCON & 0.06 & 0.02 & 0.06 & 0.36 & weight $\%$ \\
\hline AGG4 & 0.35 & 0.11 & 0.35 & 2.23 & weight $\%$ \\
\hline LAGG4 & -0.46 & 0.05 & -0.46 & 0.35 & \\
\hline AIRVOID & 0.06 & 0.00 & 0.06 & 0.06 & volume $\%$ \\
\hline LAV & -1.22 & 0.00 & -1.22 & -1.22 & \\
\hline D32AV & 1.15 & 0.48 & 0.78 & 2.94 & day * volume \% \\
\hline
\end{tabular}


Appendix 13. Details of Model Validation for Cost and Performance Models Developed for Composite Pavements Based on Routine Maintenance 
Model Validation

(1) Likelihood Ratio Test

Null hypothesis $\quad \mathrm{H}_{0}: \quad$ All the $\beta_{\mathrm{i}} \quad=0$

Alternative hypothesis $\quad \mathrm{H}_{1}$ : At least one $\beta \neq 0$

Let $\mathrm{L}_{\mathrm{U}}=$ the Likelihood function of the Tobit model without constraints

Let $\mathrm{L}_{\mathrm{R}}=$ the Likelihood function of the Tobit model with constraints

From the LIMPED output, the following is obtained:

$$
\left.-2 \ln \left(\frac{\hat{L}_{R}}{\hat{L}_{U}}\right)=-2 * \ln \left(\frac{e^{(-12,1421274)}}{e^{(-13,5934208)}}\right)=1,451.2934>\chi^{2}(0.99,2)=9.21 \text { (critical value }\right)
$$

The null hypothesis is rejected. There is relationship between the dependent variable (expected maintenance expenditures) and the dependent variables (pavement condition change and region).

(2) Goodness of Fit

$$
L R I_{\text {McFadden }}=1-\left(\frac{\ln \hat{L}_{U}}{\ln \hat{L}_{R}}\right)=1-\frac{(-12,142.1274)}{(-13,593.4208)}=0.12
$$

(3) Conditional Moment Test for Normality Assumption of Error Terms

From LIMDEP output, we have

LMSTAT $=.63221116743408670 \mathrm{D}+01$

$\mathrm{Q} \quad=.20000000000000000 \mathrm{D}+01$

Result $\quad=.95761902992717200 \mathrm{D}+00$

$$
\chi_{(\text {LMSTAT })}^{2}=6.322<\chi_{(0.99,2)}^{2}=9.21 \text { (critical value) }
$$

The hypothesis of normality is not rejected.

(4) Heteroscedasticity Test

Null hypothesis

Alternative hypothesis

From LIMPED output, the

$-2 \ln \left(\frac{\hat{L}_{\text {original }}}{\hat{L}_{\text {expanded }}}\right)=-2 *\left[-9,960.216-(-9,959.63 \supsetneqq]=0.583<\chi^{2}(0.99,2)=9.21\right.$ (critical value $)$

$\mathrm{H}_{0}$ : The error term is homoscedastic

$\mathrm{H}_{1}$ : The error term is heteroscedastic

the log-likelihood from the original model is $-9,960.216$, and

the log-likelihood from the expanded model is $-9,959.633$

Fail to reject null hypothesis. The error term is homoscedastic. 
Appendix 14. Definition of General Modeling Parameters for Rehabilitation 


\begin{tabular}{|c|c|c|}
\hline PARAMETER & DEFINITION & UNIT \\
\hline 94RCON & Expenditures of rehabilitation for pavement segment with contract awarded in 1994 & \$/lane-mile $(97 \$)$ \\
\hline 95RCON & Expenditures of rehabilitation for pavement segment with contract awarded in 1995 & \$/lane-mile (97\$) \\
\hline 96RCON & Expenditures of rehabilitation for pavement segment with contract awarded in 1996 & \$/lane-mile $(97 \$)$ \\
\hline 97RCON & Expenditures of rehabilitation for pavement segment with contract awarded in 1997 & \$/lane-mile (97\$) \\
\hline 98RCON & Expenditures of rehabilitation for pavement segment with contract awarded in 1998 & \$/lane-mile $(97 \$)$ \\
\hline $94 \mathrm{CON}$ & Expenditures of rehab. and periodic main. for pavement segment with contract awarded in 1994 & \$lane-mile (97\$) \\
\hline $95 \mathrm{CON}$ & Expenditures of rehab. and periodic main. for pavement segment with contract awarded in 1995 & \$/lane-mile (97\$) \\
\hline $96 \mathrm{CON}$ & Expenditures of rehab. and periodic main. for pavement segment with contract awarded in 1996 & \$lane-mile $(97 \$)$ \\
\hline 97CON & Expenditures of rehab. and periodic main. for pavement segment with contract awarded in 1997 & \$/lane-mile (97\$) \\
\hline $98 \mathrm{CON}$ & Expenditures of rehab. and periodic main. for pavement segment with contract awarded in 1998 & \$/lane-mile (97\$) \\
\hline 94IRI & IRI measurement in 1994 & inch/mile \\
\hline 95IRI & IRI measurement in 1995 & inch/mile \\
\hline 96IRI & IRI measurement in 1996 & inch/mile \\
\hline 97IRI & IRI measurement in 1997 & inch/mile \\
\hline 96IRICH & $\%$ change between initial and terminal IRI for segment rehabilitated in 1996 & \\
\hline 96LIRI1 & $\log _{10}(\%$ change between initial and terminal IRI for segment rehabilitated in $1996+100 \%)$ & \\
\hline 97IRICH & \% change between initial and terminal IRI for segment rehabilitated in 1997 & \\
\hline 97LIRI1 & $\log _{10}(\%$ change between initial and terminal IRI for segment rehabilitated in $1997+100 \%)$ & \\
\hline IRI0 & Initial IRI & inch/mile \\
\hline ALPHA & Predicted annual IRI increment rate & inch/mile \\
\hline RIRI & $\mathrm{R}^{2}$ of the regression model for the extrapolation of initial IRI & \\
\hline IRIT & Terminal IRI & inch/mile \\
\hline PSIO & Initial pavement serviceability index & \\
\hline PSIT & Terminal pavement serviceability index & \\
\hline FZI & Average freeze index during one life cycle & degree-day \\
\hline FZTHAW & Average freeze thaw cycle during one life cycle & no. \\
\hline DAYOSF & Average no. of days of first minimum of $0^{\circ} \mathrm{C}$ between Spring and Fall during one life cycle & day \\
\hline MEANTEM & Average annual temperature during one life cycle & ${ }^{0} \mathrm{~F}$ \\
\hline MAXTEM & Average maximum annual temperature during one life cycle & ${ }^{0} \mathrm{~F}$ \\
\hline MINTEM & Average minimum annual temperature during one life cycle & ${ }^{0} \mathrm{~F}$ \\
\hline DAY32 & Average no. of days $>32^{0} \mathrm{C}$ during one life cycle & day \\
\hline DAY0 & Average no. of days $<0^{0} \mathrm{C}$ during one life cycle & day \\
\hline PRECIP & Average annual precipitation during one life cycle & inch/year \\
\hline LPRE & $\log _{10}($ average annual precipitation during one life cycle $)$ & \\
\hline WETDAY & Average annual no. of wet days during one life cycle & day \\
\hline P200 & Subgrade percent passing \#200 sieve & weight $\%$ \\
\hline P200LPRE & Subgrade percent passing \#200 sieve $* \log _{10}$ (annual precipitation) & \\
\hline MOIST & Subgrade moisture content & $\%$ \\
\hline LL & Subgrade liquid limit & $\%$ \\
\hline PL & Subgrade plastic limit & $\%$ \\
\hline PI & Subgrade plasticity index & $\%$ \\
\hline SUBDEN & Maximum dry density of subgrade materials & lb/inch ${ }^{3}$ \\
\hline CBR93 & California bearing capacity at $93 \%$ & \\
\hline REMOD & Subgrade resilient modulus & psi \\
\hline LREMOD & $\log _{10}$ (subgrade resilient modulus) & \\
\hline 96AADT & AADT in 1996 & vehicle/day \\
\hline 96LANE & Lane traffic in 1996 & vehicle/day \\
\hline 96TRUCK & Truck percentage in traffic stream in 1996 & $\%$ \\
\hline 97AADT & AADT in 1997 & vehicle/day \\
\hline AADT2 & $($ AADT $-5,000) *$ alpha $_{1} \quad\left[\right.$ alpha $_{1}=1$, if AADT $\left.>5,000\right]$ & vehicle/day \\
\hline AADT3 & $($ AADT $-50,000) *$ alpha $_{2}\left[\mathrm{alpha}_{2}=1\right.$, if AADT $\left.>50,000\right]$ & vehicle/day \\
\hline 97LANE & Lane traffic in 1997 & vehicle/day \\
\hline 97TRUCK & Truck percentage in traffic stream in 1997 & $\%$ \\
\hline INESALs & Equivalent single axle loads computed by INDOT method & 18kips \\
\hline WHESALs & Equivalent single axle loads computed by Whitford method & 18kips \\
\hline 96ESALs & Equivalent single axle loads in 1996 computed by Weighted-LEF method & 18kips \\
\hline AVEESALs & Average equivalent single axle loads during $1995-97$ computed by Weighted-LEF method & 18kips \\
\hline CESALs & Cumulative ESALs during one life cycle computed by Weighted-LEF method & 18kips \\
\hline LCESALS & $\log _{10}$ (cumulative ESALs during one life cycle computed by Weighted-LEF method) & 18kips \\
\hline LESALAB & $\log _{10[}$ cumulative ESALs during one life cycle/(sub/base+HMAC or slab thickness)] & \\
\hline PSIESAL & PSI-cumulative ESALs loss during one life cycle & \\
\hline 96AGE & Pavement age in 1996 & year \\
\hline 97AGE & Pavement age in 1997 & year \\
\hline
\end{tabular}




\begin{tabular}{|c|c|}
\hline AGE2 & beta $_{1}=1$, if age $>5$ for flexible or $>8$ for rigid) \\
\hline AGE3 & (Pavement age-10 or 15$) *$ beta $_{2}\left[\right.$ beta $_{2}=1$, if age $>10$ for flexible or $>15$ for rigid) \\
\hline DRAINCO & Drainage coefficient \\
\hline BASETH & Sub/base thickness \\
\hline BASELPRE & Sub/base thickness $* \log _{10}$ (average annual precipitation during on life cycle) \\
\hline BASECOM & Sub/base compaction \\
\hline НMАСТН & Hot mix asphalt concrete (HMAC) thickness \\
\hline SLABTH & Concrete slab thickness \\
\hline THICK & Sub/base thickness + HMAC or slab thickness \\
\hline CESAL/TH & Cumulative ESALs during one life cycle / (sub/base + HMAC or slab thickness) \\
\hline LESALTH & $\log _{10}[$ cumulative ESALs during one life cycle / (sub/base + HMAC or slab thickness)] \\
\hline $\mathrm{AC} 32$ & HMAC thickness $*$ no. of days $>32^{\circ} \mathrm{C}$ \\
\hline SLAB32 & Slab thickness $*$ no. of days $>32^{\circ} \mathrm{C}$ \\
\hline LACBASE & $\log _{10}$ (sub/base thickness + HMAC thickness) \\
\hline LSLBASE & $\log _{10}($ sub/base thickness + slab thickness $)$ \\
\hline ASPHCON & Asphalt content \\
\hline AGG4 & Percent of aggregate in HMAC passing \#4 sieve \\
\hline LP4 & $\log _{10}$ (percent of aggregate in HMAC passing \#4 sieve) \\
\hline AIRVOID & Air voids in HMAC \\
\hline LAV & $\log _{10}$ (air voids in HMAC) \\
\hline D32AV & No. of days $>32^{\circ} \mathrm{C} *$ Air voids in HMAC \\
\hline ELASMOD & Modulus of elasticity of concrete pavement \\
\hline RUPMOD & Modulus of rupture of concrete pavement \\
\hline JOINT & Joint spacing between concrete slabs \\
\hline DOWEL & Diameter of dowel \\
\hline
\end{tabular}

year
year
inch
inch * (inch/year)
$\%$
inch
inch
18kips/inch
inch * day
inch * day

weight $\%$
weight $\%$
volume $\%$
day * volume $\%$
psi
psi
foot
inch


Appendix 15. Variables Considered for the Model Development of Flexible Pavements with Rehabilitation work 
Regression Model

Dependent Variable

Rehabilitation Expenditures required for the flexible pavements after

\$/lane-mile one service life (in 97 )

Independent Variables

Region: Dummy variables

District: Dummy variables

Road Type: Dummy variables

$\%$ change in IRI of the flexible pavements during one life cycle

Average freeze index during one life cycle

degree-day

Average freeze-thaw cycle during one life cycle

Average no. of days between last Spring and first Fall of minimum of $0^{\circ} \mathrm{C}$

no. of days

during one life cycle

Average mean annual temperature during one life cycle

Average maximum annual temperature during one life cycle

Average minimum annual temperature during one life cycle

Average no. of days $>32^{\circ} \mathrm{C}$ during one life cycle

Average no. of days $<0^{\circ} \mathrm{C}$ during one life cycle

Average annual precipitation during one life cycle

Average no. of wet days during one life cycle

Subgrade \% passing \#200 sieve

Subgrade moisture content

Subgrade plastic index

Maximum dry density of subgrade material

no. of days

Subgrade modulus of resilience

AADT

AADT2: Dummy variable

AADT3: Dummy variable

$\%$ Truck in traffic stream

Lane distribution based on WIM data

Vehicle composition based on WIM data

Vehicle operating weight distribution based on WIM data

ESALs

Pavement age

Age2: Dummy variable (for age group of 6-10 years)

Age 3: Dummy variable (for age group of 10 years up)

Drainage coefficient

Sub/base thickness

Base thickness * precipitation

Base compaction

Hot mix asphalt concrete (HMAC) thickness

HMAC thickness $*$ no. of days $>32^{\circ} \mathrm{C}$

ESALs/ (sub/base thickness + HMAC thickness)

Asphalt content in HMAC

Hot mix asphalt concrete \% aggregate < \#4 sieve

Air voids in hot mix asphalt concrete

No. of days $>32^{\circ} \mathrm{C} *$ air voids

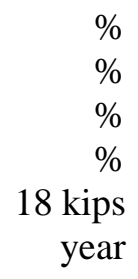

$\%$

$\%$

$\%$

18 kips

year

no. of days

no. of days

inches/year

no. of days

weight $\%$

$\%$

$\%$

psi

psi

vehicles/day

$\mathrm{F}$

酯

r
$\%$
i
i


Appendix 16. Descriptive Statistics of All Variables Initially Considered for Flexible Pavement Modeling Based on Rehabilitation and Periodic Maintenance 


\begin{tabular}{|c|c|c|c|c|c|}
\hline Flexible pavements & Mean & Std deviation & Minimum & Maximum & Unit \\
\hline 96RCON & $151,807.21$ & $291,605.22$ & 0.00 & $1,347,963.64$ & \$/lane-mile (97\$) \\
\hline 97RCON & $35,083.61$ & $75,286.04$ & 0.00 & $378,189.50$ & \$/lane-mile $(97 \$)$ \\
\hline $96 \mathrm{CON}$ & $151,807.21$ & $291,605.22$ & 0.00 & $1,347,963.64$ & $\$$ /lane-mile (97\$) \\
\hline $97 \mathrm{CON}$ & $35,122.90$ & $75,280.60$ & 0.00 & $378,189.50$ & \$/lane-mile $(97 \$)$ \\
\hline IRICH & 1.40 & 3.72 & 0.01 & 45.50 & \\
\hline LIRI1 & 0.27 & 0.25 & 0.00 & 1.67 & \\
\hline $\mathrm{IRI}_{0}$ & 78.38 & 32.40 & 3.00 & 233.63 & \\
\hline $\mid \mathrm{RI} \mathrm{T}_{\mathrm{T}}$ & 140.14 & 48.65 & 56.18 & 242.82 & \\
\hline $\mathrm{FZI}$ & 197.12 & 127.37 & 54.28 & 494.30 & degree-day \\
\hline FZTHAW & 95.22 & 11.59 & 74.00 & 127.00 & no. of cycles \\
\hline DAYOSF & 178.15 & 7.42 & 165.00 & 192.75 & day \\
\hline MEANTEM & 52.48 & 2.44 & 48.30 & 55.49 & ${ }^{0} \mathrm{~F}$ \\
\hline MAXTEM & 55.25 & 2.81 & 49.20 & 58.77 & ${ }^{0} \mathrm{~F}$ \\
\hline MINTEM & 49.14 & 1.44 & 46.70 & 51.74 & ${ }^{0} \mathrm{~F}$ \\
\hline DAY32 & 28.93 & 11.55 & 13.00 & 49.00 & day \\
\hline DAYO & 108.16 & 9.02 & 96.00 & 124.00 & day \\
\hline PRECIP & 41.92 & 3.34 & 35.05 & 46.25 & inch/year \\
\hline LPRE & 1.62 & 0.04 & 1.54 & 1.67 & \\
\hline WETDAY & 115.80 & 11.55 & 95.00 & 134.00 & day \\
\hline P200 & 0.73 & 0.21 & 0.16 & 1.00 & weight $\%$ \\
\hline P200LPRE & 1.18 & 0.35 & 0.26 & 1.65 & \\
\hline MOIST & 0.17 & 0.03 & 0.08 & 0.22 & $\%$ \\
\hline PI & 12.92 & 7.64 & 3.00 & 32.00 & $\%$ \\
\hline REMOD & $6,585.89$ & $2,081.35$ & $2,850.00$ & $12,000.00$ & psi \\
\hline LREMOD & 3.80 & 0.14 & 3.45 & 4.08 & \\
\hline AADT & $7,513.99$ & $9,187.26$ & 507.32 & $49,181.73$ & vehicle/day \\
\hline AADT2 & $4,110.49$ & $8,230.40$ & 0.00 & $44,181.73$ & vehicle/day \\
\hline AADT3 & 0.00 & 0.00 & 0.00 & 0.00 & vehicle/day \\
\hline CESALS & $2,197,968.69$ & $5,937,541.35$ & $14,871.49$ & $44,119,137.13$ & 18kips \\
\hline LCESALS & 5.46 & 0.85 & 4.17 & 7.64 & \\
\hline AGE & 12.34 & 5.43 & 3.00 & 27.00 & age \\
\hline AGE2 & 0.83 & 1.63 & 0.00 & 5.00 & age \\
\hline AGE3 & 3.26 & 4.44 & 0.00 & 17.00 & age \\
\hline DRAINCO & 1.04 & 0.05 & 1.00 & 1.10 & \\
\hline BASETH & 11.29 & 3.35 & 2.30 & 17.00 & inch/year \\
\hline BASELPRE & 18.27 & 5.32 & 3.55 & 27.47 & \\
\hline BASECOM & 0.95 & 0.00 & 0.95 & 0.95 & $\%$ \\
\hline HMACTH & 2.46 & 2.40 & 0.60 & 16.00 & inch/year \\
\hline THICK & 13.76 & 3.72 & 4.70 & 22.00 & inch/year \\
\hline CESAL/TH & $202,955.62$ & $755,071.63$ & 929.47 & $6,388,975.52$ & 18kips/inch \\
\hline LESALTH & 4.34 & 0.87 & 2.97 & 6.81 & \\
\hline AC32 & 82.94 & 116.72 & 10.00 & 784.00 & inch * day \\
\hline ASPHCON & 0.06 & 0.00 & 0.06 & 0.07 & weight $\%$ \\
\hline AGG4 & 0.35 & 0.00 & 0.35 & 0.35 & weight $\%$ \\
\hline LP4 & -0.46 & 0.00 & -0.46 & -0.46 & \\
\hline AIRVOID & 0.06 & 0.00 & 0.06 & 0.06 & volume $\%$ \\
\hline LAV & -1.22 & 0.00 & -1.22 & -1.22 & \\
\hline D32AV & 1.74 & 0.69 & 0.78 & 2.94 & day * volume $\%$ \\
\hline
\end{tabular}

Note: The detailed explanations of the variables listed above are given in Appendix 14. 
Appendix 17. Details of Model Validation for Cost Models Developed for Flexible Pavements Based on Rehabilitation /and Periodic Maintenance 
I. Details of cost model developed for flexible pavements based on rehabilitation

Model Validation

(1) ANOVA Hypothesis Test

$\mathrm{H}_{0}$ : EXPEND and Cumulative ESALs, THICKNESS, P200, MOIST, FZI, DRAINCO and AGE are linearly independent

$\mathrm{H}_{1}$ : EXPEND and Cumulative ESALs, THICKNESS, P200, MOIST, FZI, DRAINCO and AGE are linearly dependent

From the SAS/INSIGHT ANOVA table, we get a P-value $=0.0001<0.01$. Therefore, there is enough evidence from the data, to conclude that EXPEND and Cumulative ESALs, THICKNESS, P200, MOIST, FZI, DRAINCO and AGE are linearly related.

(2) Goodness of Fit

Based on SAS output, the adjust $\mathrm{R}^{2}=0.9666$, which indicates a good fit of the model.

(3) Correlation Test for Normality of the Error Term

$\mathrm{H}_{0}$ : If correlation coefficient $\mathrm{r}>$ critical value at level of significance 0.01 , the distribution of error term is normal

$\mathrm{H}_{1}$ : If correlation coefficient $\mathrm{r}<$ critical value at level of significance 0.01 , the distribution of error term is not normal

From the SAS/INSIGHT ANOVA table, we get correlation coefficient $r=\sqrt{ }(\operatorname{SSR} / S S T)=\sqrt{ }(3.797 / 3.924)=0.984>0.982 \quad($ critical value $)$. Therefore, the assumption of normally distributed error term is satisfied.

(4) Modified Levene Test for Constant Variance of the Error Term

$\mathrm{H}_{0}$ : The error term variances are constant

$\mathrm{H}_{1}$ : The error term variances are nonconstant

The Levene SAS program from the EXPEND data gives a P-value of 0.13175.

Since the P-value $=0.13175>0.01$, there is not enough evidence to reject the null hypothesis of constant variances. Therefore, the assumption of constant variance of the error term is not violated. 
II. Details of cost model developed for flexible pavements based on rehabilitation and periodic maintenance

Model Validation

(1) ANOVA Hypothesis Test

$\mathrm{H}_{0}$ : EXPEND and Cumulative ESALs, THICKNESS, P200, MOIST, FZI, DRAINCO and AGE are linearly independent

$\mathrm{H}_{1}$ : EXPEND and Cumulative ESALs, THICKNESS, P200, MOIST, FZI, DRAINCO and AGE are linearly dependent

From the SAS/INSIGHT ANOVA table, we get a P-value $=0.0001<0.01$. Therefore, there is enough evidence from the data, to conclude that EXPEND and Cumulative ESALs, THICKNESS, P200, MOIST, FZI, DRAINCO and AGE are linearly related.

(2) Goodness of Fit

Based on SAS output, the adjust $\mathrm{R}^{2}=0.9668$, which indicates a good fit of the model.

(3) Correlation Test for Normality of the Error Term

$\mathrm{H}_{0}$ : If correlation coefficient $\mathrm{r}>$ critical value at level of significance 0.01 , the distribution of error term is normal

$\mathrm{H}_{1}$ : If correlation coefficient $\mathrm{r}<$ critical value at level of significance 0.01 , the distribution of error term is not normal

From the SAS/INSIGHT ANOVA table, we get correlation coefficient $\mathrm{r}=\sqrt{ }(\mathrm{SSR} / \mathrm{SST})=\sqrt{ }(3.797 / 3.923)=0.984>0.982 \quad$ (critical value). Therefore, the assumption of normally distributed error term is satisfied.

(4) Modified Levene Test for Constant Variance of the Error Term

$\mathrm{H}_{0}$ : The error term variances are constant

$\mathrm{H}_{1}$ : The error term variances are nonconstant

The Levene SAS program from the EXPEND data gives a P-value of 0.12563.

Since the P-value $=0.12563>0.01$, there is not enough evidence to reject the null hypothesis of constant variances. Therefore, the assumption of constant variance of the error term is not violated.

Note:

EXPEND $=$ Rehabilitation /and Periodic Maintenance Expenditures 
Appendix 18. Variables Considered for the Model Development of JCP pavements with Rehabilitation Work 
Regression Model

Dependent Variable

Rehabilitation expenditures required for PCC pavements after one service life

\$lane-mile (in 97 \$)

Independent Variables

Region: Dummy variables

District: Dummy variables

Road Type: Dummy variables

$\%$ change in IRI of the PCC pavements during one life cycle

Average freeze index during one life cycle

Average freeze-thaw cycle during one life cycle

Average no. of days between last Spring and first Fall of minimum of $0^{\circ} \mathrm{C}$

during one life cycle

Average mean annual temperature during one life cycle

Average maximum annual temperature during one life cycle

Average minimum annual temperature during one life cycle

Average no. of days $>32^{\circ} \mathrm{C}$ during one life cycle

Average no. of days $<0^{\circ} \mathrm{C}$ during one life cycle

Average annual precipitation during one life cycle

Average no. of wet days during one life cycle

Subgrade \% passing \#200 sieve

Subgrade moisture content

Subgrade plastic index

Maximum dry density of subgrade material

Subgrade modulus of resilience

AADT

AADT2: Dummy variable

AADT3: Dummy variable

$\%$ Truck in traffic stream

degree-day

no. of days

no. of days

ESALs

Pavement age

Age2: Dummy variable

Age3: Dummy variables

Drainage coefficient

Subbase thickness

Base thickness * precipitation

Base compaction

Slab thickness

Slab thickness $*$ no. of days $>32^{\circ} \mathrm{C}$

ESALs/ (sub/base thickness + slab thickness)

Concrete modulus of elasticity

Concrete modulus of rupture

Joint spacing of concrete pavement

Diameter of dowels in concrete pavement

no. of days

no. of days inches/year no. of days weight $\%$

18 kips

year

inches

inches $^{2}$

$\%$

inches

inches $*$ days

18kips/inch

psi

psi

feet

inches 
Appendix 19. Descriptive Statistics of All Variables Initially Considered for JCP Pavement Modeling Based on Rehabilitation and Periodic Maintenance 


\begin{tabular}{|c|c|c|c|c|c|}
\hline JCP pavements & Mean & Std. Deviation & Minimum & Maximum & Unit \\
\hline 96RCON & $391,881.21$ & $613,734.42$ & 0.00 & $2,471,043.33$ & $\$$ /lane-mile $(97 \$)$ \\
\hline 97RCON & $69,755.82$ & $231,082.08$ & 0.00 & $1,234,118.07$ & \$/lane-mile (97\$) \\
\hline 96CON & $397,977.69$ & $610,056.29$ & 0.00 & $2,471,043.33$ & $\$$ /lane-mile $(97 \$)$ \\
\hline $97 \mathrm{CON}$ & $69,892.87$ & $231,053.82$ & 0.00 & $1,234,118.07$ & $\$$ /lane-mile $(97 \$)$ \\
\hline IRICH & 0.62 & 1.36 & 0.00 & 7.46 & \\
\hline LIRI1 & 0.14 & 0.20 & 0.00 & 0.93 & \\
\hline $\mathrm{IRI} \mathrm{I}_{0}$ & 98.60 & 48.23 & 7.88 & 208.50 & \\
\hline $\mid \mathrm{R} \mathrm{I}_{\mathrm{T}}$ & 128.55 & 54.33 & 55.44 & 229.63 & \\
\hline $\mathrm{FZI}$ & 151.12 & 72.50 & 54.28 & 325.50 & degree-day \\
\hline FZTHAW & 88.78 & 11.72 & 74.00 & 127.00 & no. of cycles \\
\hline DAYOSF & 179.40 & 6.82 & 167.00 & 192.75 & day \\
\hline MEANTEM & 53.37 & 1.56 & 50.20 & 55.49 & ${ }^{0} \mathrm{~F}$ \\
\hline MAXTEM & 55.85 & 1.88 & 52.10 & 58.77 & ${ }^{0} \mathrm{~F}$ \\
\hline MINTEM & 49.71 & 1.21 & 46.91 & 51.74 & ${ }^{0} \mathrm{~F}$ \\
\hline DAY32 & 31.76 & 11.88 & 16.00 & 49.00 & day \\
\hline DAYO & 108.69 & 11.54 & 96.00 & 124.00 & day \\
\hline PRECIP & 43.14 & 2.71 & 35.05 & 46.25 & inch/year \\
\hline LPRE & 1.63 & 0.03 & 1.54 & 1.67 & \\
\hline WETDAY & 115.82 & 12.60 & 95.00 & 128.00 & day \\
\hline P200 & 0.74 & 0.23 & 0.25 & 1.00 & weight $\%$ \\
\hline P200LPRE & 1.21 & 0.38 & 0.39 & 1.65 & \\
\hline MOIST & 0.18 & 0.03 & 0.10 & 0.24 & $\%$ \\
\hline PI & 13.15 & 4.66 & 2.90 & 26.00 & $\%$ \\
\hline REMOD & $6,716.33$ & $2,542.50$ & $2,100.00$ & $12,300.00$ & psi \\
\hline LREMOD & 3.80 & 0.17 & 3.32 & 4.09 & \\
\hline AADT & $26,015.45$ & $34,495.02$ & $1,756.52$ & $119,040.00$ & vehicle/day \\
\hline AADT2 & $5,967.51$ & $8,486.34$ & 0.00 & $35,265.18$ & vehicle/day \\
\hline AADT3 & $8,056.94$ & $19,680.01$ & 0.00 & $69,040.00$ & vehicle/day \\
\hline CESALS & $18,939,793.71$ & $42,326,065.19$ & $243,724.97$ & $169,060,969.84$ & 18kips \\
\hline LCESALS & 6.54 & 0.79 & 5.39 & 8.23 & \\
\hline AGE & 11.43 & 5.89 & 4.00 & 22.00 & age \\
\hline AGE2 & 1.10 & 2.04 & 0.00 & 6.00 & age \\
\hline AGE3 & 1.10 & 1.98 & 0.00 & 7.00 & age \\
\hline DRAINCO & 1.09 & 0.02 & 1.00 & 1.10 & \\
\hline BASETH & 13.31 & 4.68 & 2.50 & 20.00 & inch/year \\
\hline BASELPRE & 21.82 & 7.82 & 3.96 & 33.30 & \\
\hline BASECOM & 0.95 & 0.00 & 0.95 & 0.95 & $\%$ \\
\hline SLABTH & 8.73 & 3.45 & 0.63 & 14.00 & inch/year \\
\hline THICK & 22.04 & 6.25 & 5.50 & 30.00 & inch/year \\
\hline CESAL/TH & $908,640.70$ & $2,066,465.45$ & $9,026.85$ & $8,453,048.49$ & 18kips/inch \\
\hline LESALTH & 5.22 & 0.80 & 3.96 & 6.93 & \\
\hline ELASMOD & $4,000,000.00$ & 0.00 & $4,000,000.00$ & $4,000,000.00$ & psi \\
\hline RUPMOD & 662.50 & 0.00 & 662.50 & 662.50 & psi \\
\hline DOWEL & 1.17 & 0.54 & 0.00 & 1.50 & inch \\
\hline
\end{tabular}

Note: The detailed explanations of the variables listed above are given in Appendix 14. 
Appendix 20. Details of Model Validation for Cost Models Developed for JCP Pavements Based on Rehabilitation /and Periodic Maintenance 
I. Details of cost model developed for JCP pavements based on rehabilitation

Model Validation

(1) ANOVA Hypothesis Test

$\mathrm{H}_{0}$ : EXPEND and Cumulative ESALs, SLABTH, DAY32 and AGE are linearly independent

$\mathrm{H}_{1}$ : EXPEND and Cumulative ESALs, SLABTH, DAY32 and AGE are linearly dependent

From the SAS/INSIGHT ANOVA table, we get a P-value $=0.0001<0.01$. Therefore, there is enough evidence from the data, to conclude that EXPEND and Cumulative ESALs, SLABTH, DAY32 and AGE are linearly related.

(2) Goodness of Fit

Based on SAS output, the adjust $\mathrm{R}^{2}=0.8823$ which indicates a good fit of the model.

(3) Correlation Test for Normality of the Error Term

$\mathrm{H}_{0}$ : If correlation coefficient $\mathrm{r}>$ critical value at level of significance 0.01 , the distribution of error term is normal

$\mathrm{H}_{1}$ : If correlation coefficient $\mathrm{r}<$ critical value at level of significance 0.01 , the distribution of error term is not normal

From the SAS/INSIGHT ANOVA table, we get correlation coefficient $\mathrm{r}=\sqrt{ }(\mathrm{SSR} / \mathrm{SST})=\sqrt{ }(1.024 / 1.141=0.9473>0.947$ (critical value). Therefore, the assumption of normally distributed error term is satisfied.

(4) Modified Levene Test for Constant Variance of the Error Term

$\mathrm{H}_{0}$ : The error term variances are constant

$\mathrm{H}_{1}$ : The error term variances are nonconstant

The Levene SAS program from the EXPEND data gives a P-value of 0.078824 .

Since the P-value $=0.078824>0.01$, there is not enough evidence to reject the null hypothesis of constant variances. Therefore, the assumption of constant variance of the error term is not violated. 
II. Details of cost model developed for JCP pavements based on rehabilitation and periodic maintenance

Model Validation

(1) ANOVA Hypothesis Test

$\mathrm{H}_{0}$ : EXPEND and Cumulative ESALs, SLABTH, DAY32 and AGE are linearly independent

$\mathrm{H}_{1}$ : EXPEND and Cumulative ESALs, SLABTH, DAY32 and AGE are linearly dependent

From the SAS/INSIGHT ANOVA table, we get a P-value $=0.0001<0.01$. Therefore, there is enough evidence from the data, to conclude that EXPEND and Cumulative ESALs, SLABTH, DAY32 and AGE are linearly related.

(2) Goodness of Fit

Based on SAS output, the adjust $\mathrm{R}^{2}=0.8911$, which indicates a good fit of the model.

(3) Correlation Test for Normality of the Error Term

$\mathrm{H}_{0}$ : If correlation coefficient $\mathrm{r}>$ critical value at level of significance 0.01 , the distribution of error term is normal

$\mathrm{H}_{1}$ : If correlation coefficient $\mathrm{r}<$ critical value at level of significance 0.01 , the distribution of error term is not normal

From the SAS/INSIGHT ANOVA table, we get correlation coefficient $\mathrm{r}=\sqrt{ }(\mathrm{SSR} / \mathrm{SST})=\sqrt{ }(1.019 / 1.126=0.9513>0.947$ (critical value). Therefore, the assumption of normally distributed error term is satisfied.

(4) Modified Levene Test for Constant Variance of the Error Term

$\mathrm{H}_{0}$ : The error term variances are constant

$\mathrm{H}_{1}$ : The error term variances are nonconstant

The Levene SAS program from the EXPEND data gives a P-value of 0.062801 .

Since the P-value $=0.062801>0.01$, there is not enough evidence to reject the null hypothesis of constant variances. Therefore, the assumption of constant variance of the error term is not violated.

Note:

EXPEND $=$ Rehabilitation /and Periodic Maintenance Expenditures 
Appendix 21. Variables Considered for the Model Development of Composite Pavements with Rehabilitation Work 


\section{Regression Model}

Dependent Variable

Rehabilitation expenditures required for composite pavements after

\$lane-mile one service life (in 97 \$)

\section{Independent Variables}

Region: Dummy variables

District: Dummy variables

Road Type: Dummy variables

$\%$ change in IRI of the composite pavements during one life cycle

Average freeze index during one life cycle

Average freeze-thaw cycle during one life cycle

Average no. of days between last Spring and first Fall of minimum of 00C during one life cycle

Average mean annual temperature during one life cycle

Average maximum annual temperature during one life cycle

Average minimum annual temperature during one life cycle

Average no. of days $>320 \mathrm{C}$ during one life cycle

Average no. of days $<00 \mathrm{C}$ during one life cycle

Average annual precipitation during one life cycle

Average no. of wet days during one life cycle

Subgrade \% passing \#200 sieve

Subgrade moisture content

Subgrade plastic index

Maximum dry density of subgrade material

Subgrade modulus of resilience

AADT

AADT2: Dummy variable

AADT3: Dummy variable

Cumulative ESALs

Pavement age

Age2: Dummy variable

Age3: Dummy variables

Drainage coefficient

Sub/base thickness

Base thickness $*$ precipitation

Base compaction

Hot mix asphalt concrete (HMAC) thickness

HMAC thickness $*$ no. of days $>32^{\circ} \mathrm{C}$

Cumulative ESALs/ (sub/base thickness + HMAC thickness)

Asphalt content in HMAC

Hot mix asphalt concrete \% aggregate $<\# 4$ sieve

Air voids in hot mix asphalt concrete

No. of days $>32^{\circ} \mathrm{C} *$ air voids

degree-day

no. of days

no. of days

${ }^{0} \mathrm{~F}$

${ }^{0} \mathrm{~F}$

${ }^{0} \mathrm{~F}$

no. of days

no. of days

inches/year

no. of days

weight $\%$

$\%$

$\%$

psi

psi

vehicles/day

18 kips

year

inches inches ${ }^{2}$

$\%$

inches

inches $*$ days

18kips/inch

weight $\%$

volume $\%$

days*volume $\%$ 
Appendix 22. Descriptive Statistics of All Variables Initially Considered for Composite Pavement Modeling Based on Rehabilitation and Periodic Maintenance 


\begin{tabular}{|c|c|c|c|c|c|}
\hline Composite pavements & Mean & Std. Deviation & Minimum & Maximum & Unit \\
\hline 96RCON & $182,948.75$ & $529,721.03$ & 0.00 & $6,006,712.56$ & $\$ /$ lane-mile (97\$) \\
\hline 97RCON & $64,275.31$ & $214,584.72$ & 0.00 & $1,928,454.75$ & \$/lane-mile (97\$) \\
\hline $96 \mathrm{CON}$ & $184,872.75$ & $529,853.95$ & 0.00 & $6,006,712.56$ & $\$ /$ lane-mile (97\$) \\
\hline 97CON & $66,117.64$ & $214,720.01$ & 0.00 & $1,928,454.75$ & $\$ /$ lane-mile (97\$) \\
\hline IRICH & 0.73 & 1.10 & 0.00 & 11.50 & \\
\hline LIRI1 & 0.19 & 0.18 & 0.00 & 1.10 & \\
\hline$|R|_{0}$ & 77.50 & 35.49 & 12.10 & 220.06 & \\
\hline$|R|_{T}$ & 115.60 & 41.28 & 49.45 & 258.72 & \\
\hline $\mathrm{FZI}$ & 239.99 & 119.51 & 54.28 & 494.30 & degree-day \\
\hline FZTHAW & 91.84 & 11.52 & 31.00 & 127.00 & no. of cycles \\
\hline DAYOSF & 177.19 & 7.08 & 165.00 & 192.75 & day \\
\hline MEANTEM & 51.68 & 2.15 & 48.30 & 55.49 & ${ }^{0} \mathrm{~F}$ \\
\hline MAXTEM & 54.46 & 2.68 & 49.20 & 58.77 & ${ }^{0} \mathrm{~F}$ \\
\hline MINTEM & 48.62 & 1.43 & 46.40 & 51.74 & ${ }^{0} \mathrm{~F}$ \\
\hline DAY32 & 22.49 & 10.89 & 13.00 & 49.00 & day \\
\hline DAYO & 112.67 & 9.79 & 96.00 & 124.00 & day \\
\hline PRECIP & 41.07 & 3.19 & 35.05 & 48.13 & inch/year \\
\hline LPRE & 1.61 & 0.03 & 1.54 & 1.68 & \\
\hline WETDAY & 120.12 & 10.27 & 95.00 & 134.00 & day \\
\hline P200 & 0.69 & 0.22 & 0.11 & 1.00 & weight $\%$ \\
\hline P200LPRE & 1.11 & 0.36 & 0.18 & 1.67 & \\
\hline MOIST & 1.42 & 6.45 & 0.08 & 47.10 & $\%$ \\
\hline $\mathrm{Pl}$ & 15.98 & 18.99 & 1.90 & 125.10 & $\%$ \\
\hline REMOD & $6,306.28$ & $2,204.48$ & 0.00 & $12,300.00$ & psi \\
\hline LREMOD & 3.80 & 3.34 & 0.00 & 4.09 & \\
\hline AADT & $20,033.05$ & $20,160.17$ & $1,856.32$ & $164,856.89$ & vehicle/day \\
\hline AADT2 & $9,938.37$ & $10,422.25$ & 0.00 & $40,678.80$ & vehicle/day \\
\hline AADT3 & $1,897.34$ & $10,001.50$ & 0.00 & $114,856.89$ & vehicle/day \\
\hline CESALs & $4,121,405.48$ & $8,384,099.11$ & $37,874.23$ & $134,647,222.64$ & 18kips \\
\hline LCESALS & 6.18 & 0.60 & 4.58 & 8.13 & \\
\hline AGE & 8.91 & 3.74 & 1.00 & 23.00 & age \\
\hline AGE2 & 1.31 & 1.78 & 0.00 & 5.00 & age \\
\hline AGE3 & 1.09 & 1.98 & 0.00 & 13.00 & age \\
\hline DRAINCO & 1.09 & 0.03 & 1.00 & 1.10 & \\
\hline BASETH & 11.56 & 3.83 & 2.50 & 20.00 & inch/year \\
\hline BASELPRE & 18.64 & 6.19 & 3.96 & 33.03 & \\
\hline BASECOM & 0.95 & 0.00 & 0.95 & 0.95 & $\%$ \\
\hline HMACTH & 2.56 & 2.50 & 0.27 & 16.00 & inch/year \\
\hline THICK & 14.12 & 3.41 & 5.00 & 23.00 & inch/year \\
\hline CESAL/TH & $335,893.09$ & $797,017.17$ & $2,999.94$ & $12,823,545.01$ & 18kips/inch \\
\hline LESALTH & 5.04 & 0.62 & 3.48 & 7.11 & \\
\hline AC32 & 60.06 & 99.31 & 4.05 & 784.00 & inch * day \\
\hline ASPHCON & 0.06 & 0.00 & 0.06 & 0.07 & weight $\%$ \\
\hline AGG4 & 0.35 & 0.00 & 0.35 & 0.35 & weight \% \\
\hline LP4 & -0.46 & 0.00 & -0.46 & -0.46 & \\
\hline AIRVOID & 0.06 & 0.00 & 0.06 & 0.06 & volume \% \\
\hline LAV & -1.22 & 0.00 & -1.22 & -1.22 & \\
\hline D32AV & 1.35 & 0.65 & 0.78 & 2.94 & day * volume \% \\
\hline
\end{tabular}

Note: The detailed explanations of the variables listed above are given in Appendix 14 . 
Appendix 23. Details of Model Validation for Cost Models Developed for Composite Pavements Based on Rehabilitation /and Periodic Maintenance 
I. Details of cost model developed for composite pavements based on rehabilitation

Model Validation

(1) ANOVA Hypothesis Test $\mathrm{H}_{0}$ : EXPEND and ESALTH, MOFZI, MINTEM, and AGE are linearly independent $\mathrm{H}_{1}$ : EXPEND and ESALTH, MOFZI, MINTEM, and AGE are linearly dependent From the SAS/INSIGHT ANOVA table, we get a P-value $=0.0001<0.01$. Therefore, there is enough evidence from the data, to conclude EXPEND and ESALTH, MOFZI, MINTEM, and AGE are linearly related.

(2) Goodness of Fit

Based on SAS output, the adjust $\mathrm{R}^{2}=0.8990$, which indicates a good fit of the model.

(3) Correlation Test for Normality of the Error Term

$\mathrm{H}_{0}$ : If correlation coefficient $\mathrm{r}>$ critical value at level of significance 0.01 , the distribution of error term is normal

$\mathrm{H}_{1}$ : If correlation coefficient $\mathrm{r}<$ critical value at level of significance 0.01 , the distribution of error term is not normal

From the SAS/INSIGHT ANOVA table, we get correlation coefficient $r=\sqrt{ }($ SSR $/ S S T)=\sqrt{ }(6.310 / 7.012=0.95<0.979$ (critical value). The residual plot shows that the error terms are normally distributed.

(4) Modified Levene Test for Constant Variance of the Error Term

$\mathrm{H}_{0}$ : The error term variances are constant

$\mathrm{H}_{1}$ : The error term variances are nonconstant

The Levene SAS program from the EXPEND data gives a P-value of 0.36187.

Since the P-value $=0.36187>0.01$, there is not enough evidence to reject the null hypothesis of constant variances. Therefore, the assumption of constant variance of the error term is not violated. 
II. Details of cost model developed for composite pavements based on rehabilitation and periodic maintenance

Model Validation

(1) ANOVA Hypothesis Test $\mathrm{H}_{0}$ : EXPEND and ESALTH, MOFZI, MINTEM, and AGE are linearly independent $\mathrm{H}_{1}$ : EXPEND and ESALTH, MOFZI, MINTEM, and AGE are linearly dependent

From the SAS/INSIGHT ANOVA table, we get a P-value $=0.0001<0.01$. Therefore, there is enough evidence from the data, to conclude EXPEND and ESALTH, MOFZI, MINTEM, and AGE are linearly related.

(2) Goodness of Fit

Based on SAS output, the adjust $\mathrm{R}^{2}=0.8847$ hich indicates a good fit of the model.

(3) Correlation Test for Normality of the Error Term

$\mathrm{H}_{0}$ : If correlation coefficient $\mathrm{r}>$ critical value at level of significance 0.01 , the distribution of error term is normal

$\mathrm{H}_{1}$ : If correlation coefficient $\mathrm{r}<$ critical value at level of significance 0.01 , the distribution of error term is not normal

From the SAS/INSIGHT ANOVA table, we get correlation coefficient $r=\sqrt{ }(\mathrm{SSR} / \mathrm{SST})=\sqrt{ }(6.140 / 6.932=0.941<0.979$ (critical value). The residual plot shows that the error terms are normally distributed.

(4) Modified Levene Test for Constant Variance of the Error Term

$\mathrm{H}_{0}$ : The error term variances are constant

$\mathrm{H}_{1}$ : The error term variances are nonconstant

The Levene SAS program from the EXPEND data gives a P-value of 0.16752.

Since the P-value $=0.16752>0.01$, there is not enough evidence to reject the null hypothesis of constant variances. Therefore, the assumption of constant variance of the error term is not violated.

Note:

EXPEND $=$ Rehabilitation /and Periodic Maintenance Expenditures 
Appendix 24. The 1984 Indiana HCAS Approach 


\subsection{Pavement Routine Maintenance}

As described in Chapter 2, the 1984 Indiana HCAS approach also related pavement performance to routine maintenance cost [Sinha et al., 1984]. The AASHTO present serviceability index (PSI) and concept of PSI-ESAL value as an aggregate representation of pavement deterioration due to cumulative traffic loading under a certain level of maintenance treatment was introduced. The pure load share was then determined as the ratio of PSI-ESAL value associated with AASHTO design curve and zero maintenance curve.

Following this concept, the load shares of pavement damage for each road class by different pavement type was separately established on the basis of the one-mile homogeneous segments within the road class. The average load share for each pavement type was then obtained as the average of the load shares among different road classes for the same type of pavement.

In order to compute the pavement PSI-ESAL value associated with AASHTO design curve after cumulative use, the 1993 AASHTO design equations [AASHTO, 1993] [Mannering and Kilareski, 1998] for flexible and rigid pavements were used. The equations are as follows: a. 1993 AASHTO Equation for Flexible Pavement Design

$$
\log _{10} W_{18}=Z_{R} S_{o}+9.36\left[\log _{10}(S N+1)\right]-0.20+\frac{\log _{10}[\Delta P S I /(2.7)]}{0.4+\left[1,094 /(S N+1)^{5.19}\right]}+2.32 \log _{10} M_{R}-8.07
$$

where

$$
\begin{aligned}
& \mathrm{W}_{18} \quad=\text { Cumulative ESALs in 18kips; } \\
& \mathrm{Z}_{\mathrm{R}} \quad=\text { Probability that pavement serviceability being maintained at adequate levels; } \\
& \mathrm{S}_{\mathrm{O}} \quad=\text { Overall standard deviation, which is in the order of } 0.30 \text { to } 0.50 ; \\
& \mathrm{SN} \quad=\text { Structure numbers of the pavement, which is related to the thicknesses of the } \\
& \quad \text { wearing, surface, base and subbase layers (in inches) and layer coefficients; }
\end{aligned}
$$


Delta-PSI = Amount of serviceability loss;

$\mathrm{M}_{\mathrm{R}} \quad=$ Resilient modulus of the subgrade in psi.

b. 1993 AASHTO Equation for Rigid Pavement Design

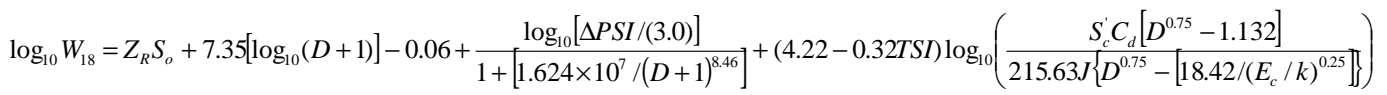

$$
\begin{aligned}
& \text { where } \\
& \text { W18 = Cumulative ESALs in 18kips; } \\
& \mathrm{Z}_{\mathrm{R}} \quad=\text { Probability that pavement serviceability being maintained at adequate levels; } \\
& \mathrm{S}_{\mathrm{o}} \quad=\text { Overall standard deviation, which is in the order of } 0.30 \text { to } 0.50 \text {; } \\
& \mathrm{D}=\text { PCC slab thickness in inches; } \\
& \text { Delta-PSI } \quad=\text { Amount of serviceability loss; } \\
& \text { TSI = Pavement's terminal serviceability index, usually is } 2.5 \text {; } \\
& \mathrm{S}_{\mathrm{c}}{ }^{\prime} \quad=\text { Concrete modulus of rupture in psi; } \\
& \mathrm{C}_{\mathrm{d}} \quad=\text { Drainage coefficient; } \\
& \mathrm{J}=\text { Load transfer coefficient, pavement with dowel bars are typically designed } \\
& \text { with a } \mathbf{J} \text { value of } 3.2 \text {; } \\
& \mathrm{E}_{\mathrm{c}} \quad=\text { Concrete modulus of elasticity in psi; } \\
& \mathrm{k} \quad=\text { Modulus of subgrade reaction in pci. }
\end{aligned}
$$

For both flexible and composite pavements, the PSI loss was calculated in accordance with the cumulative ESALs applied to the pavement segment, structural numbers, subgrade modulus of resilience, cumulative percent probabilities of confidence and the overall standard deviation. 
Similarly, the PSI loss for rigid pavement was also obtained based on the cumulative ESALs applied to the pavement segment, slab thickness, terminal serviceability index, concrete modulus of rupture, drainage coefficient, load transfer coefficient, concrete modulus of elasticity, modulus of subgrade reaction, cumulative percent probabilities of confidence and the overall standard deviation.

Furthermore, the PSI-ESAL value associated with design curve was established by taking integral of PSI loss with respect to cumulative ESALs adopted.

On the other hand, the zero maintenance PSI-ESAL value for the same route was extrapolated based on the relationship between different maintenance levels, expressed by average annual per lane-mile maintenance expenditure, and PSI-ESAL value among the homogeneous segments.

The load share of routine maintenance expenditures for flexible pavements was derived from 14 different routes, comprised of 209 one-mile segments. The descriptive statistics of those segments are presented in Table A17.1.

Table A17.1 Descriptive Statistics of Variables Initially Considered for Determining the Load Share of Routine Maintenance Expenditures for Flexible Pavements Using 1984 HCAS Approach

\begin{tabular}{|c|c|c|c|c|c|}
\hline Flexible pavement & Mean & Std. Deviation & Minimum & Maximum & Unit \\
\hline AVE567T & 214.83 & 650.92 & 0 & $3,989.00$ & \$/lane-mile/year \\
\hline AVE9567 & 69.54 & 115.37 & 0 & 468.00 & \$/lane-mile/year \\
\hline $\mathrm{PSI}_{0}$ & 4.03 & 0.36 & 2.80 & 5 & \\
\hline $\mathrm{PSI}_{\mathrm{T}}$ & 3.53 & 0.50 & 2.44 & 4 & \\
\hline DELTA-PSI & 0.32 & 0.25 & 0.07 & 2 & \\
\hline Cumulative ESALs & $625,518.53$ & $1,780,620.89$ & $4,338.80$ & $10,548,189.00$ & 18kips \\
\hline PSI-ESALs loss(design) $_{\text {PI }}$ & $128,054.37$ & $415,909.54$ & 152.79 & $4,302,291.00$ & \\
\hline AGE & 8.51 & 4.97 & 3 & 18 & year \\
\hline THICKNESS & 15.92 & 3.10 & 10.00 & 22 & inch \\
\hline STRUCTURAL NO. & 5.28 & 1.26 & 3.35 & 9 & \\
\hline RESILIENT MODULUS & $6,067.46$ & $1,439.49$ & $3,600.00$ & $9,600.00$ & psi \\
\hline
\end{tabular}

The load share of routine maintenance expenditures for JCP pavements was derived from 4 different routes, comprised of 29 one-mile segments. The descriptive statistics of those segments are presented in Table A17.2. 
Table A17.2 Descriptive Statistics of Variables Initially Considered for Determining the Load Share of Routine Maintenance Expenditures for JCP Pavements Using 1984 HCAS Approach

\begin{tabular}{|c|c|c|c|c|c|}
\hline JCP pavement & Mean & Std. Deviation & Minimum & Maximum & Unit \\
\hline AVE567T & 190.07 & 212.52 & 0.00 & 621.00 & \$/lane-mile/year \\
\hline AVE9567 & 100.79 & 101.75 & 0.00 & 397.00 & \$/lane-mile/year \\
\hline $\mathrm{PSI}_{0}$ & 3.97 & 0.55 & 3.19 & 5 & \\
\hline PSI $_{\mathrm{T}}$ & 3.40 & 0.53 & 2.47 & 4 & \\
\hline DELTA-PSI & 0.57 & 0.61 & 0.03 & 2 & \\
\hline Cumulative ESALs & $2,424,128.36$ & $1,355,034.56$ & $520,546.87$ & $4,161,230.00$ & 18kips \\
\hline PSI-ESAL loss(design) & $853,004.28$ & $899,734.63$ & $8,302.32$ & $2,135,836.00$ & \\
\hline AGE & 9.59 & 4.62 & 7 & 21 & year \\
\hline SLAB THICKNESS & 10.80 & 3.16 & 0.63 & 14 & inch \\
\hline DRAINAGE COEFF. & 1.06 & 0.05 & 1.0 & 1.1 & \\
\hline RESILIENT MODULUS & $5,074.14$ & $1,647.60$ & $3,000.00$ & $6,750.00$ & psi \\
\hline MODULUS OF ELASTICITY & $4,000,000.00$ & 0.00 & $4,000,000.00$ & $4,000,000.00$ & psi \\
\hline MODULUS OF RUPTURE & 662.50 & 0 & 662.50 & 662.50 & psi \\
\hline
\end{tabular}

The load share of routine maintenance expenditures for CRC pavements was derived from one route, comprised of 12 one-mile segments. The descriptive statistics of those segments are presented in Table A17.3.

Table A17.3 Descriptive Statistics of Variables Initially Considered for Determining the Load Share of Routine Maintenance Expenditures for CRC Pavements Using 1984 HCAS Approach

\begin{tabular}{|c|c|c|c|c|c|}
\hline CRC pavement & Mean & Std. Deviation & Minimum & Maximum & Unit \\
\hline AVE567T & $4,921.41$ & $8,905.23$ & 0.00 & $20,637.00$ & \$/lane-mile/year \\
\hline AVE9567 & 18.04 & 11.09 & 0.00 & 25.00 & \$/lane-mile/year \\
\hline $\mathrm{PSI}_{0}$ & 3.84 & 0.37 & 3.42 & 5.00 & \\
\hline $\mathrm{PSI}_{\mathrm{T}}$ & 2.27 & 0.39 & 2.00 & 3.00 & \\
\hline DELTA-PSI & 1.57 & 0.20 & 1.45 & 2.00 & \\
\hline Cumulative ESALs & $1,184,502$ & 150,882 & $1,092,367$ & $1,643,840$ & 18kips \\
\hline PSI-ESALs ${ }_{\text {loss(design) }}$ & 944,174 & 274,976 & 790,968 & $1,791,185$ & \\
\hline AGE & 23 & 0 & 23 & 24 & year \\
\hline SLAB THICKNESS & 7.92 & 0.29 & 7.00 & 8.00 & inch \\
\hline DRAINAGE COEFF. & 1.0 & 0 & 1.0 & 1.1 & \\
\hline RESILIENT MODULUS & $5,625.00$ & 678.40 & $4,500.00$ & $6,000.00$ & psi \\
\hline MODULUS OF ELASTICITY & $4,000,000.00$ & 0 & $4,000,000.00$ & $4,000,000.00$ & psi \\
\hline MODULUS OF RUPTURE & 662.5 & 0 & 662.5 & 662.5 & psi \\
\hline
\end{tabular}

The load share of routine maintenance expenditures for composite pavements was derived from 27 different routes, comprised of 713 one-mile segments. The descriptive statistics of those segments are presented in Table A17.4. 
Table A17.4 Descriptive Statistics of Variables Initially Considered for Determining the Load Share of Routine Maint. Expenditures for Composite Pavements Using 1984 HCAS Approach

\begin{tabular}{|c|c|c|c|c|c|}
\hline Composite pavement & Mean & Std. Deviation & Minimum & Maximum & Unit \\
\hline AVE567T & 595.45 & $2,984.17$ & 0.00 & $21,919.00$ & \$/lane-mile/year \\
\hline AVE9567 & 74.89 & 152.53 & 0.00 & 911.00 & \$/lane-mile/year \\
\hline $\mathrm{PSI}_{0}$ & 4.08 & 0.32 & 2.99 & 5 & \\
\hline $\mathrm{PSI}_{\mathrm{T}}$ & 3.70 & 0.29 & 2.68 & 4 & \\
\hline DELTA-PSI & 0.24 & 0.15 & 0.07 & 1 & \\
\hline Cumulative ESALs & $1,037,440.99$ & $1,618,408.40$ & $72,453.47$ & $9,964,675.00$ & 18kips \\
\hline PSI-ESALs $_{\text {loss(design) }}$ & $148,118.55$ & $263,640.28$ & $4,095.34$ & $2,615,791.00$ & \\
\hline AGE & 7.35 & 2.33 & 1.67 & 16 & year \\
\hline THICKNESS & 15.96 & 2.46 & 7.50 & 28 & inch \\
\hline STRUCTURAL NO. & 6.96 & 1.13 & 3.30 & 12 & \\
\hline RESILIENT MODULUS & $7,019.50$ & $1,817.83$ & $2,850.00$ & $11,100.00$ & psi \\
\hline
\end{tabular}

The summarized results of load shares of routine maintenance expenditures for flexible, JCP, CRC and composite pavements based on 1984 Indiana HCAS approach are listed in Table A17.5. 
Table A17.5 Summary of Load Shares of Pavement Maintenance Expenditures for Flexible, JCP, CRC and Composite Pavements Using 1984 Indiana HCAS Approach

\section{Flexible Pavements}

District

4

4

4

2

2

2

1

1

1

3

3

6

5

5

$$
\text { Type }
$$

SR

SR

US

SR

SR

SR

SR

SR

US

US

US

I

I

US
Route

25

49

421

3

13

19

26

63

231

27

52

64

65

421

Average

Route

65

49

69

31

Average

Route

37
I

US
SR

Type
5

District
Load Share

$24 \%$

$14 \%$

$15 \%$

$28 \%$

$20 \%$

$16 \%$

$5 \%$

$19 \%$

$30 \%$

$11 \%$

$27 \%$

$33 \%$

$41 \%$

$15 \%$

$21 \%$

Load Share

$91 \%$

$14 \%$

$94 \%$

$18 \%$

$54 \%$

Load Share

$100 \%$

$100 \% * 1$ 
Table A17.5 (continued) Summary of Load Shares of Pavement Maintenance Expenditures for Flexible, JCP, CRC and Composite Pavements Using 1984 Indiana HCAS Approach

\begin{tabular}{|c|c|c|c|}
\hline \multicolumn{4}{|c|}{ IV. Composite Pavements } \\
\hline District & Type & Route & Load Share \\
\hline 4 & US & 6 & $27 \%$ \\
\hline 4 & US & 20 & $26 \%$ \\
\hline 4 & US & 30 & $35 \%$ \\
\hline 4 & US & 31 & $37 \%$ \\
\hline 4 & US & 41 & $17 \%$ \\
\hline 4 & US & 231 & $40 \%$ \\
\hline 2 & US & 20 & $37 \%$ \\
\hline 2 & US & 24 & $15 \%$ \\
\hline 2 & US & 27 & $13 \%$ \\
\hline 2 & US & 30 & $48 \%$ \\
\hline 2 & US & 33 & $36 \%$ \\
\hline 2 & US & 35 & $14 \%$ \\
\hline 1 & I & 74 & $36 \%$ \\
\hline 1 & US & 41 & $18 \%$ \\
\hline 1 & US & 52 & $53 \%$ \\
\hline 3 & I & 74 & $51 \%$ \\
\hline 3 & SR & 19 & $33 \%$ \\
\hline 3 & US & 27 & $17 \%$ \\
\hline 3 & US & 31 & $5 \%$ \\
\hline 3 & US & 35 & $37 \%$ \\
\hline 6 & I & 64 & $19 \%$ \\
\hline 5 & I & 65 & $41 \%$ \\
\hline 5 & SR & 46 & $20 \%$ \\
\hline 5 & US & 50 & $21 \%$ \\
\hline 5 & US & 52 & $26 \%$ \\
\hline 5 & US & 421 & $36 \%$ \\
\hline & & Average & $29 \%$ \\
\hline
\end{tabular}

Note: 1) For CRC pavements, only one route was included into current analysis due to data constraint. The $\mathrm{R}^{2}$ value associated with the calculation of zero-maintenance cost was very low. Hence, this result may not be representative of all pavements in that category. 


\subsection{Pavement Rehabilitation}

Similar to the computation made for the comparison based on routine maintenance, the PSI losses for pavement segments with rehabilitation during one service life was calculated separately in accordance with the AASHTO design formulas for flexible, JCP and composite pavements respectively.

Furthermore, the PSI-ESAL value associated with design curve for each pavement segment was established by taking integral of PSI loss with respect to cumulative ESALs adopted during the course of one service life.

On the other hand, the actual PSI loss in relation to the field performance curve for the same pavement segment in one life cycle was extrapolated on the basis of initial and terminal PSI values, and PSI decrement rate in one service life. Accordingly, the actual PSI-ESAL value for the same segment in one service life was obtained by taking integral of actual PSI loss with respect to cumulative ESALs applied in one service life.

Following this concept, the PSI-ESAL values both relevant to the design curve and field performance curve for each pavement segment was established. Then, load share of rehabilitation and periodic maintenance expenditures for each pavement segment was attained as the ratio of the two values. Finally, the average load share for each pavement type was separately established as the average of the load shares among different road classes for the same type of pavement. By taking the linear proportionality assumption (as discussed in Chapter 2), the load-related portion of the interaction between load/non-load factors was also computed.

The load share of rehabilitation and periodic maintenance expenditures for flexible pavements was derived from 15 different routes, comprised of 99 one-mile segments. The descriptive statistics of those segments are presented in Table A17.6. 
Table A17.6 Descriptive Statistics of Variables Initially Considered for Determining the Load Share of Rehabilitation Expenditures for Flexible Pavements Using 1984 HCAS Approach

\begin{tabular}{|c|c|c|c|c|c|}
\hline Flexible pavement & Mean & Std. Deviation & Minimum & Maximum & Unit \\
\hline $\mathrm{EXPEND}_{\text {(rehab.) }}$ & $129,936.72$ & $257,802.52$ & $24,694.01$ & $1,347,964.00$ & \$/lane-mile/year \\
\hline EXPEND (rehab. \& periodic main.) & $129,969.13$ & $257,791.68$ & $25,721.49$ & $1,347,964.00$ & \$/lane-mile/year \\
\hline $\mathrm{PSI}_{0}$ & 4.09 & 0.36 & 2.62 & 5 & \\
\hline $\mathrm{PSI}_{\mathrm{T}}$ & 3.18 & 0.42 & 2.51 & 4 & \\
\hline DELTA-PSI & 0.41 & 0.48 & 0.05 & 2 & \\
\hline Cumulative ESALs & $2,388,843.80$ & $7,655,790.36$ & $14,871.49$ & $44,119,137.00$ & 18kips \\
\hline PSI-ESALs ${ }_{\operatorname{loss}(\text { design) }}$ & $1,282,356.11$ & $5,316,140.75$ & 425.23 & $33,520,436.00$ & \\
\hline AGE & 12 & 4 & 4 & 24 & year \\
\hline THICKNESS & 13.64 & 3.97 & 4.70 & 22 & inch \\
\hline STRUCTURAL NO. & 5.13 & 1.59 & 1.94 & 9 & \\
\hline RESILIENT MODULUS & $6,212.12$ & $2,053.46$ & $2,850.00$ & $12,000.00$ & psi \\
\hline
\end{tabular}

The load share of rehabilitation expenditures for JCP pavements was derived from 10 different routes, comprised of 32 one-mile segments. The descriptive statistics of those segments are presented in Table A17.7.

Table A17.7 Descriptive Statistics of Variables Initially Considered for Determining the Load Share of Rehabilitation Expenditures for JCP Pavements Using 1984 HCAS Approach

\begin{tabular}{|c|c|c|c|c|c|}
\hline JCP pavement & Mean & Std. Deviation & Minimum & Maximum & Unit \\
\hline $\mathrm{EXPEND}_{\text {(rehab.) }}$ & $438,929.33$ & $698,278.73$ & $23,999.24$ & $2,471,043.00$ & \$/lane-mile/year \\
\hline EXPEND (rehab. \& periodic main.) & $448,313.89$ & $693,328.56$ & $24,274.63$ & $2,471,043.00$ & \$/lane-mile/year \\
\hline $\mathrm{PSI}_{0}$ & 3.73 & 0.57 & 2.75 & 5 & \\
\hline $\mathrm{PSI}_{\mathrm{T}}$ & 3.31 & 0.50 & 2.59 & 4 & \\
\hline DELTA-PSI & 0.96 & 0.60 & 0.01 & 2 & \\
\hline Cumulative ESALs & $12,181,027.05$ & $20,194,232.00$ & $243,724.97$ & $75,600,499.00$ & 18kips \\
\hline PSI-ESAL ${ }_{\text {loss(design) }}$ & $7,243,285.89$ & $12,662,790.76$ & $14,381.76$ & $53,388,919.00$ & \\
\hline AGE & 13 & 5 & 4 & 22 & year \\
\hline SLAB THICKNESS & 9.06 & 3.38 & 3 & 14 & inch \\
\hline DRAINAGE COEFF. & 1.09 & 0.03 & 1.00 & 1.10 & \\
\hline RESILIENT MODULUS & $6,932.81$ & $2,519.43$ & $4,350.00$ & $12,300.00$ & psi \\
\hline MODULUS OF ELASTICITY & $4,000,000.00$ & 0.00 & $4,000,000.00$ & $4,000,000.00$ & psi \\
\hline MODULUS OF RUPTURE & 662.50 & 0.00 & 662.50 & 662.50 & psi \\
\hline
\end{tabular}

The load share of rehabilitation expenditures for composite pavements was derived from 33 different routes, comprised of 263 one-mile segments. The descriptive statistics of those segments are presented in Table A17.8. 
Table A17.8 Descriptive Statistics of Variables Initially Considered for Determining the Load Share of Rehabilitation Expenditures for Composite Pavements Using 1984 HCAS Approach

\begin{tabular}{|c|c|c|c|c|c|}
\hline Composite pavement & Mean & Std. Deviation & Minimum & Maximum & Unit \\
\hline EXPEND $_{\text {(rehab.) }}$ & $256,238.19$ & $314,207.01$ & $16,646.66$ & $1,920,874.00$ & \$/lane-mile/year \\
\hline EXPEND (rehab. \& periodic main.) & $257,036.94$ & $313,873.35$ & $16,646.66$ & $1,920,874.00$ & \$/lane-mile/year \\
\hline $\mathrm{PSI}_{0}$ & 4.16 & 0.32 & 2.89 & 5 & \\
\hline $\mathrm{PSI}_{\mathrm{T}}$ & 3.58 & 0.38 & 2.39 & 4 & \\
\hline DELTA-PSI & 0.68 & 0.59 & 0.07 & 2 & \\
\hline Cumulative ESALs & $6,435,642.90$ & $10,647,153.12$ & $37,874.23$ & $134,647,223.00$ & 18kips \\
\hline PSI-ESALs ${ }_{\operatorname{loss}(\text { design })}$ & $3,963,144.39$ & $10,223,662.68$ & $1,484.22$ & $138,430,494.00$ & \\
\hline AGE & 9 & 4 & 1 & 23 & year \\
\hline THICKNESS & 14.85 & 3.46 & 5.38 & 23 & inch \\
\hline STRUCTURAL NO. & 6.50 & 1.55 & 2.37 & 10 & \\
\hline RESILIENT MODULUS & $6,196.95$ & $2,525.84$ & $2,850.00$ & $10,050.00$ & psi \\
\hline
\end{tabular}

The summarized results of the load shares of rehabilitation expenditures for flexible, JCP and composite pavements based on 1984 Indiana HCAS approach are listed in Table A17.9.

Table A17.9 Summary of Load Shares of Rehabilitation Expenditures for Flexible, JCP and Composite Pavements Using 1984 Indiana HCAS Approach

\begin{tabular}{crrr}
\hline $\begin{array}{c}\text { I. Flexible Pavements } \\
\text { District }\end{array}$ & Type & Route & Load Share \\
& & & \\
4 & US & 421 & $37 \%$ \\
2 & SR & 13 & $22 \%$ \\
2 & SR & 25 & $32 \%$ \\
2 & SR & 109 & $32 \%$ \\
2 & US & 31 & $25 \%$ \\
1 & SR & 25 & $8 \%$ \\
1 & SR & 26 & $31 \%$ \\
1 & US & 41 & $100 \%$ \\
3 & SR & 13 & $34 \%$ \\
3 & US & 52 & $27 \%$ \\
6 & I & 64 & $18 \%$ \\
6 & I & 164 & $72 \%$ \\
6 & US & 231 & $100 \%$ \\
5 & I & 65 & $100 \%$ \\
5 & SR & 56 & $23 \%$ \\
5 & SR & 67 & $17 \%$ \\
& & & $42 \%$ \\
\hline
\end{tabular}


Table A17.9 (continued) Summary of Load Shares of Rehabilitation Expenditures for Flexible, JCP and Composite Pavements Using 1984 Indiana HCAS Approach

\begin{tabular}{crrr}
\hline $\begin{array}{l}\text { II. JCP Pavements } \\
\text { District }\end{array}$ & Type & Route & Load Share \\
2 & & & \\
2 & I & 69 & $100 \%$ \\
1 & SR & 3 & $91 \%$ \\
3 & US & 41 & $21 \%$ \\
3 & I & 70 & $100 \%$ \\
3 & I & 465 & $100 \%$ \\
6 & SR & 37 & $100 \%$ \\
6 & I & 64 & $100 \%$ \\
5 & I & 164 & $94 \%$ \\
5 & US & 50 & $45 \%$ \\
& US & 421 & $100 \%$ \\
& & & $85 \%$
\end{tabular}

III. Composite Pavements

District

4
4
4
4
2
2
2
2
2
2
1
1
1
3
3
3
3
3
3
3
3
3
6
6
6

Type

US

US

US

US

I

US

US

US

US

US

I

I

I

I

I

I

SR

SR

US

US

US

US

I

US
Route

6

20

35

231

69

20

24

30

31

33

65

70

74

69

70

465

3

67

27

31

35

52

64

41
Load Share

$35 \%$

$41 \%$

$36 \%$

$63 \%$

$62 \%$

$43 \%$

$59 \%$

$70 \%$

$20 \%$

$27 \%$

$100 \%$

$100 \%$

$59 \%$

$100 \%$

$100 \%$

$100 \%$

$33 \%$

$36 \%$

$44 \%$

$52 \%$

$52 \%$

$26 \%$

$15 \%$

$46 \%$

$64 \%$ 
Table A17.9 (continued) Summary of Load Shares of Rehabilitation Expenditures for Flexible, JCP and Composite Pavements Using 1984 Indiana HCAS Approach

\begin{tabular}{crrr}
\hline III. Composite Pavements & & & \\
6 & US & 231 & $79 \%$ \\
5 & I & 65 & $70 \%$ \\
5 & I & 74 & $48 \%$ \\
5 & SR & 3 & $55 \%$ \\
5 & SR & 46 & $64 \%$ \\
5 & SR & 62 & $61 \%$ \\
5 & US & 31 & $37 \%$ \\
5 & US & 50 & $53 \%$ \\
& & & $56 \%$ \\
\hline
\end{tabular}

Note: 1) No analysis was conducted for CRC pavements due to lack of data. 